\title{
Empowering married young women and improving their sexual and reproductive health: Effects of the First-time Parents Project
}

\author{
K.G. Santhya \\ Population Council \\ Nicole Haberland \\ Population Council \\ Arup Das \\ F. Ram \\ R.K. Sinha
}

See next page for additional authors

Follow this and additional works at: https://knowledgecommons.popcouncil.org/departments_sbsr-pgy

Part of the Demography, Population, and Ecology Commons, Family, Life Course, and Society Commons, and the International Public Health Commons How does access to this work benefit you? Let us know!

\section{Recommended Citation}

Santhya, K.G., Nicole Haberland, Arup Das, F. Ram, R.K. Sinha, Usha Ram, and S.K. Mohanty. 2008.

"Empowering married young women and improving their sexual and reproductive health: Effects of the First-time Parents Project." New Delhi: Population Council. 


\section{Authors}

K.G. Santhya, Nicole Haberland, Arup Das, F. Ram, R.K. Sinha, Usha Ram, and S.K. Mohanty

This report is available at Knowledge Commons: https://knowledgecommons.popcouncil.org/departments_sbsr-pgy/ 

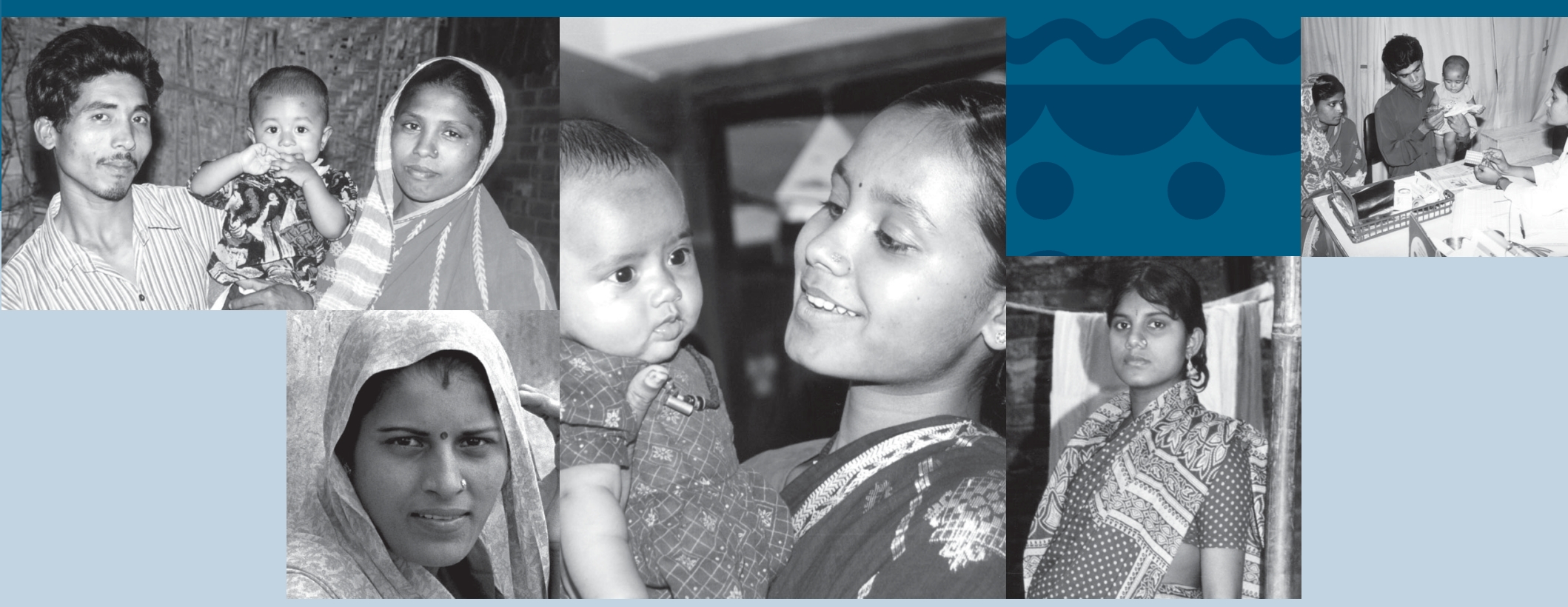

Empowering married young women and improving their sexual and reproductive health: Effects of the First-time Parents Project 
This report is the result of a collaborative study undertaken by International Institute for Population Sciences, Mumbai and the Population Council to evaluate the effectiveness of an intervention project that focused on married young women. The project was implemented in Gujarat by Deepak Charitable Trust, Vadodara and in West Bengal by Child In Need Institute, Kolkata, in partnership with the Population Council.

\section{For additional copies of this report, please contact:}

Population Council

Zone 5-A, Ground Floor

India Habitat Centre

Lodi Road

New Delhi 110003

Phone: 011-2464 2901/02 email: info-india@ popcouncil.org

Web site: http://www.popcouncil.org/asia/india.html

Child In Need Institute (CINI), a non-governmental organisation established in 1974 in West Bengal, aims to achieve sustainable health and nutrition development for women and children. CINI's activities focus on areas such as safe motherhood and child survival, nutritional services for vulnerable groups, reproductive health services for adolescents, male involvement in reproductive health, and gender relations and women's empowerment.

Deepak Charitable Trust (DCT), a non-governmental organisation established in 1981 in Gujarat, seeks to improve the quality of life of women through developmental activities and interventions. Its main focus has been in areas such as reproductive and sexual health education, livelihoods and women's empowerment. DCT reaches out to people across 50 villages in Vadodara and Surendranagar districts in Gujarat and Raigarh district in Maharashtra.

International Institute for Population Sciences (IIPS) is a teaching and research institute that offers academic courses in population sciences. IIPS has been actively involved in building the capacity of Population Research Centres, and other state and central government offices that address demographic issues in the country. It has a proven record in conducting national- and sub-national-level studies in reproductive health, including the National Family Health Surveys.

The Population Council is an international, non-profit, non-governmental organisation that seeks to improve the wellbeing and reproductive health of current and future generations around the world and to help achieve a humane, equitable and sustainable balance between people and resources. The Council conducts biomedical, social science and public health research, and helps build research capacities in developing countries.

Copyright @ 2008 Population Council

Suggested citation: Santhya, K.G., N. Haberland, A. Das et al. 2008. Empowering married young women and improving their sexual and reproductive health: Effects of the First-time Parents Project. New Delhi: Population Council. 


\title{
Empowering married young women and improving their sexual and reproductive health: \\ Effects of the First-time Parents Project
}

\author{
K. G. Santhya \\ Nicole Haberland \\ Population Council \\ Arup Das \\ Child In Need Institute
}

Aruna Lakhani

Deepak Charitable Trust

F. Ram

R. K. Sinha

Usha Ram

S. K. Mohanty

International Institute for Population Sciences 



\section{Contents}

List of tables, figures and appendices

\begin{tabular}{ll} 
Acknowledgements & vii \\
\hline
\end{tabular}

Executive summary viii

\begin{tabular}{ll} 
Chapter 1: Introduction & 1 \\
\hline
\end{tabular}

Background 2

Study setting $\quad 4$

Study design $\quad 5$

$\begin{array}{ll}\text { Response rates } & 6\end{array}$

Limitations $\quad 7$

Structure of the report 9

Chapter 2: Social and reproductive health situation of married young women $\quad 10$

$\begin{array}{ll}\text { Background characteristics } & 10\end{array}$

Agency, gender role attitudes and social support networks 11

Decision-making 11

Mobility 11

Gender role attitudes 11

Attitudes towards domestic violence 12

Social support networks $\quad 12$

Knowledge of sexual and reproductive health matters $\quad 13$

Reproductive health practices $\quad 14$

$\begin{array}{ll}\text { Partner communication and support } & 15\end{array}$

$\begin{array}{ll}\text { Chapter 3: The intervention } & 17\end{array}$

$\begin{array}{ll}\text { Intervention design and objectives } & 17\end{array}$

$\begin{array}{ll}\text { Intervention activities } & 17\end{array}$

Provision of information $\quad 18$

$\begin{array}{ll}\text { Adjustments in health services } & 18\end{array}$

Group formation 19

Extent of exposure to intervention activities 20

Challenges faced in implementing intervention activities 21 
Effects of exposure to the intervention on married young women's agency, gender role $\begin{array}{ll}\text { attitudes and social support networks } & 22\end{array}$

$\begin{array}{ll}\text { Role in household decision-making } & 23\end{array}$

$\begin{array}{ll}\text { Mobility } & 23\end{array}$

$\begin{array}{lr}\text { Gender role attitudes } & 25\end{array}$

$\begin{array}{ll}\text { Attitudes towards domestic violence } & 25\end{array}$

$\begin{array}{ll}\text { Social support networks } & 26\end{array}$

Friends in the marital village 26

$\begin{array}{ll}\text { Extent of peer support } & 27\end{array}$

Effects of exposure to the intervention on married young women's sexual and reproductive $\begin{array}{ll}\text { health knowledge } & 28\end{array}$

Effects of exposure to the intervention on married young women's reproductive health practices 29

Use of contraceptives to delay the first birth 30

Maternal health care seeking during pregnancy, delivery and the postpartum period for

the first birth $\quad 32$

Antenatal care: Timing of first antenatal check-up $\quad 32$

Antenatal care: Number of antenatal check-ups 33

Antenatal care: Comprehensive antenatal services $\quad 34$

Delivery care: Preparations for delivery $\quad 35$

Delivery care: Institutional delivery $\quad 36$

$\begin{array}{ll}\text { Postpartum care } & 37\end{array}$

Newborn care: Initiation of breastfeeding $\quad 38$

$\begin{array}{ll}\text { Newborn care: Feeding colostrum } & 39\end{array}$

Effects of exposure to the intervention on partner communication and support 40

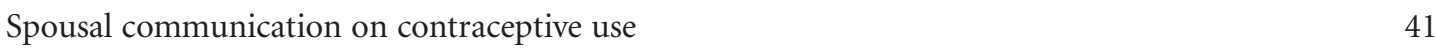

$\begin{array}{ll}\text { Partner support and nature of spousal relationship } & 41\end{array}$

Husbands' support to wives during family conflicts $\quad 42$

Expressing own opinion to husbands when they disagreed with them 43

Chapter 5: Summary and recommendations 44

$\begin{array}{ll}\text { Summary } & 44\end{array}$

$\begin{array}{ll}\text { Recommendations } & 46\end{array}$

$\begin{array}{ll}\text { References } & 48\end{array}$

$\begin{array}{ll}\text { Appendices } & 50\end{array}$

\begin{tabular}{ll} 
Authors & 54 \\
\hline
\end{tabular} 


\section{List of tables, figures and appendices}

Table 1.1: $\quad$ Profile of study districts and states $\quad 5$

$\begin{array}{lll}\text { Table 1.2: } & \text { Response rates at baseline and endline surveys } & 7\end{array}$

$\begin{array}{lll}\text { Table 1.3: } & \text { Follow-up rate } & 7\end{array}$

Table 2.1: $\quad$ Characteristics of married young women, baseline survey $\quad 10$

Table 3.1: Extent of married young women's exposure to the intervention, endline survey 20

Table 3.2: Breadth of exposure to intervention activities, endline survey 21

Table 4.1: Effects of exposure to the intervention on married young women's agency and gender role attitudes: Summary of regression results $\quad 24$

Table 4.2: $\quad$ Effects of exposure to the intervention on married young women's social $\begin{array}{ll}\text { support networks: Summary of regression results } & 27\end{array}$

Table 4.3: Effects of exposure to the intervention on married young women's knowledge of sexual $\begin{array}{ll}\text { and reproductive health matters: Summary of regression results } & 29\end{array}$

Table 4.4: Effects of exposure to the intervention on married young women's contraceptive use: Summary of regression results using the DiD model 7 10 20

Table 4.5: Effects of exposure to the intervention on use of appropriate antenatal services by first-time mothers: Summary of regression results using the DiD model

first-time mothers: Summary of regression results using the DiD model

Figure 2.1: Married young women's gender role attitudes and attitudes towards domestic violence, baseline survey

Figure 2.2: $\quad$ Married young women's connections with peer networks, baseline survey

Figure 2.3: $\quad$ Married young women who wanted to delay the first pregnancy and who had used a contraceptive method to delay first pregnancy, baseline survey

Figure 2.4: Maternal and child health practices reported by first-time mothers, baseline survey

Figure 2.5: Spousal communication on sexual and reproductive health topics reported by married young women, baseline survey

Figure 2.6: Married young women who were supported by their husbands during family conflicts and who expressed their opinion when they disagreed with their husbands, baseline survey

Figure 4.1: Married young women's role in household decision-making, baseline and endline surveys

Figure 4.2: $\quad$ Married young women's mobility, baseline and endline surveys 
Figure 4.3: Married young women's gender role attitudes, baseline and endline surveys

Figure 4.4: Married young women's attitudes towards non-acceptability of wife-beating, baseline and endline surveys

Figure 4.5: Married young women who reported having friends in the marital village, baseline and endline surveys

Figure 4.6: Extent of married young women's peer support, baseline and endline surveys

Figure 4.7: Married young women's knowledge of sexual and reproductive health matters, baseline and endline surveys

Figure 4.8: Use of contraceptives reported by married young women to delay first birth, baseline and endline surveys

Figure 4.9: First-time mothers who reported receiving their first antenatal check-up in the first trimester, baseline and endline surveys

Figure 4.10: Mean number of antenatal check-ups received by first-time mothers, baseline and endline surveys

Figure 4.11: Comprehensive antenatal care received by first-time mothers, baseline and endline surveys

Figure 4.12: Extent of delivery preparations made by first-time mothers, baseline and endline surveys

Figure 4.13: First-time mothers who reported an institutional delivery, baseline and endline surveys

Figure 4.14: First-time mothers who reported receiving a routine check-up within six weeks postpartum, baseline and endline surveys

Figure 4.15: First-time mothers who reported breastfeeding their newborns immediately after delivery, baseline and endline surveys

Figure 4.16: First-time mothers who reported feeding colostrum to their newborns, baseline and endline surveys

Figure 4.17: Extent of spousal communication on contraceptive use, baseline and endline surveys

Figure 4.18: Married young women who reported that their husbands always supported them during family conflicts, baseline and endline surveys

Figure 4.19: Married young women who expressed their opinion to their husbands when they disagreed with them, baseline and endline surveys

Appendix 1: Reasons for loss to follow-up of baseline respondents at endline

Appendix 3: Participation in activities similar, but external to, the intervention

Appendix 4: Characteristics of baseline respondents who were exposed to the intervention and those who were not

Appendix 5: Characteristics of baseline respondents who were followed up at endline and those who were not

Appendix 6: Computation of standard of living index 


\section{Acknowledgements}

This study has benefited immeasurably from the input of many. We are enormously grateful for the partnership and support of the Department for International Development (DFID), the Bill \& Melinda Gates Foundation, the Hewlett Foundation, the John D. and Catherine T. MacArthur Foundation, the Andrew W. Mellon Foundation, and the Summit Foundation/ the Community Foundation for the National Capital Region, which made this study possible.

We would like to thank the young women of Diamond Harbour and Vadodara who participated in the intervention and surveys, and their families and the wider community, including panchayat leaders, for support to the project. Our thanks also go to the investigators and other members of the field team who painstakingly collected the data - often in trying circumstances - as well as the research officers who ably supervised the data collection and analysis.

We are grateful to Archana Joshi and colleagues at Operations Research Group, Vadodara for conducting the diagnostic study which informed the intervention design; Mina Das and Tapan Das from Nishtha, Kolkata for conducting training workshops for project staff and providing on-going field support, particularly in Diamond Harbour; and Nirmala Murthy and Deepak Dhongde from Foundation for Research in Health Systems, Ahmedabad for helping to develop the monitoring system for the project.

Our technical advisory group - Halida Hanum Akhter, Shireen Jejeebhoy, Michael Koenig and Janet Molzan Turan - provided invaluable advice in developing the study design and intervention plans. We are grateful to Judith Bruce and Saroj Pachauri for their guidance throughout the project, and to Beverly Winikoff for her guidance during the formative stage of the project.

A special thanks goes to Shireen Jejeebhoy for her collegial support, mentoring and guidance at every stage of the project. The contributions of Elizabeth McGrory in designing the intervention and the baseline survey, Ajay Kumar Singh in monitoring the endline survey and Saswata Ghosh in data analysis are acknowledged. We would also like to thank Dinesh Agarwal, Dipa Nag Chowdhury and P.M. Kulkarni for reviewing an earlier draft of this report and providing helpful comments. We are grateful to Deepika Ganju for her editorial contribution and careful attention to detail. Finally, we would like to thank Asha Matta, Komal Saxena and M.A. Jose for their valuable support at different stages of the project. 


\section{Executive summary}

While age at marriage is increasing among younger cohorts, as recently as in 2005-06, more than two-fifths of all women in India aged 20-24 were married by 18 years. A growing body of evidence from India and elsewhere shows that the reproductive health situation and needs of married adolescent and young women are different from both that of unmarried adolescent girls and married adult women, posing distinct programme challenges. Although recent policies and programmes have recognised the special needs of married adolescents and young women, their effective implementation has been handicapped by the lack of evidence on the kind of intervention models that are feasible and effective in improving the situation of this group.

In this background, the Population Council, in partnership with Child In Need Institute (CINI) in Kolkata, Deepak Charitable Trust (DCT) in Vadodara and International Institute for Population Sciences, Mumbai, initiated an intervention project, the First-time Parents Project. The project aimed to develop and test an integrated package of health and social interventions to improve married young women's reproductive and sexual health knowledge and practices, enhance their ability to act in their own interest and expand their social support networks. The project was formulated on the hypothesis that the periods immediately following marriage and surrounding the first pregnancy and birth, though periods of substantial vulnerability, offer a unique and powerful entry point for improving the situation of married young women.

The First-time Parents Project was implemented in two rural settings in India-Diamond Harbour Block in the state of West Bengal and Vadodara Block in the state of Gujarat. The intervention served several participants: newly-married young women, young women pregnant for the first time, postpartum first-time mothers, husbands of these young women, mothers and mothers-in-law, health care providers and the wider community. The intervention comprised of three mutually reinforcing components: information provision, health care service adjustments and group formation as a means of enhancing young women's social support networks. Intervention activities were implemented in a total of 24 villages - 2 in Diamond Harbour and 12 in Vadodara, each with a population of about 25,000. The intervention was launched in January 2003 and concluded in December 2004. In order to track the extent of married young women's exposure to the intervention and assess the intensity and breadth of their participation in intervention activities, a system of monitoring was adopted. This system also enabled CINI and DCT to monitor the progress of each component of the intervention and make adjustments in the implementation process, if necessary.

A quasi-experimental research design, with cross-sectional surveys undertaken prior to the implementation of intervention activities (baseline) and at its conclusion (endline) in control and intervention villages, was used to evaluate the effects of the intervention. Respondents for the baseline survey included young women married during the two years preceding the survey, young women pregnant for the first time at the time of the survey and young women who had delivered their first child during the 18 months preceding the survey. At the endline, the eligibility criteria were expanded in order to track as many baseline respondents as possible. Hence, respondents for the endline survey included young women married between 0 months and 4 years prior to the endline survey and who had never been pregnant; young women who were pregnant for 
the first time at the time of the endline survey; and young women who had delivered their first child up to 4 years prior to the survey. Respondents for the baseline and endline surveys were identified through a household listing in the study area, and all eligible women were invited to participate in the survey.

The findings from this study are encouraging. Findings indicate that in both sites the intervention had a significant, positive net effect on most indicators reflecting married young women's autonomy, social support networks, partner communication and knowledge of sexual and reproductive health. However, the net effect of exposure to the intervention was mixed with regard to indicators related to gender role attitudes and attitudes towards domestic violence. While exposure to the intervention had a significant, positive net effect on gender role attitudes in one of the sites, it did not influence attitudes towards domestic violence in either site.

The net effect of exposure to the intervention was mixed with regard to reproductive health practices as well. While exposure to the intervention had a significant, positive net effect on such indicators as use of contraceptives to delay the first birth, comprehensive antenatal care, delivery preparations, routine postpartum check-ups and breastfeeding practices in one or both sites, it did not appear to positively influence institutional delivery at first birth in either site.

While this study has several limitations that may have exaggerated the effects of the intervention, such as some self-selection of young women into the intervention activities and loss to follow-up, other shortcomings may have worked to conceal the effects of the intervention. Most notably, while few baseline respondents in control villages reported receiving reproductive health services, at endline it was evident that a substantial proportion of married young women in these villages had received information and services from government programmes during the course of the intervention. This made it difficult to compare the situation of intervention and control groups at the endline and to identify changes entirely attributable to exposure to the intervention. Also, due to the movement of young women between their marital and natal homes, exposure to the intervention was diminished for many of the participants. However, the overall pattern and general consistency of the findings give us confidence in the results.

Several lessons can be drawn from the experience of implementing the First-time Parents Project, which could be relevant for programmes targeted at married young women. First, even within the subset of young women who are married, there is diversity; for example, those who are trying to conceive, hoping to delay the first pregnancy, those who are pregnant and recent mothers. Hence there is a critical need to tailor the provision of information and services to the distinct life stages and needs of each group within the subset of married young women. Second, married young women in many settings in India travel frequently to their natal home, and often go there to deliver; it is therefore important to ensure that young women continue to maintain their ties with the intervention, even after they leave the intervention area. Third, given that many influential adults in the family were apprehensive of the social empowerment component of the intervention, it is important to train staff to build in activities into interventions that allay the fears of influential adults in the family, when working with married young women. Fourth, evidence shows that as a result of their lack of awareness, decision-making authority, control over resources and restricted mobility, married young women in India are less likely to seek appropriate and timely health care than older women. Providers need to be 
sensitised to the special needs of married young women, and it is essential to make special efforts to provide sexual and reproductive health information and services directly to this group through outreach services. Finally, the experience of several livelihoods programmes and social cohesion building interventions for adolescent girls has shown that these efforts may not reach - or may not adequately reach-many adolescent girls who are married; the experience of the First-time Parents Project shows that married young women can participate in such initiatives, but require specially focused efforts. Moreover, findings suggest that efforts to enhance married young women's agency and reduce their social isolation can also contribute to improve their reproductive health practices.

In short, the experience of the intervention demonstrates that it is feasible to improve married young women's reproductive health knowledge and practices, expand their sources of social support and involve them in activities with peers in safe spaces outside the home, and through the process empower them in their marital and familial relationships. Indeed, this approach can be considered as a model to replicate in other settings where early marriage is common. The positive effects of the intervention on women's agency and maternal and newborn health practices are significant, and could have a beneficial influence on other longer-term indicators not captured in this study, such as practices surrounding the second birth, child health outcomes, and indicators such as girls education that are affected by a mother's status. This model could also be integrated into existing NGO or government services, and could be tested for implementation on a larger scale. 


\section{Introduction}

A growing body of evidence from India and other countries shows that the situation and needs of married adolescent girls and young women are different from both that of unmarried adolescent girls and married adult women, posing distinct programme challenges (Clark, Bruce and Dude, 2006; Haberland, Chong and Bracken, 2004; Jejeebhoy, 2006; National Research Council and Institute of Medicine, 2005; Santhya and Jejeebhoy, 2003). For example, given the pressure to initiate childbearing soon after marriage in India, married young women are far more likely to experience regular sexual relations, less likely to use condoms and less likely to refuse sex than are unmarried sexually active adolescents or adult women. This places married young women at higher risk than unmarried sexually active adolescents of acquiring sexually transmitted infections and, among those under 16, at higher risk than married adult women of experiencing obstetric complications associated with early childbearing. Moreover, married young women are socially and economically more disadvantaged than their unmarried peers and married adult counterparts (Santhya and Jejeebhoy, 2003). For example, married adolescents are far less likely than older married women to report involvement in decision-making pertaining to their own lives, access to economic resources or mobility within and outside the marital village. These differences call for specific strategies to meet the special needs of married adolescent girls and young women.

While recent policies and programmes have recognised the special needs of married adolescents and young women, their effective implementation has been handicapped by the lack of evidence on the kinds of intervention models that are feasible and effective in improving the situation of this group. In this background, the Population Council, in partnership with Child In Need Institute (CINI) in Kolkata, Deepak Charitable Trust (DCT) in Vadodara and International Institute for Population Sciences, Mumbai, initiated an intervention project, the First-time Parents Project. The project aimed to develop and test an integrated package of health and social interventions to improve married young women's reproductive and sexual health knowledge and practices, increase their ability to act in their own interest and expand their social support networks.

The project was formulated on the hypothesis that the periods immediately following marriage and surrounding the first pregnancy and birth, though periods of substantial vulnerability, offer a unique and powerful entry point for improving the situation of married young women.

This report describes the First-time Parents Project and examines the extent to which the intervention improved the social and reproductive health situation of married young women. Specifically, the report assesses the extent to which exposure to the intervention influenced young women's agency and social support networks; knowledge of key reproductive health issues; reproductive health behaviours, including the use of contraceptives to delay pregnancy and the use of appropriate pregnancy-related health services; and partner communication and support. 


\section{Background}

While age at marriage has been increasing among younger cohorts, as recently as in 2005-06, more than two-fifths (47\%) of all women in India aged 20-24 were married by 18 years (IIPS and Macro International, 2007a). Marriage at an early age not only violates girls' rights and truncates their childhood, it also places them at risk of an array of adverse sexual and reproductive health outcomes. For example, emerging evidence suggests that in settings where marriage marks sexual initiation for girls, but not necessarily for boys, early marriage may place young females at special risk of acquiring HIV and other sexually transmitted infections (Clark, Bruce and Dude, 2006; National Research Council and Institute of Medicine, 2005). A recent review of evidence on the prevalence of HIV infection among married young women in India reports that in a number of hospital-based retrospective studies conducted among HIV-positive women, a substantial proportion of those infected were young women whose only HIV risk factor was sexual relations with their spouses (Santhya and Jejeebhoy, 2007). HIV prevalence rates ranging from $0.3-1.3$ percent among young women attending antenatal clinics to 15-21 percent among young women attending sexually transmitted diseases (STD) clinics are reported in various studies (Kumar et al., 2006; Mehta et al., 2006). Likewise, while evidence on the precise mechanism that places adolescent girls at greater risk of adverse maternal health outcomes than older women remains sketchy (Jejeebhoy, 2006), findings from community-and facility-based studies in India show that adolescent girls are significantly more likely to experience maternal morbidity and mortality than are older women (Bhatia, 1988; Krishna, 1995; Mishra and Dawn, 1986; Pachauri and Jamshedji, 1983; Pal, Gupta and Randhawa, 1997 ; Swain et al., 1993).
Peri-natal and neonatal mortality rates are also found to be significantly higher among adolescent mothers than among mothers in their 20s and 30s (Hirve and Ganatra, 1994; IIPS and Macro International, 2007a).

Moreover, a number of social and economic disadvantages are associated with early marriage. For example, girls who marry early typically have lower levels of educational attainment, limited or even absent peer networks, restricted mobility and less access to mass media than boys, unmarried girls or married adult women (Haberland, Chong and Bracken, 2004; IIPS and Population Council, 2007; Santhya and Jejeebhoy, 2006). In addition, married adolescents are far less likely than older married women to report involvement in decisions pertaining to their own lives and access to economic resources (Santhya and Jejeebhoy, 2006).

Insulated from new ideas, and isolated from support networks, married adolescent girls are similarly less likely than older women to be aware of key sexual and reproductive health issues (Santhya and Jejeebhoy, 2006). While awareness of contraceptives is almost universal among both married adolescent and adult females, awareness of specific contraceptive methods, especially reversible methods that are more appropriate for adolescents, is relatively limited among married adolescent girls. For example, an analysis of National Family Health Survey (NFHS-2) data shows that only three-fifths of married adolescent girls were aware of condoms, compared to over four-fifths of 20-24 year-old women married at 18 years or above. Age-specific differences with regard to awareness of AIDS are similarly wide: fewer than one-third of evermarried adolescents compared to almost three-fifths of 20-24 year-old women married at 18 years or above had ever heard of AIDS (Santhya and Jejeebhoy, 2006). 
Also notable is evidence from a number of studies that shows that despite being at special risk of experiencing adverse sexual and reproductive health outcomes, married adolescent girls are as likely or even less likely to seek prompt and appropriate sexual and reproductive health services as compared to older women. For example, an analysis of NFHS-2 data shows that compared to women who delivered at ages 19-23, women who delivered at ages below 18 years were less likely to use antenatal services and skilled delivery care (Reynolds, Wong and Tucker, 2006). Likewise, while about the same proportion of adolescents and 20-24 year-old women married at 18 years and above reported symptoms of abnormal vaginal discharge (26\%), adolescent girls were considerably less likely to seek care for this condition: 26 percent compared to 38 percent (Santhya and Jejeebhoy, 2006). Such disparities persist in the use of family planning methods as well - only 13 percent of currently married adolescent women were practising some form of contraception in 2005-06 compared to 33 percent of 20-24 year-old married women (IIPS and Macro International, 2007a). Unfortunately, few providers and programmes have been sensitive to the significant differences in the situation of married adolescents and young women and, as a result, have continued to address their needs as they would the needs of married adults (Jejeebhoy, 2006). Indeed, a recent study conducted among health care providers in rural settings in two states in India reports that a large proportion of providers believe that the health service needs of married females are similar, irrespective of whether they are young or adult (Santhya et al., 2007).

The policy and programme environment in India has only recently begun to recognise adolescents as a vulnerable group with special sexual and reproductive health needs. The National Population
Policy 2000 recognised, for the first time, that adolescents constitute an under-served group and underscored the need to "ensure for adolescents access to... counselling and services, including reproductive health services, that are affordable and accessible," and to "strengthen primary health centres and sub-centres to provide counselling, both to adolescents and also to newly-weds" (MOHFW, 2000). Likewise, the National Youth Policy 2003 recommended the establishment of "adolescent clinics" to provide counselling and treatment, and "youth health associations" at the grassroots level to provide family welfare and counselling services to young people (Ministry of Youth Affairs and Sports, 2003). The Reproductive and Child Health (RCH) Programme II notes that friendly services are to be made available for adolescents, married and unmarried, girls and boys (MOHFW, 2006). While these initiatives are commendable, most of the programmes have been recently launched and are yet to be effectively implemented across the country. Moreover, there is a tendency to overlook the fact that newly-married young women often do not have the mobility, decision-making ability or access to resources in their marital homes to seek information, counselling or care on their own; therefore they require more concerted provider contacts within the home than older women, as well as focused interventions that aim to ameliorate the social disadvantages faced by these young women.

In India, non-governmental organisations (NGOs) have pioneered a number of interventions targeted at adolescents. However, while several interventions aim to address the factors underlying the social and economic disadvantages that adolescent girls face, most of these have typically focused on unmarried adolescents. Although some projects have made efforts to include all adolescent girls regardless 
of their marital status, it has been noted that by and large few married girls participate in such interventions. For example, a livelihoods programme for adolescents conducted by SEWA and the Population Council was open to both married and unmarried girls; however, only 3 percent of the participants were married (Kalyanwala et al., 2006).

Only a few intervention projects that target married adolescents, such as the First-time Parents Project, have been implemented in India. Each project is unique, not only in terms of its geographic location but also in terms of its approach - some focus on the provision of information, some are clinic-based and others address influential adults (Haberland, Chong and Bracken, 2004). Indeed, findings from these programmes could provide an important insight into what does and does not work with regard to programming for married young women in India.

\section{Study setting}

The First-time Parents Project was implemented in two rural settings in India -- Diamond Harbour Block in the state of West Bengal and Vadodara Block in the state of Gujarat. The project sites and states were purposely selected, taking into consideration the presence of NGOs with an interest in working with married young women, the NGOs' ties to the communities where they work and their experience in both clinic and outreach programmes.

West Bengal, situated in the eastern part of the country, has a total population (projected population for the year 2007) of 86.1 million (Office of the Registrar General and Census Commissioner, India, 2006). Latest evidence from the NFHS (2005-06) indicates that 53 percent of women aged 20-24 were married by age 18 in the state. In rural areas, as many as 63 percent of 20-24 year-olds were married by age 18. Moreover, one-fourth of 15-19 year-old girls were already mothers or pregnant at the time of the survey (IIPS and Macro International, 2007b). Gujarat, situated on the west coast of India, has a total population (projected population for the year 2007) of 55.8 million (Office of the Registrar General and Census Commissioner, India, 2006). Compared to West Bengal, a smaller proportion of 20-24 year-old women were married by age 18 in Gujarat - 38 percent in rural areas and 34 percent in the state as a whole. Likewise, far fewer 15-19 year-old girls (13\%) were already mothers or pregnant in Gujarat (IIPS and Macro International, 2007c). In both states, as in most parts of India, the sex ratio is skewed in favour of males over females, but more dramatically skewed in Gujarat than West Bengal (see Table 1.1). Gujarat is comparatively more urbanised than West Bengal (37\% versus $28 \%$ ) (RGI, 2001).

A few key indicators of the study districts, and the states in which they are located, are presented in Table 1.1.

The intervention villages were selected by CINI and DCT in their respective areas. The intervention sites in Diamond Harbour included 12 villages where no activities had been initiated by any NGO prior to the implementation of the project. Another 13 villages without any NGO intervention activities served as control villages. The intervention sites in Vadodara included 12 villages where DCT has ongoing activities on safe motherhood, adolescent reproductive health, sexual health, gender-based violence and self-help groups. Since it was not possible to select control sites from villages with similar interventions, 12 villages were chosen as control sites that had not been the focus of DCT intervention activities but were comparable with the experimental villages in terms of the socio-demographic characteristics of the residents. 
Table 1.1:

\section{Profile of study districts and states}

\begin{tabular}{|c|c|c|c|c|}
\hline Characteristics & $\begin{array}{l}\text { South } 24 \text { Pargana } \\
\text { District, } \\
\text { West Bengal }\end{array}$ & $\begin{array}{c}\text { West Bengal } \\
\text { State }\end{array}$ & $\begin{array}{l}\text { Vadodara } \\
\text { District, } \\
\text { Gujarat }\end{array}$ & $\begin{array}{l}\text { Gujarat } \\
\text { State }\end{array}$ \\
\hline Population $^{1}$ & $6,909,015$ & $86,125,000$ & $3,639,775$ & $55,808,000$ \\
\hline Overall sex ratio ${ }^{2}$ & 938 & 934 & 919 & 921 \\
\hline Child sex ratio ( $0-6$ years $)^{2}$ & 969 & 963 & 875 & 878 \\
\hline Male literacy $(\%)$ & 79.9 & 77.6 & 80.7 & 80.5 \\
\hline Female literacy $(\%)$ & 59.7 & 60.2 & 61.3 & 58.6 \\
\hline Current contraceptive use $(\%)^{3}$ & 73.4 & 71.2 & 61.5 & 66.6 \\
\hline $\begin{array}{l}\text { Mothers who had at least three } \\
\text { antenatal check-ups for the last } \\
\text { birth }(\%)^{3}\end{array}$ & 65.4 & 62.4 & 71.1 & 64.9 \\
\hline Institutional delivery $(\%)^{3}$ & 30.5 & 43.1 & 55.8 & 54.6 \\
\hline $\begin{array}{l}\text { Mothers who received postnatal } \\
\text { care within two days of delivery } \\
\text { for their last birth }(\%)^{3}\end{array}$ & NA & 37.8 & NA & 54.0 \\
\hline
\end{tabular}

NA: Notavailable

${ }^{1}$ District population data are from the 2001 census; the state population data are projected figures for the year 2007.

${ }^{2}$ Sex ratio: number offemales per 1,000 males.

${ }^{3}$ District-level data are from Reproductive and Child Health-District Level Household Survey 2002-04; state-level data are from NFHS, $2005-06$.

Sources: IIPS, 2006; IIPS and Macro International, 2007b; 2007c; Office of the Registrar General and Census Commissioner, India, 2006 ; RGI, 2001.

\section{Study design}

A quasi-experimental research design, with cross-sectional surveys undertaken in control and intervention villages prior to the implementation of intervention activities (baseline) and at its conclusion (endline), was used to evaluate the effects of intervention activities.

Respondents for the baseline survey included young women who were newly married, first-time pregnant and first-time mothers. Newly-married women were defined as those who had been married for two years or less at the time of the survey and had never been pregnant; first-time pregnant women were those who had not previously had a live birth but were pregnant at the time of the survey; and first-time mothers included those who had a first live birth and were within 18 months postpartum at the time of the survey. Respondents for the baseline survey were identified through a household listing in the study area and all eligible women were invited to participate in the survey. The baseline survey was conducted between September 2002 and early February 2003.

At the endline, eligibility criteria were expanded in order to track as many baseline respondents as possible. Hence, respondents for the endline survey included young women married between 0 months and 4 years prior to the endline survey who had never been pregnant; young women who were pregnant for the first time at the time of the endline survey; and young women who had delivered their first child up to 4 years prior to the survey. As with the baseline survey, respondents for the endline survey were identified through a household listing and all eligible women were invited to participate in the survey. The endline 
survey was conducted during March-December 2005 in all the villages surveyed at the baseline except one in Vadodara.

In order to track the extent of married young women's exposure to the intervention and assess the intensity and breadth of their participation in intervention activities, a system of monitoring was adopted with the support of Foundation for Research in Health Systems, Ahmedabad. This system also enabled CINI and DCT to monitor the progress of each component of the intervention and make adjustments in the implementation process, if necessary.

\section{Response rates}

Refusal rates were low at the baseline in all four sites, ranging from zero percent in control villages in Diamond Harbour to 2 percent in intervention villages in Vadodara (Table 1.2). At the endline, refusal rates were slightly higher, particularly in Diamond Harbour; 3-7 percent in intervention and control villages in Diamond Harbour compared to 1 percent or less in Vadodara. Of note is that sizeable proportions of women were lost for interview at the baseline and endline because they were not at home even after field teams made 3-4 visits. The main reason why potential respondents were not available was that, in both sites, it is common for married young women to move back and forth between their marital and natal homes during the initial months of marriage, and for pregnant young women to go back to their natal home for the first delivery. The proportion of potential respondents thus lost for interview ranged from 18 percent in control villages in Diamond Harbour to 30 percent in control villages in Vadodara at the baseline, and from 15 percent in intervention villages in Diamond Harbour to
35 percent in control villages in Vadodara at the endline.

At the baseline, 1,324 and 1,538 eligible women were identified in Diamond Harbour and Vadodara, respectively. Of those, 1,036 and 1,079 women in Diamond Harbour and Vadodara, respectively, were interviewed. While the response rate was lower in intervention villages than in control villages in Diamond Harbour (75\% versus 83\%), the rates were roughly similar in both intervention and control villages in Vadodara (71\% and 69\%, respectively).

At the endline, 2,824 eligible women were identified in Diamond Harbour, of whom 2,193 were interviewed, giving a response rate of 82 percent and 72 percent in intervention and control villages, respectively. In Vadodara, a total of 3,451 women were identified, of whom 2,362 were interviewed, with a response rate of 71 percent and 65 percent in intervention and control villages, respectively.

While the study was designed as two crosssectional surveys (one at baseline and one at endline), it also aimed to capture longitudinal changes. To do so, permission was obtained from the baseline respondents to contact them again at the endline, and the selection criteria expanded at the endline so that a significant proportion of baseline respondents would again be eligible for interview. Of the 1,036 respondents interviewed at the baseline in Diamond Harbour, a larger proportion of women in intervention villages than in control villages were interviewed at the endline (70\% versus 57\%) (see Table 1.3). In Vadodara, the follow-up rates were the same in both intervention and control villages ( $48 \%$ and $49 \%$, respectively), but were far lower than the follow-up rates in Diamond Harbour. Reasons for loss to follow-up included households having 
Table 1.2:

\section{Response rates at baseline and endline surveys}

Baseline
Number of eligible women identified
Number of women interviewed
Number of women partially interviewed
Number of women refused
Number of women not at home
Response rate (\%)
Endline
Number of eligible women identified
Number of women interviewed
Number of women partially interviewed
Number of women refused
Number of women not at home
Response rate (\%)

migrated out of project villages, particularly in Vadodara where economic opportunities for out-migration exceed those available in Diamond Harbour; non-availability of respondents even after 3-4 visits to the household due to the frequent movement of young women between their natal and marital homes; the difficulty in reaching many respondents who were interviewed in their natal home at the baseline but had gone back to their marital home by the time of the endline survey; and respondents not being eligible at the time of the endline survey (see Appendix 1).

\section{Limitations}

This study has several limitations that may affect its ability to fully assess the effects of the intervention.

Table 1.3:

\section{Follow-up rate}

\begin{tabular}{l|c|c|c|} 
& \multicolumn{2}{c|}{ Diamond Harbour } & \multicolumn{2}{c}{ Control } \\
\cline { 2 - 4 } & Intervention & Control & Intervention \\
\hline $\begin{array}{l}\text { Number of women interviewed } \\
\text { at baseline }\end{array}$ & 580 & 456 & 550 \\
$\begin{array}{l}\text { Number of women also interviewed } \\
\text { at endline }\end{array}$ & 403 & 259 & 264 \\
Follow-up rate $(\%)$ & 69.5 & 56.8 & 48.0 \\
\end{tabular}


First, intervention and control villages in both sites were not strictly comparable. In Vadodara, intervention villages had received a fair amount of programmatic input from DCT even before the First-time Parents Project began; undoubtedly, a community that has already been the focus of relatively intensive interventions is not ideal for assessing the effects of a new intervention. In Diamond Harbour, control villages differed significantly from intervention villages in terms of married young women's socio-demographic characteristics, including age, educational status, religion and standard of living; married young women in control villages were more likely to be older, more educated, from Hindu households and from economically better-off families (see Appendix 2). We note that these differences make comparisons difficult.

Second, while at the baseline few respondents in control villages reported having received any reproductive health services, this changed over the course of the project. The endline data show that control villages in both sites did receive reproductive health information and services from government programmes during the intervention period (see Appendix 3). This further compromised the comparability of intervention and control villages.

Third, we were aware of the frequent movement of married girls between their marital and natal homes during the initial months of marriage and of the practice of pregnant young women going back to their natal home for their first delivery. While we thus tried to compensate for the possible loss to follow-up as a result of these practices at the outset in both the research (interviewing all eligible married young women, irrespective of whether they were usual residents or visitors) and the intervention (reaching all eligible married women, irrespective of whether they were usual residents or not, and keeping entry into and exit out of the intervention activities open during the intervention phase), both the research and intervention activities were affected in a number of ways. For example, non-availability of respondents due to their movement between their natal and marital homes substantially reduced the coverage of both the baseline and endline surveys and contributed to loss to follow-up at the endline of married young women who participated in the baseline survey and/ or benefited from intervention activities. Moreover, movement between natal and marital homes also diminished young women's exposure to different components of the intervention. We also note the possibility of this weakening the effects of the intervention on some of the expected outcomes, including married young women's reproductive health practices, since the intervention could not influence the family or health service environment outside the project sites. For example, it is possible that a young woman who wanted to have an institutional delivery might have gone back to her natal home (outside the project site) only to find that her family was not supportive of an institutional delivery or that the health facility was not easily accessible.

Fourth, even though intervention activities were open to all eligible married young women, and CINI and DCT did their best to encourage the participation of all eligible women, self-selection of young women into intervention activities did occur. Indeed, a comparison of the background characteristics of the baseline respondents in intervention villages who were exposed to the intervention and those who were not indicates significant differences (see Appendix 4). In both Diamond Harbour and Vadodara, married young women who were exposed to the intervention 
were more likely to be recently married or first-time pregnant, less likely to be first-time mothers, more likely to have their marital home in intervention villages and less likely to have their natal home in intervention villages as compared to those who were not exposed to these activities. In Diamond Harbour, participants were also more likely to be younger, more likely to be Hindu and less likely to be Muslim. In Vadodara, participants were also more likely to be better educated.

Finally, we acknowledge that the substantial loss to follow-up raises concerns about bias. An examination of the differentials in baseline background characteristics of married young women who were followed up at the endline and those who were not indicates no significant difference between the two groups in terms of age and religion in both settings (see Appendix 5). However, women who were followed up were more likely to be from economically better-off households and to be residing in their marital home (vs. their natal home) within the project sites in both Diamond Harbour and Vadodara.
Additionally, in Diamond Harbour, married young women who were followed up were more educated than those who were not.

\section{Structure of the report}

The report is structured as follows. Chapter 2, drawing on data from the baseline survey, presents the social and reproductive health situation of married young women in the project villages. Chapter 3 briefly describes the steps that led to the design of the intervention project, the objectives of the intervention, the key components of the intervention and its reach, and the challenges faced in implementing intervention activities. Chapter 4 examines the extent to which exposure to the intervention influenced young women's agency, gender role attitudes and social support networks; reproductive health knowledge and practices; and partner support and communication. Chapter 5 summarises the main findings of the study, and highlights the lessons learnt from implementing this model, which would be relevant to programmes targeting married young women. 


\section{Social and reproductive health situation of married young women}

Drawing on data from the baseline survey, this chapter sets the context in which intervention activities were implemented. It presents the background characteristics of respondents, and profiles their social characteristics including their autonomy, mobility, social support networks and gender role attitudes. It also discusses married young women's knowledge and practices related to key sexual and reproductive health matters. The extent of partner communication and support in marital relationships is also described.

\section{Background characteristics}

Table 2.1 presents the background characteristics of respondents in Diamond Harbour and Vadodara. In both sites, the majority of respondents were adolescents (that is, aged less than 20). Husbands were typically older than their wives, particularly in Diamond Harbour. One-third of respondents were recently married and more than one-half were firsttime mothers. While the vast majority of respondents in both sites had completed some years of schooling, many had discontinued their education after primary school. The median age at marriage was 17 years in both Diamond Harbour and Vadodara.

While a significant proportion of respondents in Diamond Harbour were Muslim (54\%), respondents in Vadodara, were predominantly Hindu (99\%). The majority of respondents in Diamond Harbour, and almost all in Vadodara, lived in non-nuclear families. A sizeable proportion of married young women in Diamond Harbour lived in households with a low standard of living; in contrast, only a small proportion of respondents lived in such households in Vadodara (see Appendix 6 for details of the standard of living index).

Table 2.1:

Characteristics of married young women, baseline survey

\begin{tabular}{l|c|c|}
\hline Characteristics & $\begin{array}{c}\text { Diamond } \\
\text { Harbour } \\
(\mathbf{N}=\mathbf{1 , 0 3 6})\end{array}$ & $\begin{array}{c}\text { Vadodara } \\
(\mathbf{N}=\mathbf{1 , 0 7 9})\end{array}$ \\
\hline Age & 19.4 & 19.4 \\
Mean age & & \\
Husband's age & 25.8 & 22.2 \\
Mean age & & \\
Current status (\%) & 31.8 & 37.0 \\
Newly married & 13.8 & 11.2 \\
First-time pregnant & 54.4 & 51.8 \\
First-time mother & & \\
Years of schooling \\
completed
\end{tabular}

Note: See Appendix 6 for details of the standard of living index. 


\section{Agency, gender role attitudes and social support networks}

To capture married young women's social situation, the survey explored their involvement in decisions related to household purchases, their mobility, gender role attitudes and attitudes towards domestic violence, and social support networks. Findings, described below, indicate the profound social vulnerability of married young women.

\section{Decision-making}

Married young women's role in household decisionmaking was quantified by an index that summed responses regarding women's involvement in the purchase of five household items (food, small gifts, jewellery, clothes and other expensive items), assigning a score of 0 if the woman did not participate in the decision, 1 if she made the decision jointly with other family members and 2 if she made the decision independently. The index thus ranged from 0 to 10 (Cronbach's alpha $=0.91$ and 0.95 for

Diamond Harbour and Vadodara, respectively). Not surprisingly, the analysis indicated that married young women were clearly “junior” partners in household decision-making in both sites; the mean value of the decision-making index was 1.8 in Diamond Harbour and 1.5 in Vadodara (not shown in tabular form).

\section{Mobility}

The survey explored married young women's mobility by asking respondents whether they could go unescorted to eight destinations within and outside the marital village (to visit a relative or friend in the village, a relative or friend in a nearby village, a health facility in the village, a health facility in a nearby village, the cinema, bank, post office, and an NGO or government programme). An index of mobility summed the responses, assigning a score of 0 if the respondent had to be accompanied and 1 if she could go unescorted to each destination. The value of the index ranged from 0 , indicating no mobility, to 8 , indicating a high degree of mobility (Cronbach's alpha $=0.84)$. Findings clearly indicate that young women's mobility was extremely limited; the mean score was 0.89 in Diamond Harbour and 0.79 in Vadodara (not shown in tabular form).

\section{Gender role attitudes}

To capture married young women's gender role attitudes, respondents were asked whether they agreed or disagreed with the following seven statements: a husband should help with the children and household chores; a woman should be allowed to work for wages; girls should be allowed to decide when and whom to marry; a husband should decide how household money is spent; when money is scarce, boys' education should be given priority over that of girls; a husband cannot play any role during labour and childbirth; and if a woman's opinion differs from that of her husband's, she must accept his opinion. A principal component analysis identified the four issues that grouped together, namely, women's participation in paid work, sharing of domestic responsibilities between husband and wife, adolescent girls' right to have a say in marriage-related decisions and husband's control over household expenses. The respondent was assigned a score of 1 for each gender egalitarian statement with which she agreed and 0 if she disagreed. Similarly, a score of 1 was assigned for each gender non-egalitarian statement with which she disagreed and 0 if she agreed. Responses were summed to create an index of gender role attitudes. The value of the index ranged from 0 , indicating traditional attitudes, to 4 , indicating egalitarian attitudes (Cronbach's 
alpha $=0.48$ and 0.55 for Diamond Harbour and Vadodara, respectively). Findings suggest a mix of egalitarian and traditional gender role

attitudes; the mean value of the index was

2.4 in Diamond Harbour and 2.8 in

Vadodara (Figure 2.1).

\section{Attitudes towards domestic violence}

The survey also explored married young women's attitudes towards the non-acceptability of wife-beating. An index was created that sums women's responses to whether they thought a husband was justified in beating his wife in eight different situations: if her natal family does not give expected money, jewellery or other items; if she refuses to have sexual relations with her husband; if her husband does not like the food she cooked; if she disobeys elders in the family; if she uses contraception without her husband's permission; if she disobeys her husband; if she neglects the house or children; and if her husband suspects her of being unfaithful. The index was calculated by assigning a score of 0 if the respondent felt wife-beating was justified and 1 if she felt that

Figure 2.1:

Married young women's gender role attitudes and attitudes towards domestic violence, baseline survey

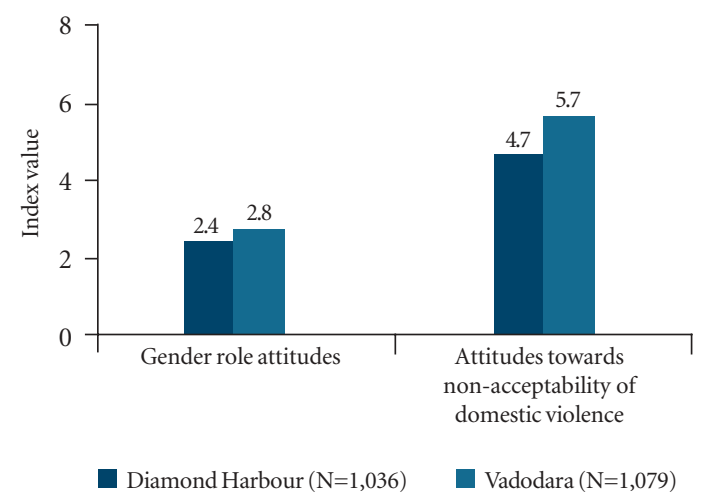

wife-beating was not justified; the value of the index ranged from 0 indicating attitudes that justified wife-beating in all circumstances to 8 indicating attitudes that did not justify wife-beating in any circumstances (Cronbach's alpha $=0.76$ and 0.79 for Diamond Harbour and Vadodara, respectively). Data indicate that the majority of young women, particularly in Vadodara, believed that wife-beating was not justified; the mean value of the index was 4.7 in Diamond Harbour and 5.7 in Vadodara (Figure 2.1).

\section{Social support networks}

The study explored the extent of married young women's social support networks, including contact with peers and membership in community organisations. In both sites, married young women had limited contact with peers in their marital village. While the majority of women reported having friends in their natal village, only 7 percent of women in Diamond Harbour and 25 percent in Vadodara reported having friends in their marital village (Figure 2.2). Moreover, among those who did report friends in the marital village, interaction with peers was limited. The study also assessed the extent to which young women reported friends as a confidante with whom they could discuss personal and health-related issues. The respondent was assigned a score of 1 if she reported that she would confide in a friend on each the following six issues: spousal relations, sex, pregnancy/childbirth, family planning, wage work and problems in the marital family, and 0 if she did not report a friend as a confidante. Responses were summed to create an index of peer support; the value of the index ranged from 0 indicating no peer support to 6 indicating strong peer support (Cronbach's alpha $=0.64$ and 0.72 for Diamond Harbour and Vadodara, respectively). 
Figure 2.2:

Married young women's connections with peer networks, baseline survey

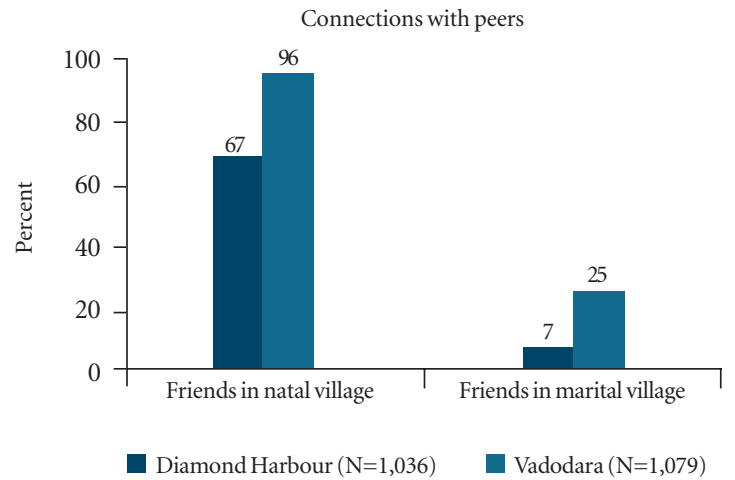

Data indicate that the majority of young women in both sites had little peer support; the mean value of the index was 0.16 in Diamond Harbour and 0.24 in Vadodara (not shown in tabular form). Further, in both sites, married young women's association with community groups and organisations was negligible, with fewer than 2 percent reporting membership in a community group or organisation (not shown in tabular form).

\section{Knowledge of sexual and reproductive health matters}

The baseline survey also assessed married young women's sexual and reproductive health knowledge, quantified by an index that summed young women's responses to 17 questions relating to sexual and reproductive health matters. These questions broadly covered their awareness of contraceptive methods, pregnancy-related issues including complications during pregnancy, delivery, the postpartum period and in newborns, newborn care, and STIs/HIV. The respondent was assigned a score of 1 for each question that was correctly answered and 0 otherwise. Scores were summed to create the index, the value of

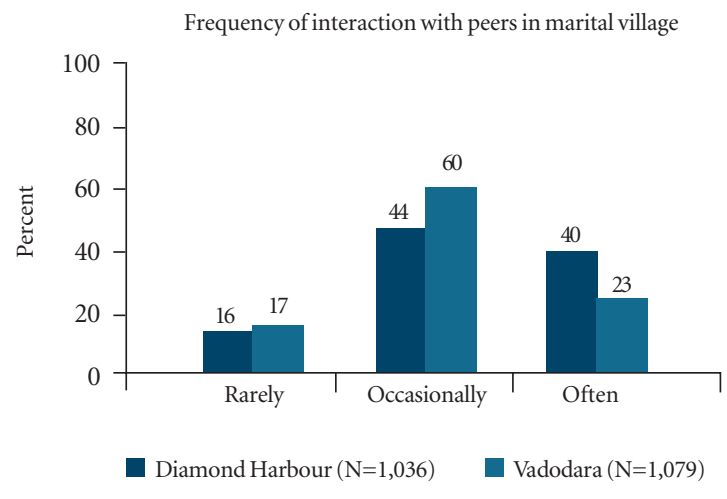

which ranged from 0 indicating no awareness to 17 indicating high levels of awareness (Cronbach's alpha $=0.71$ and 0.63 for Diamond Harbour and Vadodara, respectively). Findings indicate considerable lack of in-depth awareness of sexual and reproductive health matters; the mean value of the index was 6.9 in Diamond Harbour and 5.0 in Vadodara (not shown in tabular form).

Not surprisingly, married young women's access to reproductive health information from health care providers was limited in both sites. Only two in five women in Diamond Harbour, and no more than one in five women in Vadodara, reported that a health worker had discussed a reproductive health topic with them. Moreover, the information provided appeared to be skewed toward antenatal care. For example, while 38 percent and 21 percent of women in Diamond Harbour and Vadodara, respectively, reported that a health worker had discussed care during pregnancy with them, far fewer women (only 6\% and 4\% in Diamond Harbour and Vadodara, respectively) reported that a health worker had discussed reproductive tract infections or HIV/AIDS with them (not shown in tabular form). 


\section{Reproductive health practices}

The survey also enquired into married young women's reproductive health practices, including contraceptive use and maternal health practices, and findings indicate several areas that require attention. For example, although awareness of contraceptive methods was high, contraceptive use was limited in both sites; only 48 percent and 34 percent of married young women in Diamond Harbour and Vadodara, respectively, had ever used a contraceptive method. While a substantial proportion of women (two-thirds in both sites) had wanted to have their first pregnancy at least a year after marriage, only a small percentage had used a contraceptive method to delay the first pregnancy; indeed, only 28 percent of women in Diamond Harbour and 22 percent in Vadodara reported having used a method to delay their first pregnancy, irrespective of whether or not they had wanted to delay the first pregnancy (Figure 2.3).

With regard to maternal and child health practices, three-fifths of first-time mothers in Diamond Harbour and over one-half in Vadodara reported receiving at least three antenatal check-ups (Figure 2.4). The extent to which first-time mothers received comprehensive antenatal care was also

Figure 2.3:

Married young women who wanted to delay the first pregnancy and who had used a contraceptive method to delay first pregnancy, baseline survey

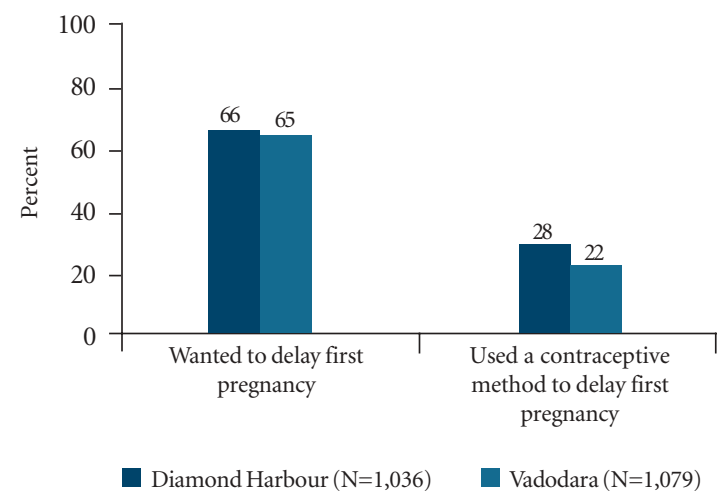

explored, and was quantified by a summary index. The respondent was assigned a score of 1 for each of the following components of care received and 0 if she reported otherwise: an early antenatal check-up, at least three antenatal check-ups, weight measured, height measured, blood pressure checked, blood tested, urine tested, abdomen examined, an internal examination, an adequate supply of iron and folic acid supplements and at least one tetanus toxoid injection. Scores were summed to create an index of comprehensive antenatal care; the value of the index ranged from 0 indicating no antenatal care to 11 indicating comprehensive care (Cronbach's alpha $=0.73$ and 0.86 for Diamond Harbour and Vadodara, respectively). Findings indicate that antenatal care received by first-time mothers was far from comprehensive; the mean value of the index was 6.2 in Diamond Harbour and 6.9 in Vadodara (not shown in tabular form).

The survey also examined the extent to which first-time mothers made preparations for delivery, and was quantified by a summary index. The respondent was assigned a score of 1 for each of the following preparations made and 0 if she reported otherwise: identified a trained birth attendant to attend the delivery or a hospital for delivery; identified a hospital where she would go for the delivery; saved money to meet delivery expenses; kept clean cotton wool, clothes and other necessities ready for use; identified a hospital to go to in case of an emergency; and identified transport by which to reach the hospital in an emergency. Scores were added to create an index of delivery preparations; the value of the index ranged from 0 indicating no delivery preparations to 6 indicating appropriate delivery preparations (Cronbach's alpha $=0.41$ and 0.89 for Diamond Harbour and Vadodara, respectively). Findings indicate that delivery preparations made by first-time mothers were rather limited; the mean value of the 
Figure 2.4:

Maternal and child health practices reported by first-time mothers, baseline survey

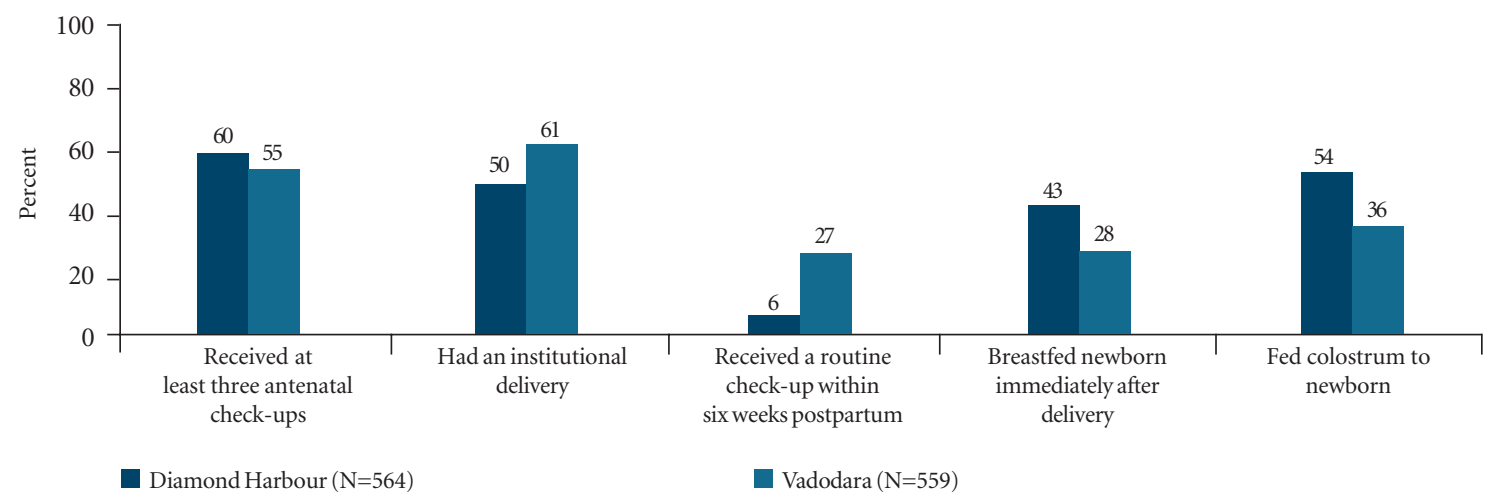

index was 2.4 in Diamond Harbour and 2.6 in

Vadodara (not shown in tabular form).

Half or more of first births took place in a health facility in both sites - 50 percent in Diamond Harbour and 61 percent in Vadodara (Figure 2.4). While the above-noted findings are to some extent encouraging, other aspects of maternal health care are not as positive. Routine postpartum check-ups were relatively rare; only 6 percent of mothers in Diamond Harbour and 27 percent in Vadodara reported having had a check-up within six weeks of delivery.

Care of newborns was also far from adequate. The majority of women in both sites did not immediately breastfeed their newborns; over two-fifths (43\%) of mothers in Diamond Harbour and a little over one-fourth (28\%) in Vadodara had started breastfeeding their newborns immediately after birth (Figure 2.4). Only 54 percent of young mothers in Diamond Harbour and 36 percent in Vadodara reported feeding colostrum to the newborn.

\section{Partner communication and support}

The extent of partner communication in marital relationships and the support that married young women received from their husbands were also explored in the baseline survey. Findings indicate that discussions between married young women and their husbands regarding contraceptive use and timing of the first pregnancy were relatively common in both sites. Three-fourths (75\%) of women in Diamond Harbour and nearly two-fifths (39\%) in Vadodara reported having discussed contraceptive use with their husbands. Likewise, 93 percent of women in Diamond Harbour and 84 percent in Vadodara reported that they had discussed the timing of their first pregnancy with their husbands (Figure 2.5).

To assess partner support, married young women were asked questions on the extent to which husbands supported them during conflicts with family members, women's ability to express their opinion in the event of a disagreement with their husbands, and the extent of support that first-time mothers had received from their husbands during pregnancy, delivery and the postpartum period. While the majority of young women in Vadodara (71\%) reported that their husbands always or frequently supported them during family conflicts, far fewer (16\%) reported similar support in Diamond Harbour. Large proportions of women in both sites reported telling their husbands when they disagreed with them $(68 \%$ in Diamond Harbour and $73 \%$ in Vadodara; see Figure 2.6). 
Sizeable proportions of first-time mothers in both sites reported having received some support from their husbands during pregnancy (not shown in tabular form). More than one-half (53\%) of young mothers in Diamond Harbour, and nearly one-half (47\%) in Vadodara had received help from their husbands in accessing health services, and

Figure 2.5:

Spousal communication on sexual and reproductive health topics reported by married young women, baseline survey

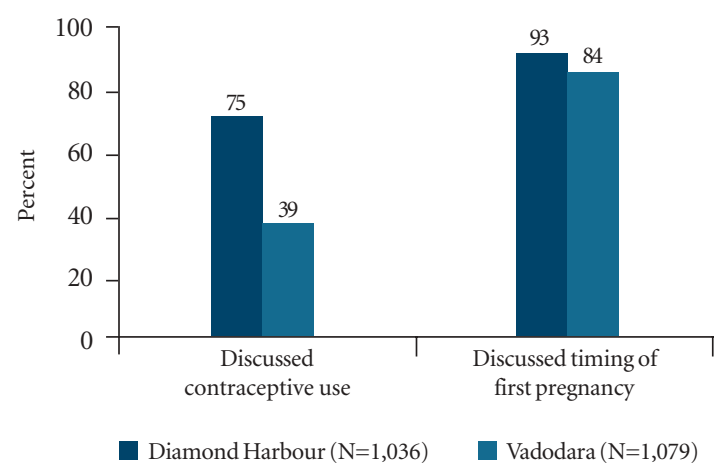

Figure 2.6:

Married young women who were supported by their husbands during family conflicts and who expressed their opinion when they disagreed with their husbands, baseline survey

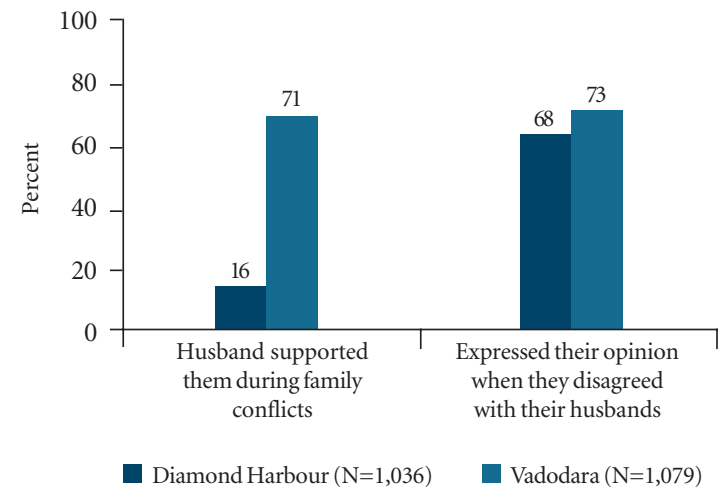

79-83 percent had received emotional support from them during this period. However, only 17-19 percent had received help from their husbands with household chores. Receiving some form of assistance from husbands in preparing for the delivery was fairly common, particularly in Diamond Harbour (with $81 \%$ of mothers in Diamond Harbour and 50\% in Vadodara reporting such assistance). The most common forms of support received from husbands in relation to delivery in both sites were saving money to meet delivery expenses (with $47 \%$ and $29 \%$ of mothers in Diamond Harbour and Vadodara, respectively, reporting so) and emotional support (59\% and 28\% in Diamond Harbour and Vadodara, respectively, reporting so). During the postpartum period, however, few mothers in both sites, particularly in Vadodara, had received any help other than emotional support from their husbands. Over one-third of young mothers in Diamond Harbour (35\%) and just 8 percent in Vadodara reported that their husbands had helped them in household chores and taking care of the newborn. In contrast, three-quarters (77\%) of young mothers in Diamond Harbour and about one-third (32\%) in Vadodara reported that they had received emotional support from their husbands.

In brief, the baseline findings show that married young women in both settings were clearly entrenched in a social milieu that isolated and silenced them.

Data also suggest that there was considerable lack of information regarding health matters and gaps in maternal health practices. It is clear from the findings that significant efforts are urgently required to convey accurate information on sexual and reproductive health matters to married young women, help young couples achieve their reproductive intentions, provide critical postpartum and neonatal guidance and care, and ameliorate young women's social disadvantages and isolation. 


\section{The intervention}

This chapter briefly describes the steps that led to the design of the intervention project, the objectives of the intervention, the key project components, extent of married young women's exposure to the intervention, and the challenges faced in implementing the intervention. Data on exposure to the intervention presented in this chapter are primarily drawn from the endline survey.

\section{Intervention design and objectives}

The design of the intervention was informed by a diagnostic study conducted by the Population Council and Operations Research Group, Vadodara.

The diagnostic study identified three general areas for action: information provision, adjustments in existing reproductive health services and group formation as a means of building social support networks. The study also highlighted the importance of working not only with married young women, but also with persons who are influential in their lives, including husbands, mothers, mothers-in-law, health care providers and members of the wider community.

Based on the findings of the diagnostic study, CINI, DCT and the Population Council worked in collaboration to develop a comprehensive intervention, taking into consideration the requirements of each site, the needs articulated by young women and influential adults in their lives during the diagnostic phase, the expertise and experience of the partners and the characteristics of the populations in the project sites.
The specific objectives of the intervention were to:

- Increase married young women's knowledge of key reproductive health issues;

- Improve married young women's reproductive health practices, especially regarding pregnancy, delivery and the postpartum period;

- Increase married young women's social support networks;

- Improve married young women's ability to participate in decision-making and act in their own interest; and

- Strengthen the capacity of health care providers to meet the special needs of married young women.

\section{Intervention activities}

The intervention served several participants: newlymarried young women, young women pregnant for the first time, first-time mothers, young women's husbands, mothers and mothers-in-law, health care providers and members of the wider community. Reflecting the needs articulated in the diagnostic study, the intervention comprised of three mutually reinforcing components: provision of information, health care service adjustments and group formation as a means of enhancing married young women's social support networks. Intervention activities were implemented in a total of 24 villages -12 in Diamond Harbour and 12 in Vadodara, each with a population of about 25,000 . The intervention was launched in January 2003 and concluded in December 2004. 


\section{Provision of information}

The primary focus of the intervention was to provide married young women with information directly through home visits by female outreach workers; counselling sessions conducted by health providers in clinic settings; discussions in young women's groups; and community activities such as health fairs and celebrations of "health days" or "health weeks". Information was also conveyed to young women's husbands through home visits by male outreach workers and discussions in neighbourhood meetings. Opportunistic interactions were sought with mothers-in-law and other senior women in married young women's families so as to provide information to them as well. Several issues were discussed during these meetings, including the transmission and prevention of reproductive tract infections; contraception; sex as a voluntary and safe experience; the need to develop a delivery plan; care during pregnancy and the postpartum period; breastfeeding; and how husbands can play a supportive role during pregnancy, delivery and the postpartum period.

Prior to launching the intervention, CINI, DCT and the Population Council organised workshops to review available information materials on reproductive and sexual health. While several existing materials developed by CINI and DCT were used in the intervention, others were modified to meet the special needs of the project beneficiaries. Some new materials were also developed; these included a fertility clock to help women identify the most fertile period during her menstrual cycle; small pictorial booklets and hand mirrors depicting pregnancy, childbirth and postpartum care; a birth clock to calculate the expected date of delivery; and a nutrition calendar. In addition, before the intervention was launched, project staff were given training on reproductive health topics, effective approaches to communicate information to project beneficiaries and strategies for social empowerment and group formation. Project staff were also given refresher training over the course of the intervention.

Project staff regularly interacted with the participants and provided information specifically tailored to each group (newly-married, first-time pregnant or first-time mothers and young women's husbands). During these meetings, the staff also provided participants with user-friendly information material for their ready reference.

\section{Adjustments in health services}

As part of the intervention, several activities were undertaken to improve the capacity of providers to meet the special needs of married young women and to encourage the utilisation of existing reproductive health services in the project sites. Orientation workshops were organised in both sites to sensitise service providers, including government and private health providers, to the special needs of married young women. In Diamond Harbour, support for existing health services included a one-day sensitisation camp for 120 health functionaries and follow-up workshops with local health staff. An orientation workshop for 26 rural medical practitioners (untrained providers) and follow-up workshops were also conducted. In Vadodara, project staff regularly interacted with local health functionaries, including those from primary health centres and private practitioners. Traditional birth attendants in both sites were also given refresher training on safe delivery, and were assured a supply of safe delivery kits. Under the project a three-day refresher training workshop for 30 traditional birth attendants in Diamond Harbour, and a four-day 
refresher training workshop for 21 traditional birth attendants in Vadodara, were conducted. CINI and DCT also worked with government sub-centres in the project area to strengthen the quality of services and make them more accessible.

Condoms and oral contraceptive pills were provided through peers and clinics. The project also strengthened existing antenatal services; detailed information on pregnancy-related care was offered when young women visited government sub-centres (in Diamond Harbour) and the NGO clinics (in Vadodara) for antenatal services. Outreach workers interacted with pregnant young women and their husbands and counselled them about developing a delivery plan. Those who required referral to a higher health facility or financial assistance to meet delivery expenses or transport facilities were provided such assistance. A health worker made a home visit to the mother and baby once within six weeks postpartum; thereafter, mothers received bi-monthly follow-up visits for a year.

\section{Group formation}

A key component of the project was the formation of women's groups in the community to help married young women expand their social support networks and enhance their ability to act in their own interest. In order to support this aspect of the intervention, the Population Council collaborated closely with both CINI and DCT to strengthen staff capacity to work in this area. In the case of CINI, a partnership with Nishtha, ${ }^{1}$ a local grassroots organisation, was formed.
Each group comprised 8-12 married young women. Project staff facilitated the formation of groups and the identification of participant roles, selection of a group leader and deputy leader, and the prioritisation of needs and concerns. These groups typically met for 2-3 hours every month. During these meetings, the groups adopted a participatory learning approach on topics such as legal literacy, enhancing vocational skills, improving access to financial resources including savings and credit management, pregnancy and postpartum care, the availability of local resources (e.g., government schemes that women can access, and public amenities), gender dynamics within and outside the family, spousal relationship issues and nutrition.

Most of the sessions were conducted by project staff; however, for specialised topics such as legal literacy, vocational training and savings and credit management, resource persons, mainly from NGOs with proficiency in the area, were brought in as trainers. In addition, groups of young women were taken on exposure visits to the village/block administrative office, bank, post office and organisations where women's groups play an active role. Group members also worked together on community development projects (for instance, some groups worked on paving roads in the village, which they had identified as a priority need), celebrated common festivals and organised functions to welcome newly-married members. A few groups created their own health fund, to be used in emergencies, through contributions from small savings of members. Some groups organised training classes in embroidery and other skills for members.

${ }^{1}$ Nishtha works to empower adolescent and adult women through group formation centred on community development activities. 


\section{Extent of exposure to intervention activities}

Table 3.1, drawing on data from the endline survey, describes the extent to which married young women were exposed to intervention activities. During the intervention period, 663 married young women in Diamond Harbour and 563 in Vadodara were contacted by female outreach workers with information on reproductive and sexual health. ${ }^{2}$ As expected, contacting husbands proved to be more difficult than reaching young women. Only 175 young women in Diamond Harbour and 89 in Vadodara reported that their husbands had been contacted by male outreach workers. ${ }^{3}$ However, it may be possible that all the young men who were contacted by outreach workers might not have informed their wives and hence, some under-reporting cannot be ruled out.

As shown in Table 3.1, during the intervention period, 532 women in Diamond Harbour and 810 women in Vadodara had sought various clinical services. A total of 467 women in Diamond Harbour and 138 in Vadodara reported having participated in group activities. ${ }^{4}$

It is also clear from the endline data that there was a considerable difference in the extent of respondents' exposure to the intervention across the two project sites. With the exception of clinic-based services, exposure to the intervention components was far lower in Vadodara than in Diamond Harbour (Table 3.1). Of particular note is women's exposure to group formation activities; only 138 respondents in Vadodara reported that they participated in group activities compared to 467 in Diamond Harbour.

As is evident from Table 3.2, the endline data indicate that the breadth of exposure to the intervention activities varied considerably within and across sites. For example, in Diamond Harbour, while 784 young women were exposed to at least one component of the intervention, only 116 were exposed to all three components. In Vadodara, while

Table 3.1:

\section{Extent of married young women's exposure to the intervention, endline survey}

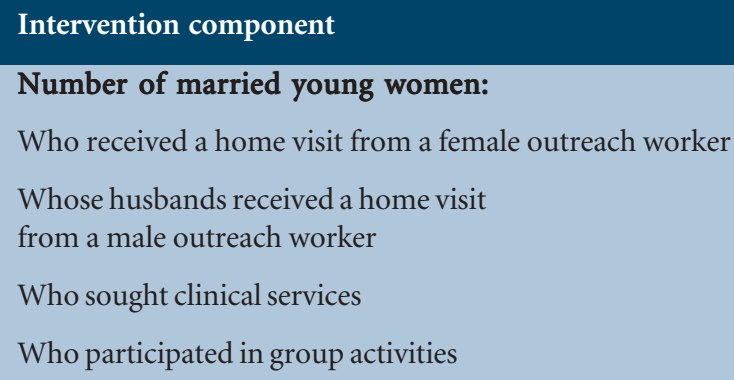

\begin{tabular}{|c|c|}
\hline Diamond Harbour & Vadodara \\
\hline 663 & 563 \\
175 & 89 \\
532 & 810 \\
467 & 138 \\
\hline
\end{tabular}

\footnotetext{
${ }^{2}$ According to the monitoring data gathered by CINI and DCT, 887 and 1,030 married young women in Diamond Harbour and Vadodara, respectively, received a home visit from a female outreach worker.

${ }^{3}$ According to the monitoring data gathered by CINI and DCT, 849 and 634 husbands in Diamond Harbour and Vadodara, respectively, received a home visit from a male outreach worker.

${ }^{4}$ According to the monitoring data gathered by CINI and DCT, 510 and 621 married young women in Diamond Harbour and Vadodara, respectively, participated in group activities.
} 
Table 3.2:

\section{Breadth of exposure to intervention activities, endline survey}

\begin{tabular}{|c|c|c|}
\hline Intervention component & Diamond Harbour & Vadodara \\
\hline \multicolumn{3}{|l|}{ Number of married young women who were: } \\
\hline Exposed to any one component of the intervention ${ }^{*}$ & 784 & 927 \\
\hline $\begin{array}{l}\text { Contacted by female outreach workers and their } \\
\text { husbands by male outreach workers }\end{array}$ & 153 & 71 \\
\hline $\begin{array}{l}\text { Contacted by female outreach workers and participated } \\
\text { in group activities }\end{array}$ & 396 & 83 \\
\hline Exposed to all the components of the intervention* & 116 & 13 \\
\hline
\end{tabular}

927 young women were exposed to at least one component, only 13 were exposed to all the components. While more respondents in Vadodara than in Diamond Harbour reported exposure to any one component of the intervention, mainly due to the strong clinic-based component in Vadodara, exposure to more than one intervention component was more frequently reported in Diamond Harbour. Twice as many married young women who received a home visit from an outreach worker in Diamond Harbour than in Vadodara reported that their husbands had also been contacted by a male outreach worker (153 in Diamond Harbour compared to 71 in Vadodara). Almost five times as many respondents in Diamond Harbour who received a home visit from an outreach worker also participated in group activities (396 women in Diamond Harbour compared to 83 in Vadodara).

\section{Challenges faced in implementing intervention activities}

Both CINI and DCT faced a number of challenges in implementing intervention activities. First, as noted earlier, the frequent movement of married young women between their natal and marital homes affected CINI's and DCT's efforts to reach this group as planned in the intervention design. It must also be acknowledged that frequent staff turnover at the NGOs also affected the scale and continuity of intervention activities in both sites. Finally, in Vadodara, intervention activities were disrupted for a few months because of political unrest; services provided by the DCT clinic were also suspended during this period.

While these challenges are unfortunate, they are not uncommon. Indeed, it is important to note that intervention programmes often operate in less than ideal conditions in "real life." 


\section{Effects of exposure to the intervention}

This chapter presents findings with regard to the effects of exposure to the intervention on a number of aspects of married young women's lives, including their agency, gender role attitudes and social support networks; sexual and reproductive health knowledge and practices; and partner support and communication.

\section{Effects of exposure to the intervention on married young women's agency, gender role attitudes and social support networks}

To assess the effects of exposure to the intervention on reducing the social disadvantages and isolation experienced by married young women, four indicators of agency- namely, young women's role in household decision-making (household decision-making index), mobility (mobility index), gender role attitudes (gender role attitudes index) and attitudes towards domestic violence (index of non-acceptability of domestic violence) - and two indicators of social support networks - namely, percentage reporting having friends in the marital village and index of peer support-were used. Respondents' endline and baseline responses were compared to ascertain the degree of change in these indicators attributable to exposure to the intervention. In view of the fact that a sizeable number of respondents in the experimental villages did not participate in the intervention, findings are presented separately for three groups: those residing in experimental villages who participated in the intervention (experimental intervention), those residing in experimental villages who did not participate in the intervention (experimental non-intervention) and those who were from control villages.

Regression models were estimated for each of the indicators to assess the net effect of exposure to the intervention on these outcome indicators after controlling for potentially confounding factors. The model varied depending on the type of outcome; linear regression was used for all continuous variables and logistic regression used for all dichotomous variables. In the regression models, endline measures of the various indicators described above were used as the outcome variables. Explanatory variables included the baseline measure of the same indicator; variables indicating exposure to the intervention; a variable reflecting changes in young women's life stage (that is, newly-married, first-time pregnant, first-time mother, second-time pregnant or second-time mother) over the intervention period; and socio-demographic characteristics, including respondent's age, education, religion and standard of living. In the regression models, respondents from the control group were compared with those from the experimental intervention and non-intervention groups, after controlling for all of the above confounding factors. However, for convenience, findings are presented that compare the situation of married young women from the experimental intervention group and those from the control group. 


\section{Role in household decision-making}

Figure 4.1 presents findings comparing the endline and baseline responses of respondents from the intervention and control villages to questions related to their role in household decision-making (see Chapter 2 for details of the household decision-making index). Data indicate that married young women's role in decision-making increased across all groups in both sites. In Diamond Harbour, the increase was largest among those who were exposed to the intervention (an increase of 105\%, versus $61 \%$ among those from the experimental non-intervention group and 65\% among those from the control group). In Vadodara too, young women's role in household decision-making improved across all groups; however, the influence of exposure to the intervention was not discernible, as seen in Figure 4.1.

The results of the regression analysis, presented in row 1 of Table 4.1, show that in Diamond Harbour, after controlling for potentially confounding factors, exposure to the intervention had a positive net effect on married young women's role in decision-making, as compared to women from the control group. In
Vadodara too, even though the comparison of mean scores showed no discernible differences, once potentially confounding effects were controlled, exposure to the intervention had a positive net effect on young women's role in decision-making. In other words, in both settings, once confounding socio-demographic factors were controlled, it was evident that exposure to the intervention did indeed have a significant effect on enhancing women's decision-making ability.

\section{Mobility}

Findings comparing young women's mobility at the baseline and endline, presented in Figure 4.2, show that young women's freedom to visit a variety of places unescorted increased significantly across all groups in both sites (see Chapter 2 for details of the mobility index). However, any possible influence of exposure to the intervention was not discernible in bivariate analysis, as seen in Figure 4.2.

The results of the regression analysis are presented in row 2 of Table 4.1. Findings indicate that in Diamond Harbour, even though the comparison of

Figure 4.1:

Married young women's role in household decision-making, baseline and endline surveys
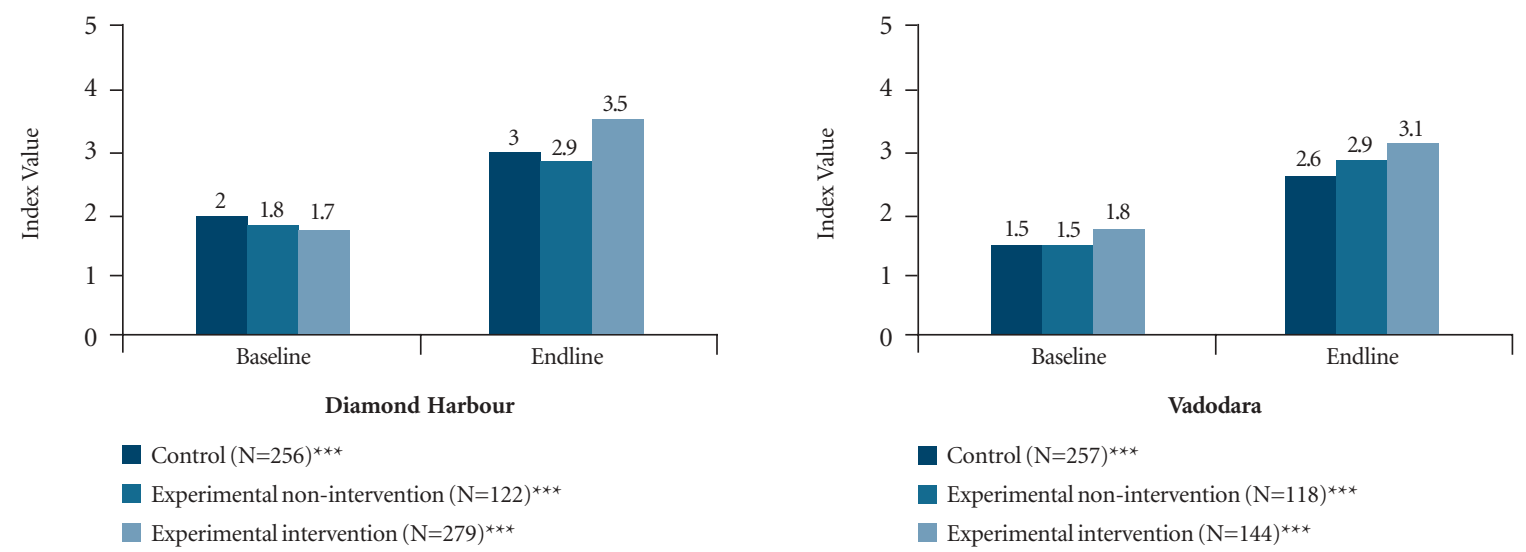

Note: ${ }^{* *}$ indicates that the difference between the baseline and endline measure is significant at $p \leq .001$. 
Table 4.1:

Effects of exposure to the intervention on married young women's agency and gender role attitudes: Summary of regression results

\begin{tabular}{|c|c|c|c|c|}
\hline \multirow[t]{2}{*}{ Dependent variable } & \multirow{2}{*}{$\begin{array}{l}\text { Analysis } \\
\text { approach }\end{array}$} & \multirow{2}{*}{$\begin{array}{l}\text { Regression } \\
\text { type }\end{array}$} & \multicolumn{2}{|c|}{ Coefficient } \\
\hline & & & $\begin{array}{l}\text { Diamond } \\
\text { Harbour }\end{array}$ & Vadodara \\
\hline Household decision-making index & $\begin{array}{l}\text { Longitudinal } \\
\text { comparison }\end{array}$ & $\begin{array}{l}\text { Linear } \\
\text { regression }\end{array}$ & $.484^{\star}$ & $.460^{\star *}$ \\
\hline Mobility index & $\begin{array}{l}\text { Longitudinal } \\
\text { comparison }\end{array}$ & $\begin{array}{l}\text { Linear } \\
\text { regression }\end{array}$ & $.496 \sim$ & $1.100^{*}$ \\
\hline Gender role attitudes index & $\begin{array}{l}\text { Longitudinal } \\
\text { comparison }\end{array}$ & $\begin{array}{l}\text { Linear } \\
\text { regression }\end{array}$ & $.348^{\star *}$ & .073 \\
\hline $\begin{array}{l}\text { Index of non-acceptability of } \\
\text { domestic violence }\end{array}$ & $\begin{array}{l}\text { Longitudinal } \\
\text { comparison }\end{array}$ & $\begin{array}{l}\text { Linear } \\
\text { regression }\end{array}$ & .025 & -1.069 \\
\hline
\end{tabular}

Note: $\sim$ indicates that the net effect of exposure to the intervention is significant at $p \leq .10 ;{ }^{*}$ at $p \leq .05 ;{ }^{* *}$ at $p \leq .01$.

Figure 4.2:

Married young women's mobility, baseline and endline surveys
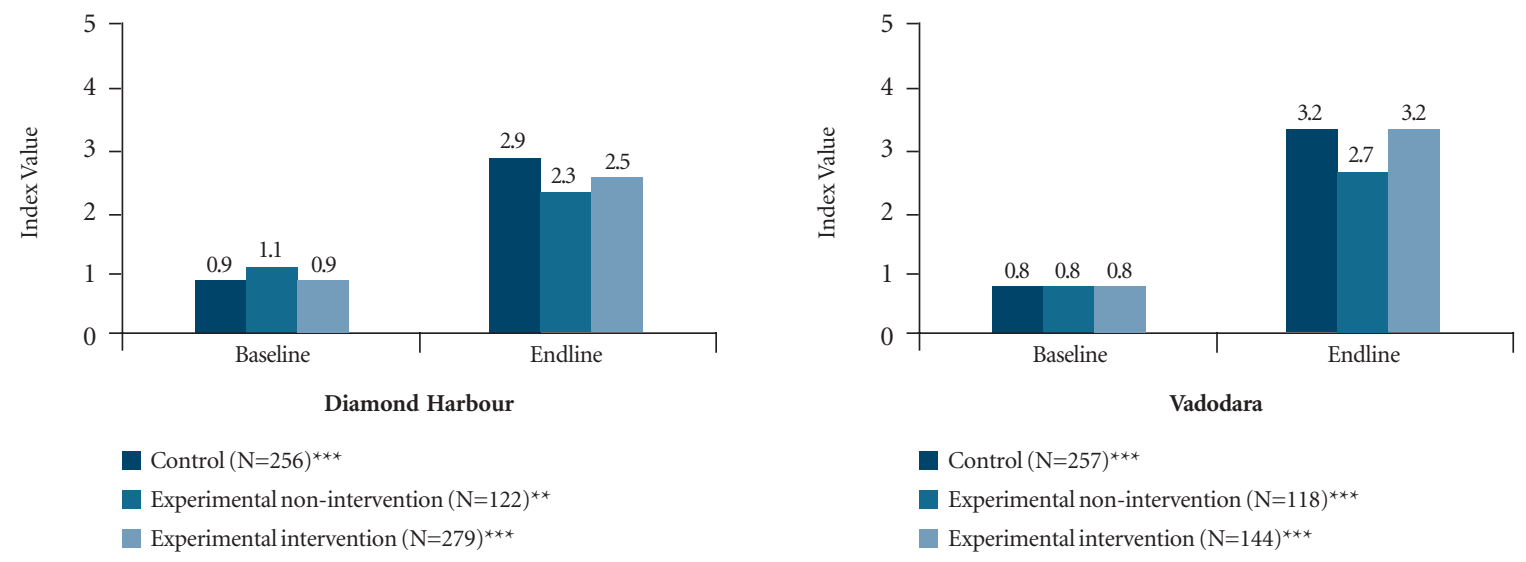

Note: ${ }^{* *}$ indicates that the difference between the baseline and endline measure is significant at $p \leq .01 ;{ }^{* * *}$ at $p \leq .001$.

mean scores showed a greater improvement in the control group than in the intervention group, once potentially confounding effects were controlled, exposure to the intervention had a positive but statistically weak net effect on married young women's mobility, as compared to young women from the control group. In Vadodara too, even though the comparison of mean scores showed similar improvements in both the intervention and control groups, once potentially confounding effects were controlled, exposure to the intervention had a positive significant net effect on young women's mobility. In other words, in both settings, once confounding socio-demographic factors were controlled, it was evident that exposure to the intervention did indeed have an effect on enhancing married young women's freedom to visit a variety of places unescorted within and outside their marital village. 


\section{Gender role attitudes}

Findings comparing married young women's gender role attitudes at baseline and at endline, presented in Figure 4.3 , show that more young women adhered to egalitarian gender attitudes at the endline than at the baseline across all groups in both sites (see Chapter 2 for details of the index). In Diamond Harbour, the increase was largest among those who were exposed to the intervention (an increase of $38 \%$, versus $30 \%$ among women from the experimental non-intervention group and 32\% among those from the control group). As seen in Figure 4.3, while gender role attitudes improved across all groups, the possible influence of exposure to the intervention was not evident in Vadodara.

The results of the regression analysis, presented in row 3 of Table 4.1, show that in Diamond Harbour, after controlling for potentially confounding factors, exposure to the intervention had a positive net effect on married young women's gender role attitudes, as compared to young women from the control group. However, in Vadodara, once potentially confounding effects were controlled, exposure to the intervention did not have a significant net effect on young women's gender role attitudes. In other words, while exposure to the intervention had a positive net effect on young women's gender role attitudes in Diamond Harbour, no such effect was noticed in Vadodara. This may be because exposure to the social empowerment component of the intervention, namely, group participation, was particularly low in Vadodara.

\section{Attitudes towards domestic violence}

Figure 4.4 presents mean index values of married young women's attitudes towards the non-acceptability of wife-beating at the baseline and endline (see Chapter 2 for details of the index). In both sites, findings show a significant change in young women's attitudes, with larger proportions at the endline than at the baseline across all groups reporting that wife-beating is not justified. In Diamond Harbour, the positive change in young women's perceptions was greatest among those who were exposed to the intervention (an increase of $42 \%$, versus 38\% among those from the experimental

Figure 4.3:

Married young women's gender role attitudes, baseline and endline surveys
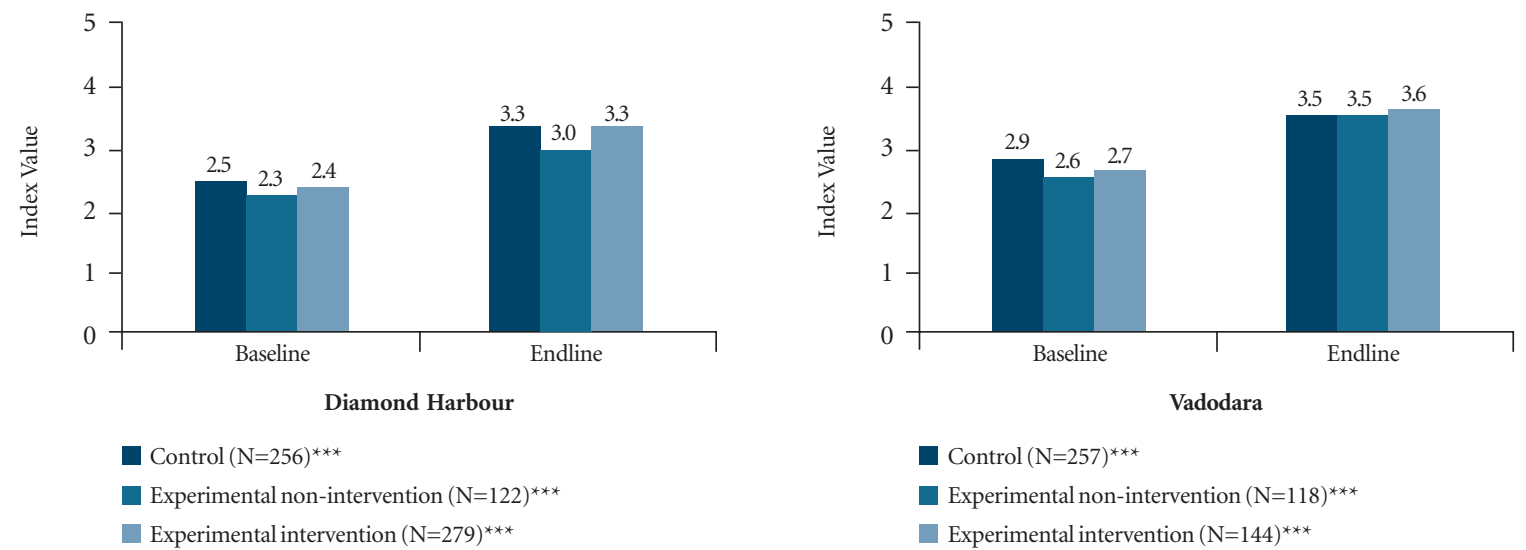

Note: ${ }^{* *}$ indicates that the difference between the baseline and endline measure is significant at $p \leq .001$. 
non-intervention group and 35\% among those from the control group). In Vadodara, the percentage change was marginal across all groups.

The results of the regression analysis, presented in row 4 of Table 4.1, comparing the attitudes of married young women from the experimental intervention group and the control group, show that exposure to the intervention per se did not have a significant net effect on young women's views regarding the non-acceptability of domestic violence in either site. In short, although attitudes had become more positive towards the non-acceptability of domestic violence across all groups, this change could not be attributed to exposure to the intervention.

\section{Social support networks}

To assess whether exposure to the intervention succeeded in reducing married young women's social isolation, findings are presented comparing the baseline and endline values of two indicators: the proportion of respondents who reported having friends in their marital village, and an index of peer support (see Chapter 2 for details of the index).

\section{Friends in the marital village}

Figure 4.5 presents findings comparing the proportion of married young women at the baseline and endline who reported having friends in their marital village. Data show that young women's peer networks significantly improved across all groups in both sites. In Diamond Harbour, the percentage point increase was similar among young women who were exposed to the intervention and those from the control group, but was lower among those from the experimental non-intervention group. In Vadodara, the percentage point increase was similar across all groups.

The results of the regression analyses are presented in Table 4.2. Findings show that in Diamond Harbour, after controlling for potentially confounding factors, married young women who were exposed to the intervention were significantly more likely to report having friends in their marital village than those from the control group. However, in Vadodara, participation in intervention activities per se did not have an independent effect in enabling young women to build friendships in their marital village.

\section{Figure 4.4:}

Married young women's attitudes towards the non-acceptability of wife-beating, baseline and endline surveys
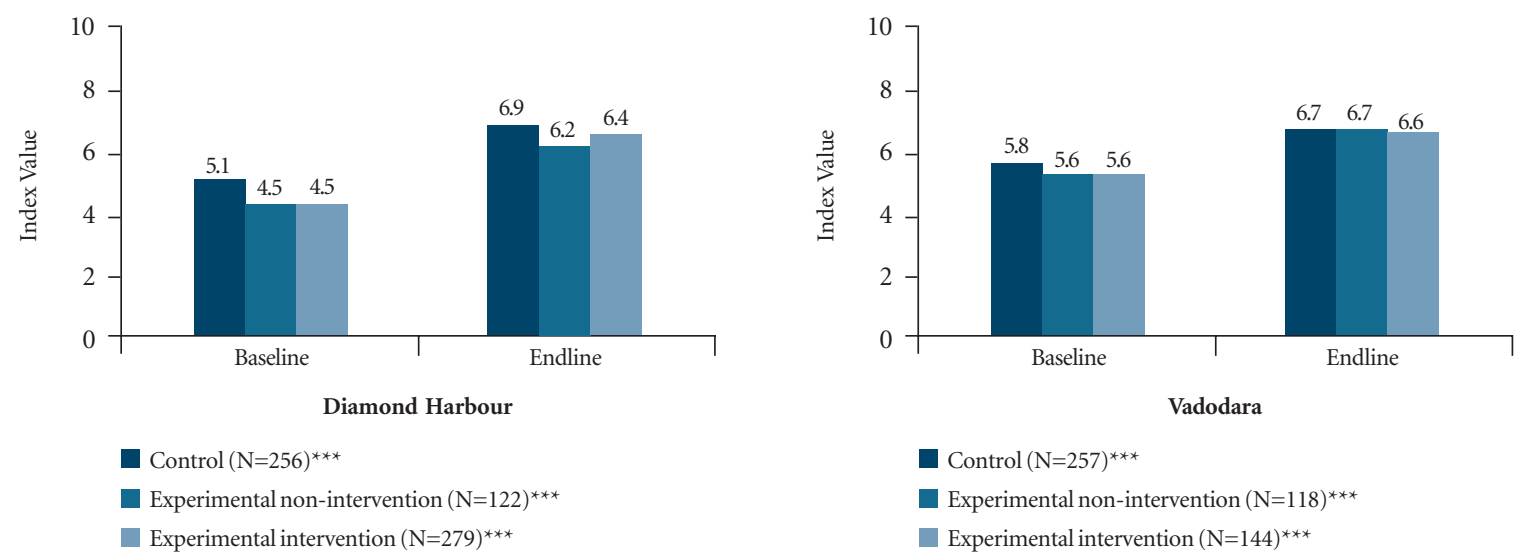

Note: ${ }^{* *}$ indicates that the difference between the baseline and endline measure is significant at $p \leq .001$. 
Figure 4.5:

Married young women who reported having friends in the marital village, baseline and endline surveys
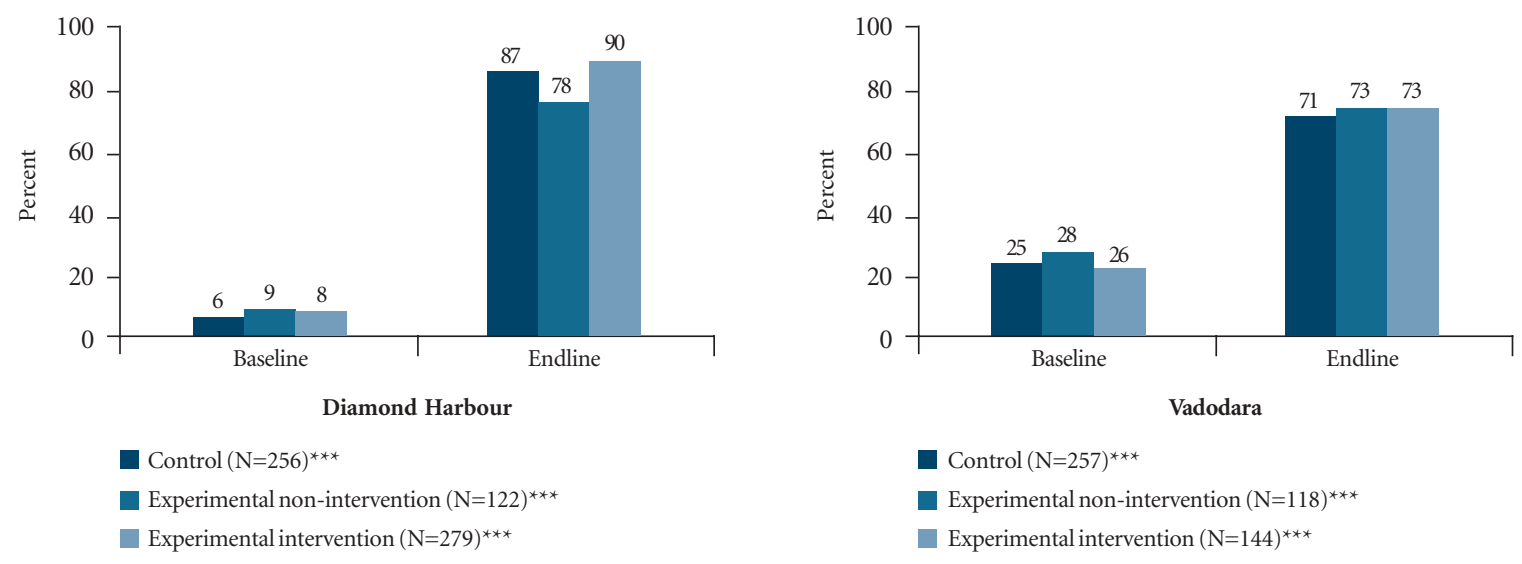

Note: ${ }^{* *}$ indicates that the difference between the baseline and endline measure is significant at $p \leq .001$.

Table 4.2:

Effects of exposure to the intervention on married young women's social support networks: Summary of regression results

\begin{tabular}{|c|c|c|c|c|}
\hline \multirow[t]{2}{*}{ Dependent variable } & \multirow{2}{*}{$\begin{array}{l}\text { Analysis } \\
\text { approach }\end{array}$} & \multirow{2}{*}{$\begin{array}{l}\text { Regression } \\
\text { type }\end{array}$} & \multicolumn{2}{|c|}{ Coefficient/odds ratio } \\
\hline & & & $\begin{array}{l}\text { Diamond } \\
\text { Harbour }\end{array}$ & Vadodara \\
\hline $\begin{array}{l}\text { Reported having friends in } \\
\text { marital village }\end{array}$ & $\begin{array}{l}\text { Longitudinal } \\
\text { comparison }\end{array}$ & $\begin{array}{l}\text { Linear } \\
\text { regression }\end{array}$ & $9.769^{\star \star}$ & .950 \\
\hline Index of peer support & $\begin{array}{l}\text { Longitudinal } \\
\text { comparison }\end{array}$ & $\begin{array}{l}\text { Linear } \\
\text { regression }\end{array}$ & $.254^{\star *}$ & $.540 \sim$ \\
\hline
\end{tabular}

Note: indicates that the net effect of exposure to the intervention is significant at $p \leq .10 ;{ }^{* *}$ at $p \leq .01$.

\section{Extent of peer support}

Figure 4.6 presents index values comparing the extent to which married young women reported having friends with whom they could discuss confidential matters at the baseline and endline. Findings show that the extent to which young women reported access to such confidantes, while still low, increased significantly across all groups in both sites.

In Diamond Harbour, the increase was larger among young women from the intervention group than those from the control group. In Vadodara too, the increase was highest among those who were exposed to the intervention as compared to those from other groups (an increase of 180\%, versus 133\% among those from the experimental non-intervention group and 125\% among those from the control group).

The regression results presented in Table 4.2 indicate that in both Diamond Harbour and Vadodara, after controlling for potentially confounding factors, exposure to the intervention had a clearly positive net effect on the extent of married young women's peer support, as compared to women 
Figure 4.6:

Extent of married young women's peer support, baseline and endline surveys
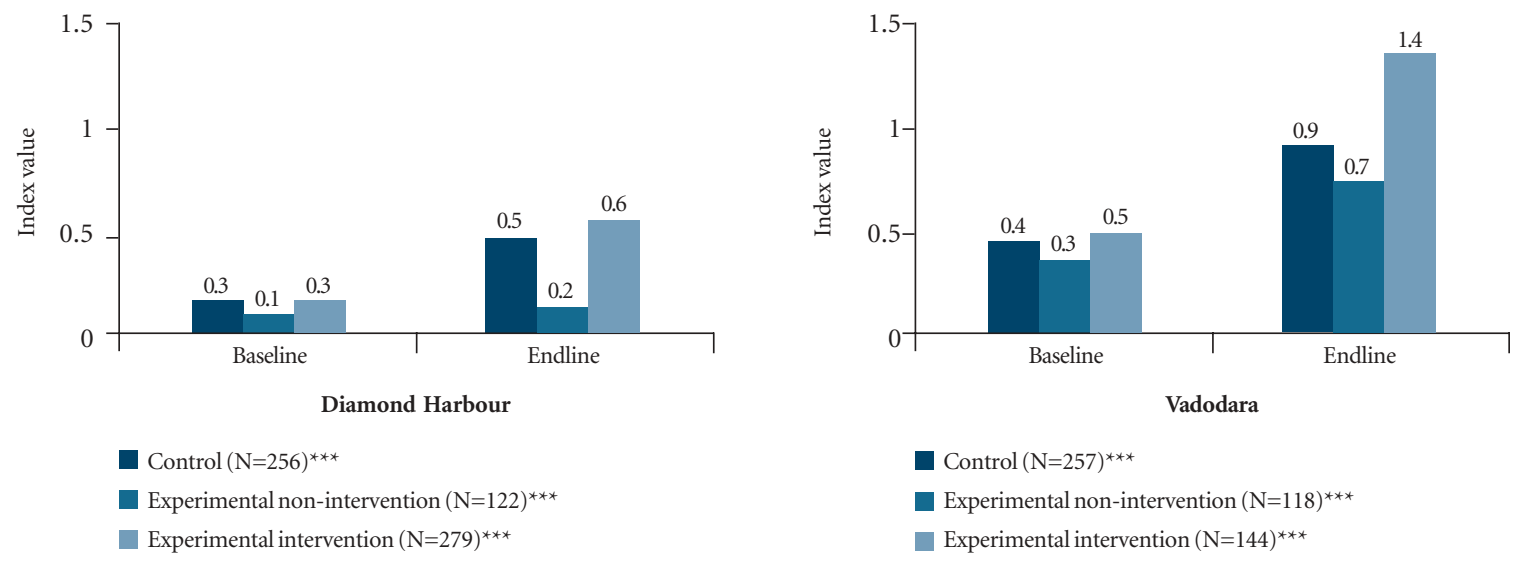

Note: ${ }^{* *}$ indicates that the difference between the baseline and endline measure is significant at $p \leq .001$.

from the control group. The net effect, however, was far more significant in Diamond Harbour than in Vadodara.

\section{Effects of exposure to the intervention on married young women's sexual and reproductive health knowledge}

To ascertain the effects of exposure to the intervention on young women's sexual and reproductive health knowledge, an indicator, namely, the index of sexual and reproductive health knowledge (see Chapter 2 for details of the index) was used. As with indicators of agency, gender role attitudes and social support networks, respondents' endline responses were compared with their baseline responses, and regression models were estimated to control for potentially confounding factors and assess the net effect of exposure to the intervention.

Findings presented in Figure 4.7 indicate that knowledge of sexual and reproductive health matters increased significantly across all groups in both sites. In Diamond Harbour, the increase was greatest among those who were exposed to the intervention (an increase of 54\%, versus 35\% among those from the experimental non-intervention group and 49\% among those from the control group). In Vadodara too, young women's knowledge of sexual and reproductive health matters increased across all groups; however, the possible influence of exposure to the intervention was not discernible, as seen in Figure 4.7.

The results of the regression analysis are presented in Table 4.3. Findings show that in Diamond Harbour, after controlling for potentially confounding factors, exposure to the intervention had a clearly positive net effect on married young women's knowledge of sexual and reproductive health matters, as compared to young women in the control group. In Vadodara too, even though the comparison of mean scores showed no discernible differences, once potentially confounding effects were controlled, exposure to the intervention had a positive net effect on young women's knowledge of sexual and reproductive health matters. In other words, in both settings, once confounding socio-demographic factors were controlled, it was evident that exposure to the intervention did indeed independently improve young women's knowledge of sexual and reproductive health matters. 
Figure 4.7:

Married young women's knowledge of sexual and reproductive health matters, baseline and endline surveys
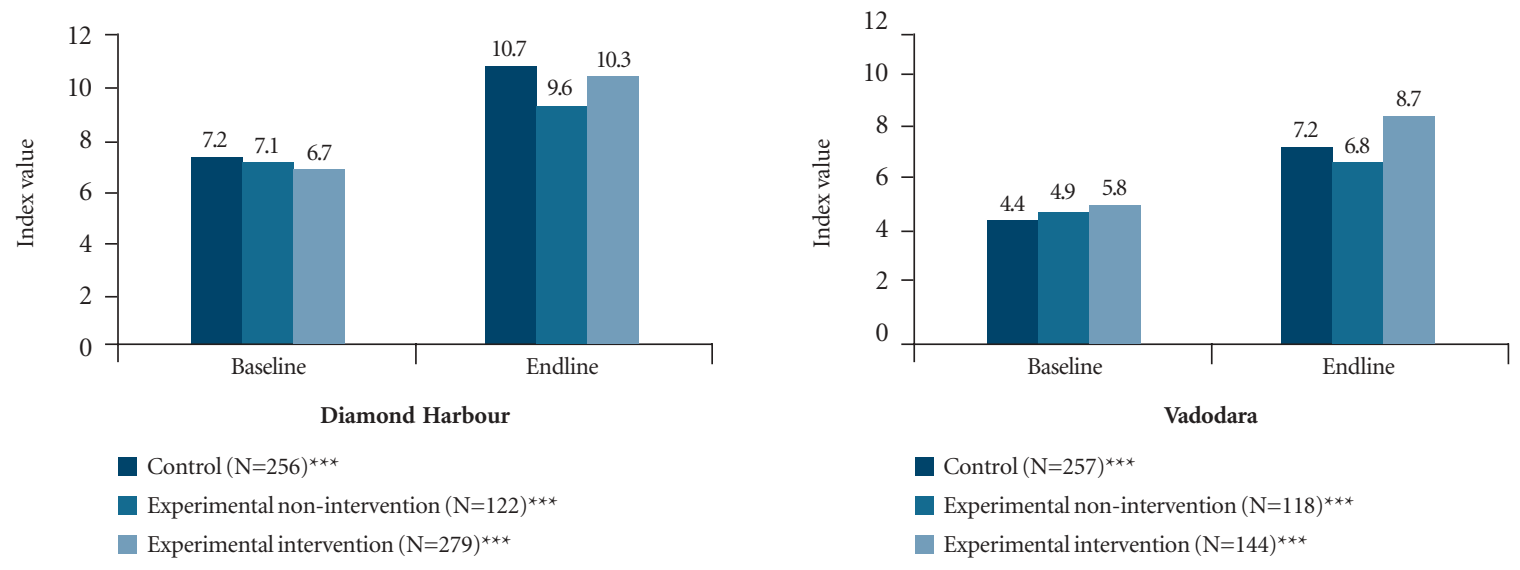

Note: ${ }^{* *}$ indicates that the difference between the baseline and endline measure is significant at $p \leq .001$.

Table 4.3:

Effects of exposure to the intervention on married young women's knowledge of sexual and reproductive health matters: Summary of regression results

\begin{tabular}{|l|l|l|l|}
\hline Dependent variable & $\begin{array}{l}\text { Analysis } \\
\text { approach }\end{array}$ & $\begin{array}{l}\text { Regression } \\
\text { type }\end{array}$ & \multicolumn{2}{|c|}{ Coefficient } \\
\cline { 3 - 4 } & $\begin{array}{l}\text { Liamond } \\
\text { Harbour }\end{array}$ & \multicolumn{1}{|c|}{ Vadodara } \\
\hline $\begin{array}{l}\text { Index of sexual and reproductive } \\
\text { health knowledge }\end{array}$ & $\begin{array}{l}\text { comparison } \\
\text { regression }\end{array}$ & $1.383^{\star * *}$ & $1.435^{\star *}$ \\
\hline
\end{tabular}

Note: ${ }^{* *}$ indicates that the net effect of exposure to the intervention is significant at $p \leq .01 ;{ }^{* * *}$ at $p \leq .001$.

\section{Effects of exposure to the intervention on married young women's reproductive health practices}

The intervention aimed to improve married young women's reproductive health practices, particularly those related to the first birth. To assess the effects of exposure to the intervention on young women's reproductive health practices, nine indicators were used that measured the following: use of contraceptives (the percentage who reported having used a contraceptive method to delay the first birth), use of appropriate pregnancy-related health services in relation to the first birth (the percentage who reported having received antenatal care in the first trimester, number of antenatal check-ups received, an index of comprehensive antenatal care received, an index of delivery preparations, the percentage who reported institutional delivery at first birth and the percentage who reported having received a routine check-up within six weeks postpartum), and the adoption of appropriate newborn care (the percentage who reported having breastfed their newborns immediately after birth and the percentage who reported having fed colostrum to their newborns).

Since comparisons of change over time in the same cohort were not possible for the indicators described above, responses of similarly situated successive cohorts drawn from the two waves of the 
survey were compared: one from the baseline and the other from the endline. As in the earlier discussion, in view of the fact that a sizeable number of respondents from the experimental villages were not exposed to the intervention, findings are presented separately for three groups: those residing in experimental villages who participated in the intervention, those residing in experimental villages who did not participate in the intervention and those from control villages.

To assess the net effect of exposure to the intervention on the outcome indicators described above, data were pooled from the two waves and used the difference-in-differences (DiD) model. The DiD model contrasts the difference in average outcome in the intervention group before and after treatment, with the difference in average outcome in the control group before and after treatment. It isolates the effects of the intervention by accounting for the effects of other factors external to the intervention that changed around the time of the intervention, and for preexisting differences between the intervention and control groups.

In these models, each outcome indicator, irrespective of whether it referred to the baseline or endline survey, was used as the dependent variable. Explanatory variables included, aside from the socio-demographic characteristics described earlier, a variable indicating time (coded 1 if the observation was from the endline survey and 0 if from the baseline survey), a variable indicating whether respondents were from the experimental intervention group or control group (coded 1 if from the experimental intervention group and 0 if not), and a variable indicating whether the observation referred to the experimental intervention group and the endline survey (coded 1 if from the intervention group and the endline survey, and 0 if otherwise). A positive coefficient implied that, after controlling for socio-demographic factors and time, exposure to the intervention had a positive net effect on the outcome indicators. In view of the fact that a sizeable proportion of the endline cohort of married young women was not exposed to the entire duration of the intervention and the breadth of exposure to intervention activities varied considerably (as noted in Table 3.2), two regression models were estimated: one showing the net effect of exposure to any one component of the intervention (interaction with female outreach workers, interaction with male outreach workers or group participation) and one reflecting the net effect of exposure to at least two components. We note that only a small number of married young women were exposed to at least two components of the intervention in Vadodara and hence, findings need to be interpreted with caution.

\section{Use of contraceptives to delay the first birth}

Drawing on data from the baseline and endline cohorts of newly-married and first-time pregnant young women, Figure 4.8 presents findings on the use of contraceptives to delay the first birth. Findings indicate a contrasting picture across the two sites. In Diamond Harbour, the endline cohort of young women was more likely to use contraceptives to delay the first birth than the baseline cohort across all groups. However, the percentage point difference between the baseline and endline cohorts was roughly similar across all groups.

In contrast, and rather unexpectedly in Vadodara, except for the experimental intervention group, the endline cohort of married young women was less likely to report contraceptive use to delay the first birth than the baseline cohort. Even in the experimental intervention group, the endline cohort was only slightly more likely to use contraceptives to delay the first birth than those in the other groups. 
Figure 4.8:

Use of contraceptives reported by married young women to delay the first birth, baseline and endline surveys
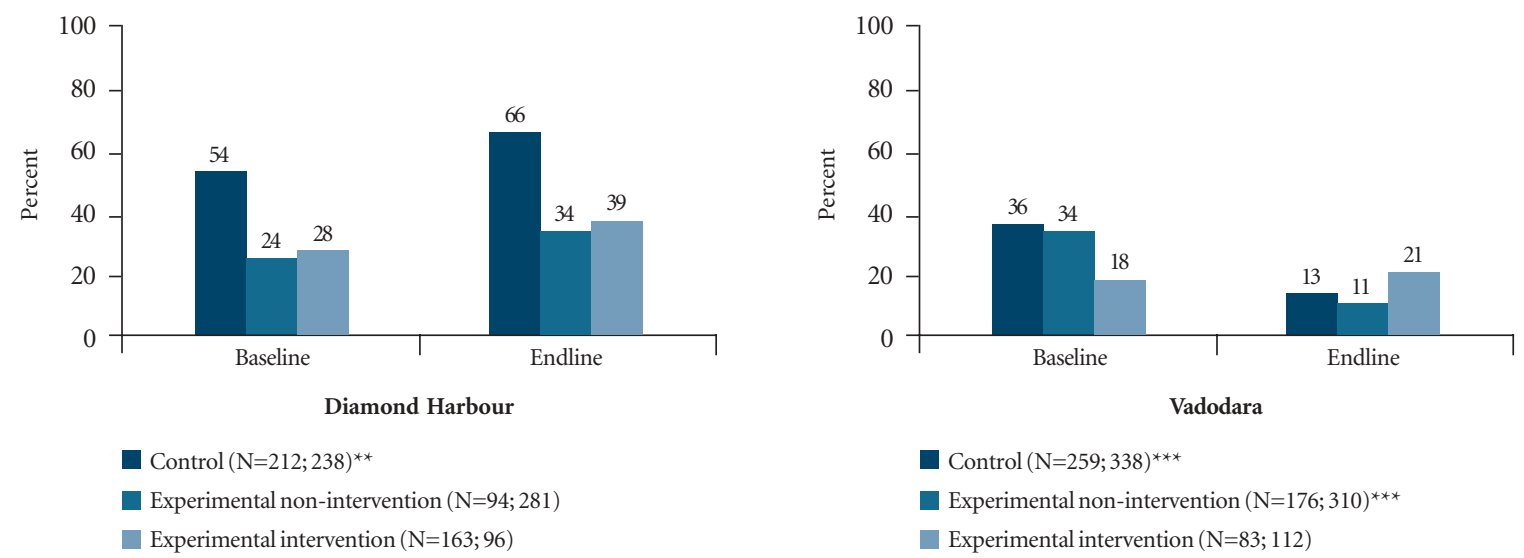

Note: ${ }^{* *}$ indicates that the difference between the baseline and endline cohorts is significant at $p \leq .01 ;{ }^{* *}$ at $p \leq .001$. Numbers in brackets refer to the baseline and endline cohorts, respectively.

The results of the logistic regression analysis using the DiD model to compare changes in contraceptive use between the baseline and endline cohorts in the intervention group and the control group are presented in Table 4.4. Findings show that in Diamond Harbour, after controlling for potentially confounding socio-demographic factors and time, married young women who were exposed to the intervention were no more likely to use contraceptives to delay the first birth than those from the control group. However, in Vadodara, once potentially confounding socio-demographic factors and time were controlled, young women who were exposed to the intervention were more likely to use contraceptives to delay the first birth than those from the control group. Moreover, the net effect of exposure to the intervention remained positive and significant in both regression models, irrespective of whether young women were exposed to one or more components of the intervention.

Table 4.4:

Effects of exposure to the intervention on married young women's contraceptive use: Summary of regression results using the $\mathrm{DiD}$ model

\begin{tabular}{|c|c|c|c|c|c|c|}
\hline \multirow[t]{3}{*}{ Dependent variable } & \multirow{3}{*}{$\begin{array}{l}\text { Analysis } \\
\text { approach }\end{array}$} & \multirow{3}{*}{$\begin{array}{l}\text { Regression } \\
\text { type }\end{array}$} & \multicolumn{4}{|c|}{ Coefficient $^{\alpha}$} \\
\hline & & & \multicolumn{2}{|c|}{ Diamond Harbour } & \multicolumn{2}{|c|}{ Vadodara } \\
\hline & & & $\begin{array}{l}\text { Exposure to } \\
\text { any one } \\
\text { component }\end{array}$ & $\begin{array}{l}\text { Exposure to } \\
\text { two or more } \\
\text { components }\end{array}$ & $\begin{array}{c}\text { Exposure to } \\
\text { any one } \\
\text { component }\end{array}$ & $\begin{array}{l}\text { Exposure to } \\
\text { two or more } \\
\text { components }\end{array}$ \\
\hline $\begin{array}{l}\text { Used contraceptives } \\
\text { to delay the first } \\
\text { birth }\end{array}$ & $\begin{array}{l}\text { Cross- } \\
\text { sectional } \\
\text { comparison }\end{array}$ & $\begin{array}{l}\text { Logistic } \\
\text { regression }\end{array}$ & .128 & .316 & $1.582^{* * *}$ & $1.965^{\star}$ \\
\hline
\end{tabular}

Note: ${ }^{\propto} A$ positive co-efficient implies a positive net effect and vice-versa. ${ }^{*}$ indicates that the net effect of exposure to the intervention is significant at $p \leq .05$; ${ }^{* *}$ at $p \leq .001$. 
Maternal health care seeking during pregnancy, delivery and the postpartum period for the first birth

Drawing on data from two successive cohorts of first-time mothers, findings are presented comparing maternal health care seeking for the first birth $^{5}$ in the experimental intervention group, experimental non-intervention group and the control group.

\section{Antenatal care: Timing of first antenatal check-up}

Figure 4.9 presents findings comparing the proportion of first-time mothers at the baseline and endline who had their first antenatal check-up in the first trimester. Findings show that the endline cohort of first-time mothers was significantly more likely to have received early antenatal services than the baseline cohort across all groups in both sites. In Diamond Harbour, the percentage point difference between the baseline and endline cohorts was roughly similar among those who were exposed to the intervention and the control group, but much smaller in the experimental non-intervention group. In Vadodara, any possible influence of exposure to the intervention was not discernible, as seen in Figure 4.9.

The results of the logistic regression analysis using the DiD model to compare changes in the practice of seeking early antenatal check-ups among first-time mothers over time in the experimental intervention group and the control group are presented in row 1 of Table 4.5. Findings show that in both sites, after controlling for potentially confounding socio-demographic factors and time, young mothers who were exposed to the intervention were no more likely to have received an early antenatal check-up than were those from the control group. Moreover, the net effect did not vary significantly, irrespective of whether young mothers were exposed to just one or at least two components of the intervention.

\section{Figure 4.9:}

First-time mothers who reported receiving their first antenatal check-up in the first trimester, baseline and endline surveys
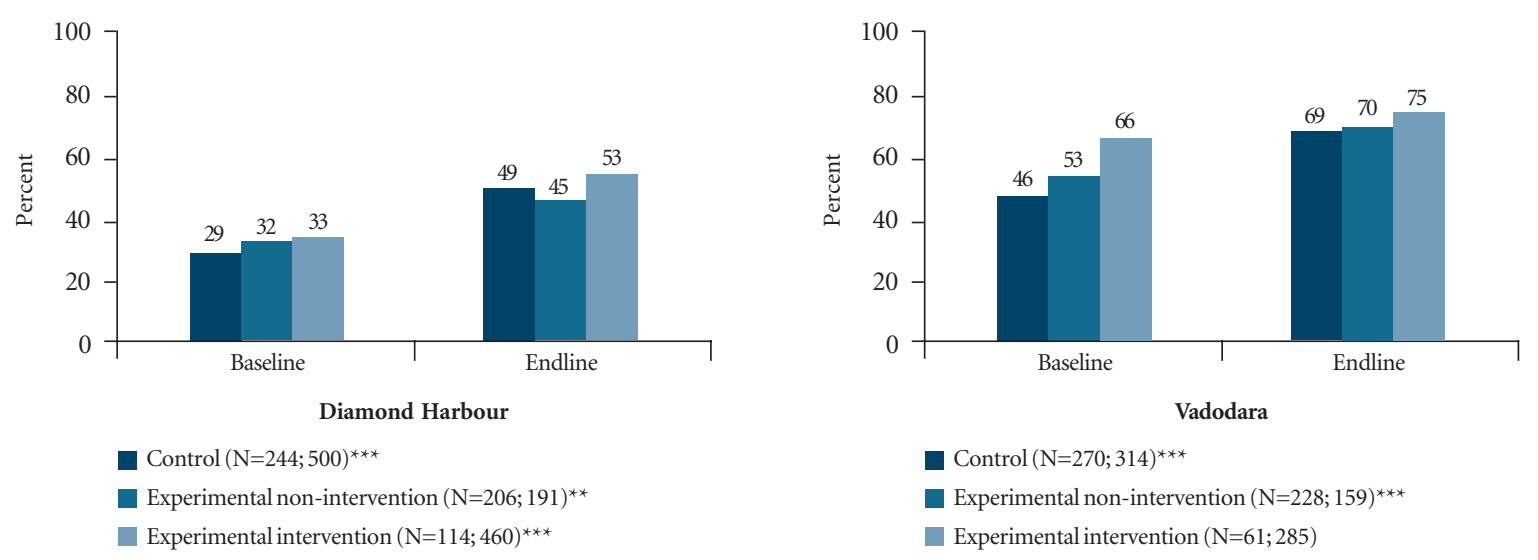

Note: ${ }^{* *}$ indicates that the difference between the baseline and endline cohorts is significant at $p \leq .01 ;{ }^{* * *}$ at $p \leq .001$. Numbers in brackets refer to the baseline and endline cohorts, respectively.

${ }^{5}$ As only a small number of first-time mothers at the baseline who became second-time mothers were followed up at the endline, an analysis of changes in maternal health care practices for the second birth is not presented in this report. 
Table 4.5:

Effects of exposure to the intervention on use of appropriate antenatal services by first-time mothers: Summary of regression results using the DiD model

\begin{tabular}{|c|c|c|c|c|c|c|}
\hline \multirow[t]{3}{*}{ Dependent variable } & \multirow{3}{*}{$\begin{array}{l}\text { Analysis } \\
\text { approach }\end{array}$} & \multirow{3}{*}{$\begin{array}{l}\text { Regression } \\
\text { type }\end{array}$} & \multicolumn{4}{|c|}{ Coefficient $^{\alpha}$} \\
\hline & & & \multicolumn{2}{|c|}{ Diamond Harbour } & \multicolumn{2}{|c|}{ Vadodara } \\
\hline & & & $\begin{array}{l}\text { Exposure to } \\
\text { any one } \\
\text { component }\end{array}$ & $\begin{array}{l}\text { Exposure to } \\
\text { two or more } \\
\text { components }\end{array}$ & $\begin{array}{l}\text { Exposure to } \\
\text { any one } \\
\text { component }\end{array}$ & $\begin{array}{l}\text { Exposure to } \\
\text { two or more } \\
\text { components }\end{array}$ \\
\hline $\begin{array}{l}\text { Received first } \\
\text { check-up in the first } \\
\text { trimester }\end{array}$ & $\begin{array}{l}\text { Cross- } \\
\text { sectional } \\
\text { comparison }\end{array}$ & $\begin{array}{l}\text { Logistic } \\
\text { regression }\end{array}$ & -.101 & .039 & -.425 & -.484 \\
\hline $\begin{array}{l}\text { Mean number of } \\
\text { antenatal check-ups } \\
\text { received }\end{array}$ & $\begin{array}{l}\text { Cross- } \\
\text { sectional } \\
\text { comparison }\end{array}$ & $\begin{array}{l}\text { Linear } \\
\text { regression }\end{array}$ & -.235 & -.219 & -.438 & -.178 \\
\hline $\begin{array}{l}\text { Index of } \\
\text { comprehensive } \\
\text { antenatal care } \\
\text { received }\end{array}$ & $\begin{array}{l}\text { Cross- } \\
\text { sectional } \\
\text { comparison }\end{array}$ & $\begin{array}{l}\text { Linear } \\
\text { regression }\end{array}$ & $.476^{*}$ & $.668^{\star}$ & $-.909^{*}$ & -.624 \\
\hline
\end{tabular}

Note: ${ }^{\alpha}$ A positive co-efficient implies a positive net effect and vice-versa. ${ }^{*}$ indicates that the net effect of exposure to the intervention is significant at $p \leq .05$.

\section{Antenatal care: Number of antenatal check-ups}

Findings comparing the mean number of antenatal check-ups received by first-time mothers reported in the baseline and endline surveys are presented in Figure 4.10. Data show that the number of antenatal check-ups received by mothers increased significantly over time across all groups in both sites; however, in both Diamond Harbour and Vadodara, the potential influence of the intervention was not discernible.

Figure 4.10:

Mean number of antenatal check-ups received by first-time mothers, baseline and endline surveys
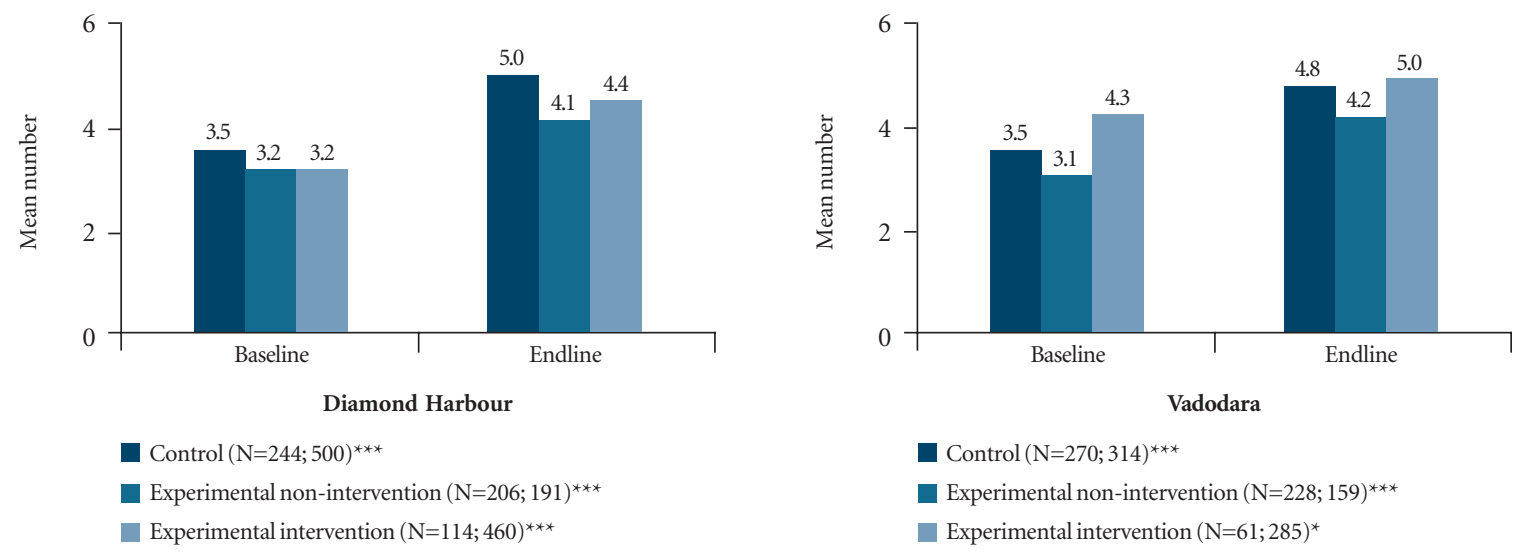

Note: ${ }^{*}$ indicates that the difference between the baseline and endline cohorts is significant at $p \leq .05 ;{ }^{* * *}$ at $p \leq .001$.

Numbers in brackets refer to the baseline and endline cohorts, respectively. 
The results of the linear regression analysis using the DiD model to compare changes in the number of antenatal check-ups received by first-time mothers between the baseline and endline cohorts in the intervention group and the control group are presented in row 2 of Table 4.5. Findings show that in both sites, after controlling for potentially confounding socio-demographic factors and time, young mothers who were exposed to the intervention were no more likely to have received more check-ups than those from the control group. Moreover, the net effect did not vary significantly, irrespective of whether young mothers were exposed to just one or at least two components of the intervention.

\section{Antenatal care: Comprehensive antenatal services}

Figure 4.11 presents the mean score on the index of comprehensive antenatal care for the baseline and endline cohorts (see Chapter 2 for details of the index). Findings indicate that the endline cohort was more likely to have received comprehensive services than the baseline cohort across all groups in both sites. In Diamond Harbour, the increase was the largest among those who were exposed to the intervention (an increase of $26 \%$, versus $15 \%$ among those from the experimental non-intervention group and $18 \%$ among those from the control group). In contrast, in Vadodara, any potential influence of exposure to the intervention was not discernible.

Table 4.5, row 3 presents results of the linear regression analysis using the $\mathrm{DiD}$ model to compare changes over time in comprehensive antenatal care received by first-time mothers from the experimental intervention group and the control group. Findings show that the effects of exposure to the intervention varied by site. In Diamond Harbour, after controlling for potentially confounding socio-demographic factors and time, young mothers who were exposed to the intervention were more likely to have received comprehensive antenatal care than those from the control group. Moreover, the net effect was greater among those who were exposed to at least two components of the intervention than those who were less exposed. In Vadodara, the opposite effect was

Figure 4.11:

Comprehensive antenatal care received by first-time mothers, baseline and endline surveys
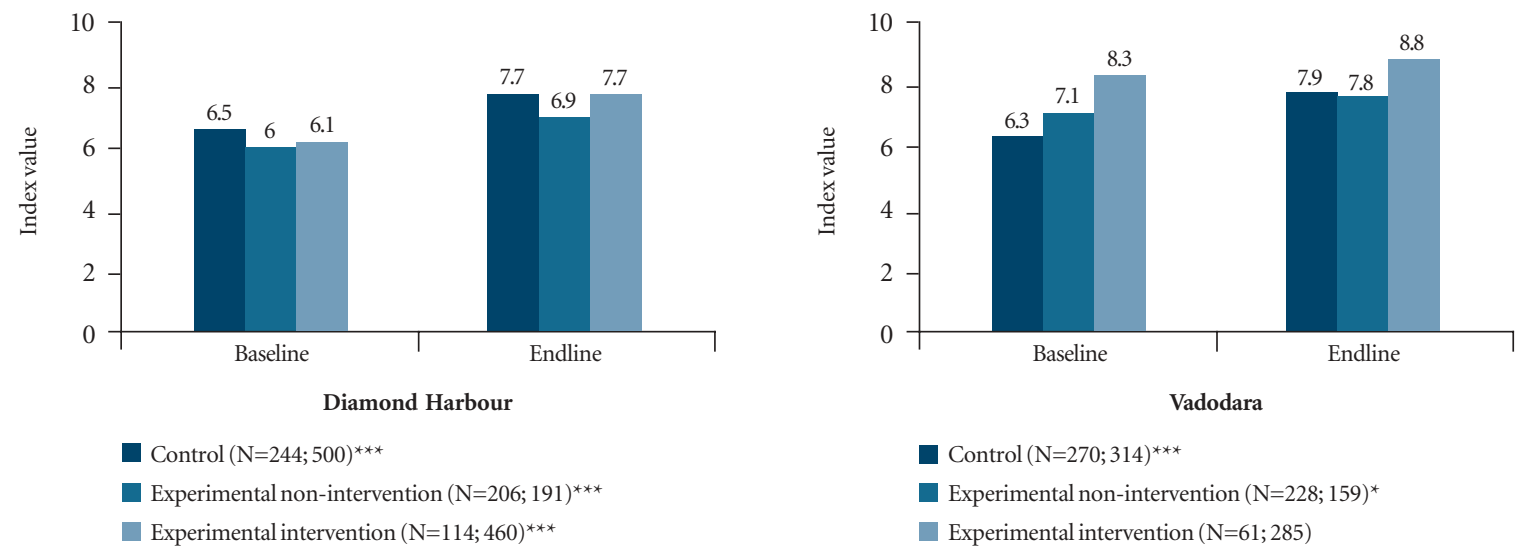

Note: ${ }^{*}$ indicates that the difference between the baseline and endline cohorts is significant at $p \leq .05 ;{ }^{* *}$ at $p \leq .001$.

Numbers in brackets refer to the baseline and endline cohorts, respectively. 
observed: young mothers who were exposed to just one component of the intervention were significantly less likely to have received comprehensive antenatal care than were those from the control group. However, in the model that compared the situation of young women who were exposed to at least two intervention components and that of the control group, the net effect remained negative, but was not statistically significant. It may be that the disruption of intervention activities, which also affected the provision of maternal health services by the DCT clinic, contributed to the negative effect.

\section{Delivery care: Preparations for delivery}

Figure 4.12 presents the mean score on the index of delivery preparations for the baseline and endline cohorts (see Chapter 2 for details of the index). Findings show that the endline cohort of first-time mothers was more likely to have made preparations for delivery than the baseline cohort across all groups in both sites. In Diamond Harbour, the increase in the mean score on the index of delivery preparations was larger in the experimental villages than the control villages (an increase of 61-62\% versus 41\%). In contrast, in Vadodara, the increase in the intervention group was less than in the other groups.

The results of the linear regression analysis using the DiD model to compare changes in the extent to which first-time mothers made preparations for delivery over time in the intervention group and the control group, presented in Table 4.6, row 1, show contrasting effects across the two sites. In Diamond Harbour, the model comparing the situation of young mothers who were exposed to any one component of the intervention and those from the control group did not show a significant positive net effect. However, the model comparing the situation of mothers who were exposed to at least two components of the intervention and that of the control group shows that after controlling for potentially confounding sociodemographic factors and time, young mothers who were exposed to the intervention were significantly more likely to have made preparations for delivery than those from the control group. In contrast, in

Figure 4.12:

Extent of delivery preparations made by first-time mothers, baseline and endline surveys
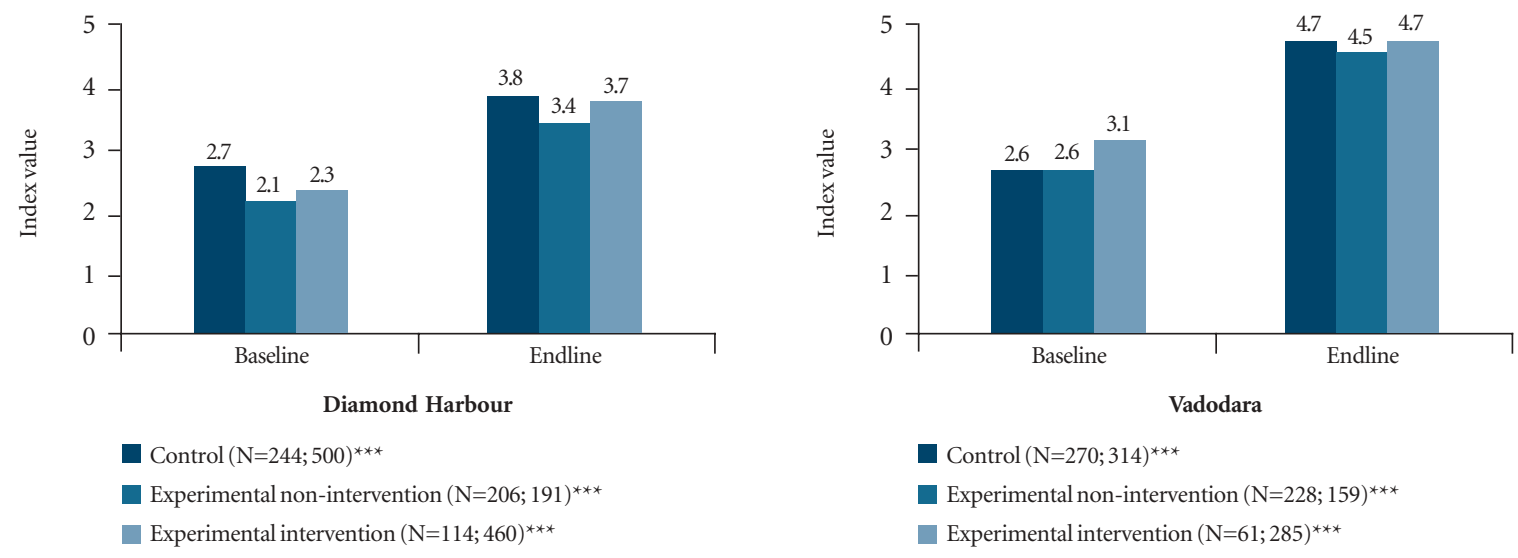

Note: ${ }^{* * *}$ indicates that the difference between the baseline and endline cohorts is significant at $p \leq .001$.

Numbers in brackets refer to the baseline and endline cohorts, respectively. 
Table 4.6:

Effects of exposure to the intervention on adoption of appropriate delivery care by first-time mothers: Summary of regression results using the DiD model

\begin{tabular}{|c|c|c|c|c|c|c|}
\hline \multirow[t]{3}{*}{ Dependent variable } & \multirow{3}{*}{$\begin{array}{l}\text { Analysis } \\
\text { approach }\end{array}$} & \multirow{3}{*}{$\begin{array}{l}\text { Regression } \\
\text { type }\end{array}$} & \multicolumn{4}{|c|}{ Coefficient $^{\alpha}$} \\
\hline & & & \multicolumn{2}{|c|}{ Diamond Harbour } & \multicolumn{2}{|c|}{ Vadodara } \\
\hline & & & $\begin{array}{l}\text { Exposure to } \\
\text { any one } \\
\text { component }\end{array}$ & $\begin{array}{l}\text { Exposure to } \\
\text { two or more } \\
\text { components }\end{array}$ & $\begin{array}{l}\text { Exposure to } \\
\text { any one } \\
\text { component }\end{array}$ & $\begin{array}{l}\text { Exposure to } \\
\text { two or more } \\
\text { components }\end{array}$ \\
\hline $\begin{array}{l}\text { Index of delivery } \\
\text { preparations }\end{array}$ & $\begin{array}{l}\text { Cross- } \\
\text { sectional } \\
\text { comparison }\end{array}$ & $\begin{array}{l}\text { Linear } \\
\text { regression }\end{array}$ & .223 & $.486^{*}$ & $-.582^{\star}$ & -.563 \\
\hline $\begin{array}{l}\text { Had institutional } \\
\text { delivery }\end{array}$ & $\begin{array}{l}\text { Cross- } \\
\text { sectional } \\
\text { comparison }\end{array}$ & $\begin{array}{l}\text { Logistic } \\
\text { regression }\end{array}$ & .011 & -.048 & -.509 & -.345 \\
\hline
\end{tabular}

Note: ${ }^{\alpha}$ A positive co-efficient implies a positive net effect and vice-versa. ${ }^{*}$ indicates that the net effect of exposure to the intervention is significant at $p \leq .05$.

Vadodara, young mothers who were exposed to any one of the intervention components were significantly less likely to have made preparations for delivery than those from the control group; and those who were exposed to at least two components of the intervention were about as likely as respondents from the control group to have made preparations for delivery.

\section{Delivery care: Institutional delivery}

Figure 4.13 presents findings comparing the proportion of baseline and endline cohorts of firsttime mothers who had their first delivery in a health facility. Findings indicate that larger proportions of the endline than the baseline cohort across most groups in both sites had their first delivery in a health facility. In Diamond Harbour the percentage point

Figure 4.13:

First-time mothers who reported an institutional delivery, baseline and endline surveys
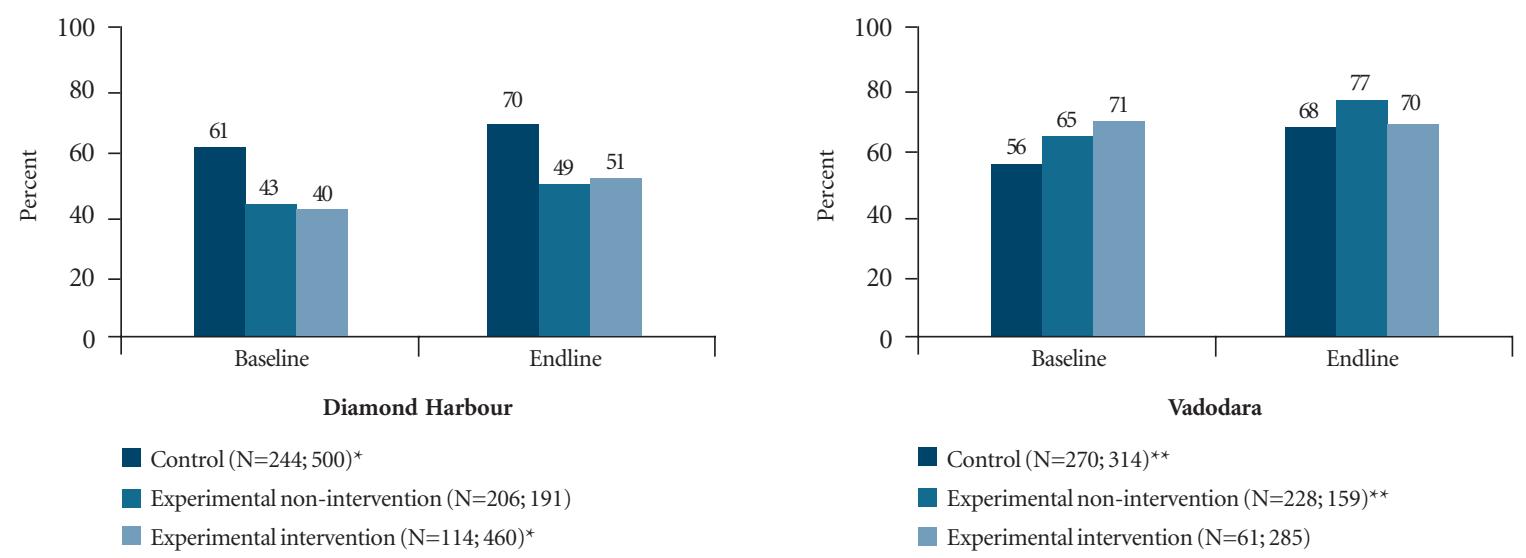

Note: ${ }^{*}$ indicates that the difference between the baseline and endline cohorts is significant at $p \leq .05 ; * *$ at $p \leq .01$.

Numbers in brackets refer to the baseline and endline cohorts, respectively. 
increase was similar in the experimental intervention group and the control group, but much smaller in the experimental non-intervention group. In Vadodara, reporting of institutional delivery remained virtually unchanged (that is, a decline of 1 percentage point) among those who were exposed to the intervention, but increased in the experimental non-intervention group and the control group.

The results of the logistic regression analysis using the DiD model to compare changes in institutional delivery over time in the intervention and control groups, presented in Table 4.6, row 2, show that in both sites, after controlling for potentially confounding socio-demographic factors and time, young mothers who were exposed to the intervention were no more likely to have had an institutional delivery than those from the control group. Moreover, the net effect did not vary significantly between the models. It is possible that this may be because many young women had gone to their natal home for their first delivery, and as discussed in the section on limitations in Chapter 1, the intervention was not able to influence the family or health service environment outside the project sites. Moreover, given the relatively high prevalence of these indicators at the baseline, especially in Vadodara, effecting change was predictably more difficult.

\section{Postpartum care}

Findings presented in Figure 4.14, comparing the percentage of the baseline and endline cohorts of first-time mothers who received a routine check-up within six weeks postpartum, show that the endline cohort was significantly more likely to have received such services than the baseline cohort across most groups in both sites. In Diamond Harbour, the increase was largest among those exposed to the intervention (an increase of 39 percentage points, versus 9 percentage points among those from the experimental non-intervention group and 21 percentage points among those from the control group). In Vadodara too, the increase in routine

\section{Figure 4.14:}

First-time mothers who reported receiving a routine check-up within six weeks postpartum, baseline and endline surveys
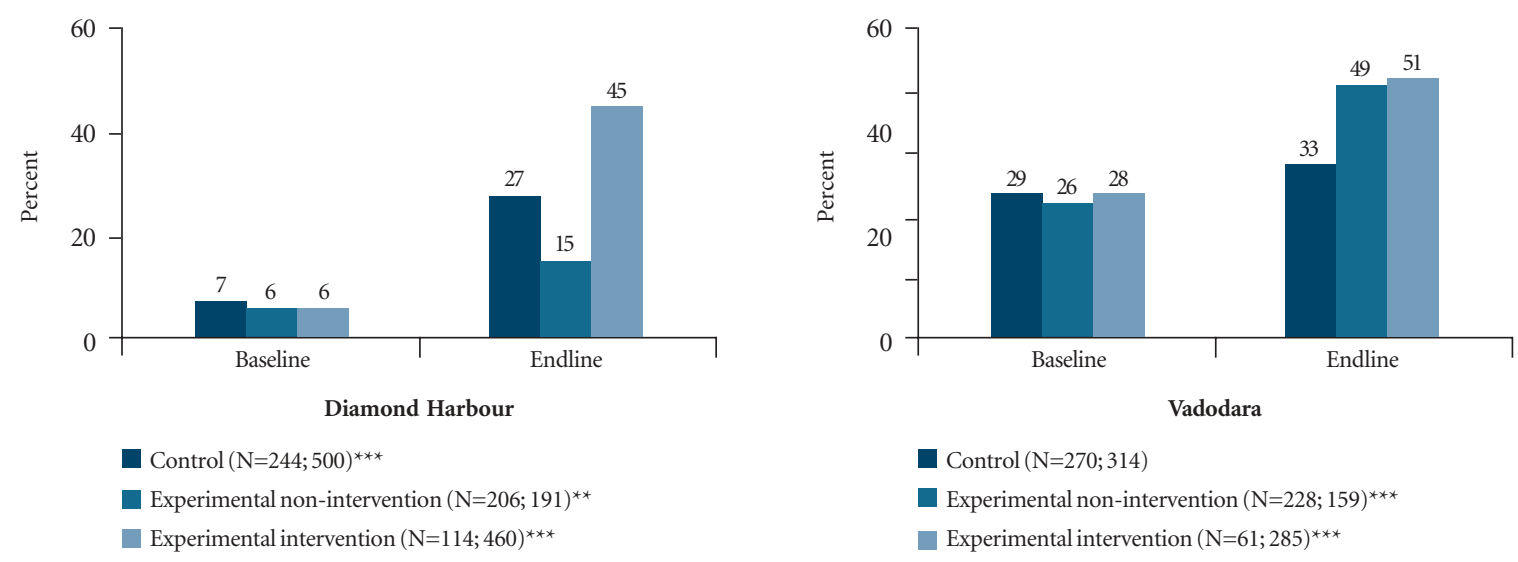

Note: ${ }^{* *}$ indicates that the difference between the baseline and endline cohorts is significant at $p \leq .01 ; * *$ at $p \leq .001$. Numbers in brackets refer to the baseline and endline cohorts, respectively. 
postpartum care was larger among those from the experimental villages than those from the control villages (an increase of 23 versus 5 percentage points).

The results of the linear regression analysis using the $\mathrm{DiD}$ model to compare changes in routine postpartum check-ups over time in the intervention group and the control group are presented in Table 4.7. Findings show that in both Diamond Harbour and Vadodara, after controlling for potentially confounding socio-demographic factors and time, young mothers who were exposed to the intervention were significantly more likely to have received a routine check-up within six weeks postpartum than those from the control group. Moreover, the positive net effect increased in the model that compared the situation of young mothers who were exposed to at least two components of the intervention and those from the control group.

\section{Newborn care: Initiation of breastfeeding}

Figure 4.15 presents findings comparing the percentage of baseline and endline cohorts of first-time mothers who reported that they had breastfed their newborns immediately after delivery. Findings show that mothers in the endline cohort were more likely to have initiated breastfeeding immediately after delivery than those in the baseline cohort across most groups in both sites. In Diamond Harbour, the increase was the largest among those who were exposed to the intervention (an increase of 30 percentage points, versus 19 percentage points among those from the experimental non-intervention group and 6 percentage points among those from the control group). In Vadodara, the proportion of young mothers who reported that they had breastfed their newborns immediately after delivery remained more or less the same over time in the experimental villages; however, in the control villages, reporting increased by 11 percentage points.

The results of the logistic regression analysis using the DiD model to compare changes in the timing of initiation of breastfeeding over time in the intervention group and the control group, presented in Table 4.8, row 1 , show contrasting effects between the two sites. In Diamond Harbour, findings show that after controlling for potentially confounding socio-demographic factors and time, young mothers who were exposed to the intervention were more likely to have breastfed their newborns immediately after

Table 4.7:

Effects of exposure to the intervention on adoption of appropriate postpartum care by first-time mothers: Summary of regression results using the DiD model

\begin{tabular}{|c|c|c|c|c|c|c|}
\hline \multirow[t]{3}{*}{ Dependent variable } & \multirow{3}{*}{$\begin{array}{l}\text { Analysis } \\
\text { approach }\end{array}$} & \multirow{3}{*}{$\begin{array}{l}\text { Regression } \\
\text { type }\end{array}$} & \multicolumn{4}{|c|}{ Coefficient $^{\alpha}$} \\
\hline & & & \multicolumn{2}{|c|}{ Diamond Harbour } & \multicolumn{2}{|c|}{ Vadodara } \\
\hline & & & $\begin{array}{l}\text { Exposure to } \\
\text { any one } \\
\text { component }\end{array}$ & $\begin{array}{l}\text { Exposure to } \\
\text { two or more } \\
\text { components }\end{array}$ & $\begin{array}{l}\text { Exposure to } \\
\text { any one } \\
\text { component }\end{array}$ & $\begin{array}{l}\text { Exposure to } \\
\text { two or more } \\
\text { components }\end{array}$ \\
\hline $\begin{array}{l}\text { Had a routine } \\
\text { check-up within six } \\
\text { weeks postpartum }\end{array}$ & $\begin{array}{l}\text { Cross- } \\
\text { sectional } \\
\text { comparison }\end{array}$ & $\begin{array}{l}\text { Logistic } \\
\text { regression }\end{array}$ & $.891^{\star * *}$ & $1.566^{\star * *}$ & $.846^{* * *}$ & $.901^{* * *}$ \\
\hline
\end{tabular}

Note: ${ }^{\alpha}$ A positive co-efficient implies a positive net effect and vice-versa. ${ }^{* * *}$ indicates that the net effect of exposure to the intervention is significant at $p \leq .001$. 
Figure 4.15:

First-time mothers who reported breastfeeding their newborns immediately after delivery, baseline and endline surveys
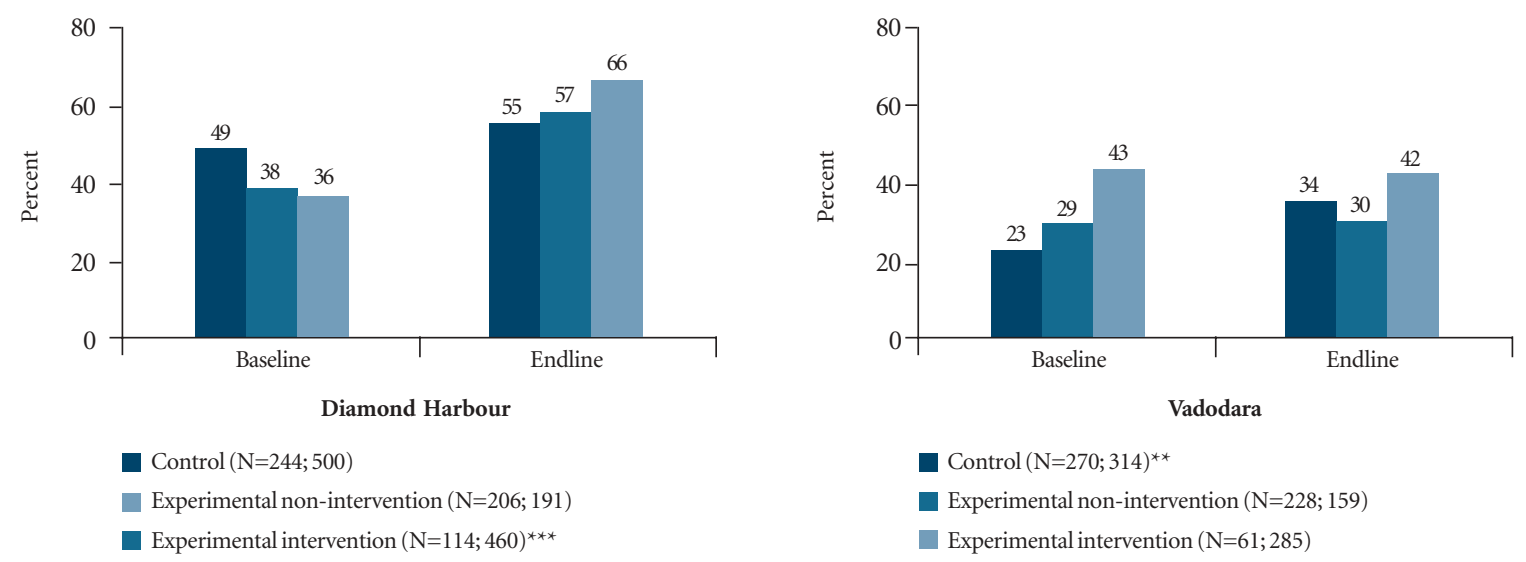

Note: ${ }^{* *}$ indicates that the difference between the baseline and endline cohorts is significant at $p \leq .01 ;{ }^{* * *}$ at $p \leq .001$. Numbers in brackets refer to the baseline and endline cohorts, respectively.

delivery than young mothers from the control group. In contrast, in Vadodara, young mothers who were exposed to the intervention were about as likely as those from the control group to have initiated breastfeeding immediately after delivery, irrespective of whether they were exposed to just one or at least two components of the intervention.

\section{Newborn care: Feeding colostrum}

Findings comparing changes in the practice of feeding colostrum to newborns from the baseline to the endline are presented in Figure 4.16. Data show that mothers in the endline cohort were more likely to have fed colostrum to their newborns than those in the baseline cohort across most groups in both sites.

Table 4.8:

Effects of exposure to the intervention on adoption of appropriate breastfeeding practices by first-time mothers: Summary of regression results using the DiD model

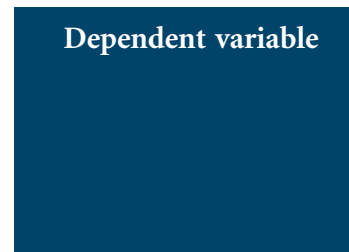

Breastfed newborn immediately after delivery

Fed colostrum to the newborn

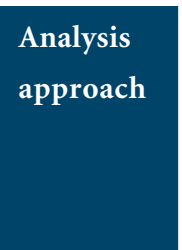

Crosssectional comparison

Crosssectional comparison

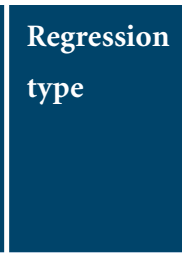

Logistic regression

Logistic regression

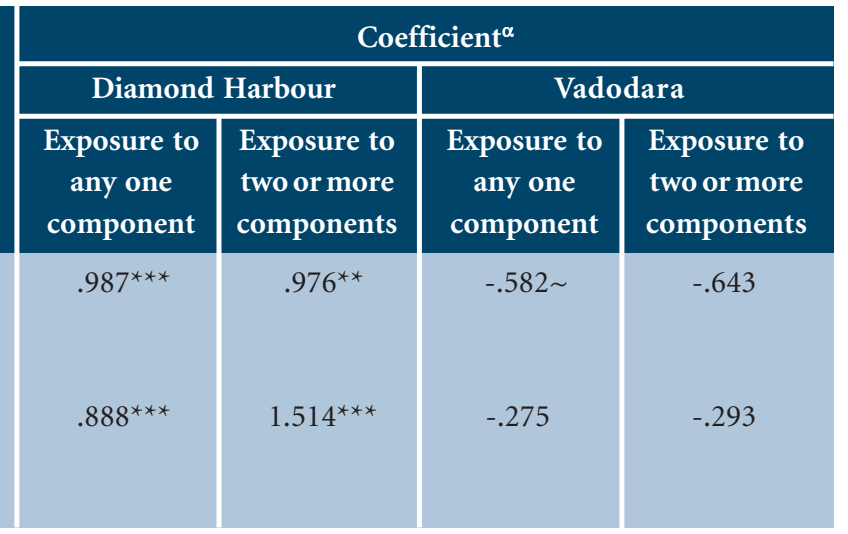

Note: ${ }^{\alpha}$ A positive co-efficient implies a positive net effect and vice-versa. $\sim$ indicates that the net effect of exposure to the intervention is significant at $p \leq .10 ;{ }^{* *} p=.01$; ${ }^{* * *} p \leq .001$. 
In Diamond Harbour, the increase was the largest among those who were exposed to the intervention (an increase of 30 percentage points, versus 15 percentage points among those from the experimental non-intervention group and 14 percentage points among those from the control group). In Vadodara, this practice improved significantly only in the control group.

The results of the logistic regression analysis using the DiD model to compare changes in the practice of feeding colostrum to newborns over time in the intervention group and the control group, presented in Table 4.8, row 2, again show contrasting effects between the two sites. In Diamond Harbour, findings show that after controlling for potentially confounding socio-demographic factors and time, young mothers who were exposed to the intervention were more likely to have fed colostrum to their newborns than were young women from the control group. Moreover, the results show a greater positive net effect among young mothers who were exposed to at least two components of the intervention than those exposed to just one component. In contrast, in Vadodara, findings show that young mothers who were exposed to the intervention were no more likely to feed colostrum to their newborns than their counterparts from the control group.

\section{Effects of exposure to the intervention on partner communication and support}

To ascertain the effects of exposure to the intervention on partner communication and support, three indicators were used: spousal communication on contraceptive use, the extent to which husbands supported their wives during conflicts with family members, and the extent to which young women were able to express their opinion when they disagreed with their husbands. As with indicators described earlier, the type of comparisons and regression models used varied depending on the nature of the outcome indicators.

Figure 4.16:

First-time mothers who reported feeding colostrum to their newborns, baseline and endline surveys
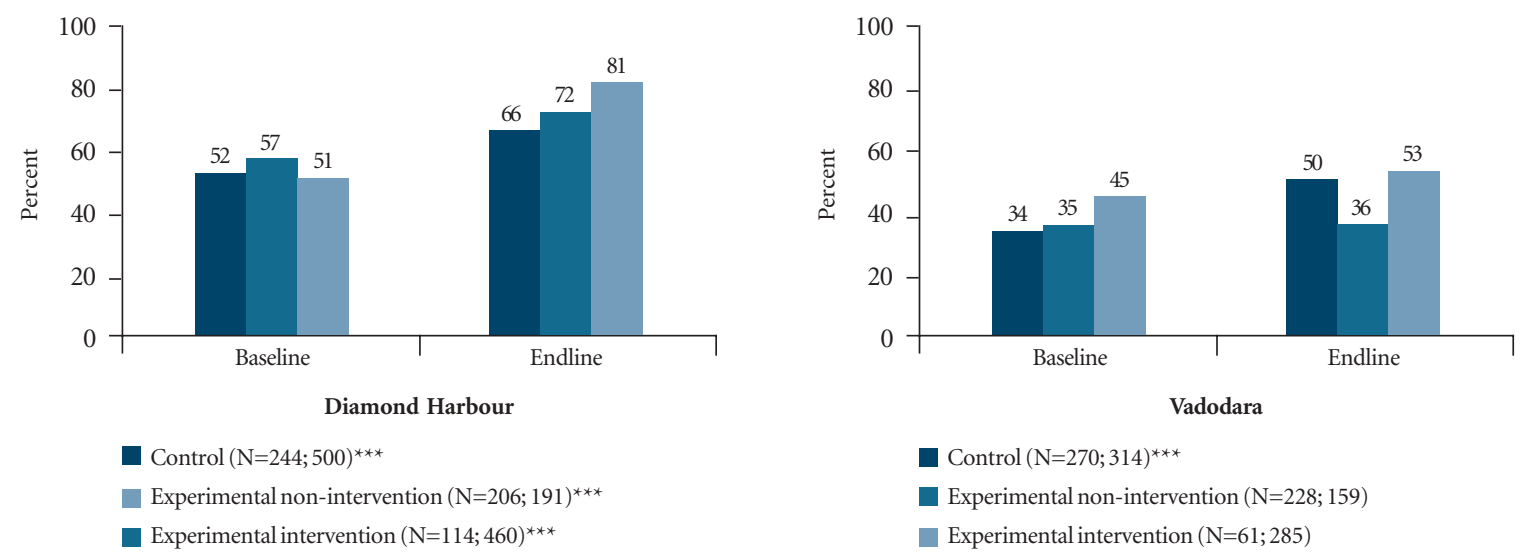

Note: ${ }^{* * *}$ indicates that the difference between the baseline and endline cohorts is significant at $p \leq .001$. Numbers in brackets refer to the baseline and endline cohorts, respectively. 


\section{Spousal communication on contraceptive use}

Drawing on data from the baseline and endline cohorts of newly-married, first-time pregnant and first-time mothers, findings are presented in Figure 4.17 on the extent to which spousal communication on contraceptive use changed over time in the study sites. Findings show that in Diamond Harbour, while spousal communication increased over time across all groups, the largest increase was observed among those who were exposed to the intervention (an increase of 31 percentage points, versus 24 percentage points among those from the experimental non-intervention group and 13 percentage points among those from the control group). In Vadodara, in contrast and rather surprisingly, findings show that while spousal communication on contraceptive use increased marginally over time in the intervention group, it declined significantly in the experimental non-intervention group and the control group.

The results of the logistic regression analysis using the DiD model to compare changes in the extent of spousal communication on contraceptive use over time in the intervention group and the control group, presented in Table 4.9, show a positive net effect in both sites. Findings show that after controlling for potentially confounding socio-demographic factors and time, married young women who were exposed to the intervention were significantly more likely to have discussed contraceptive use with their husbands than those from the control group. Moreover, the positive net effect was larger among young women who were exposed to more than one component of the intervention than among those who were exposed to any one component.

\section{Partner support and nature of spousal relationship}

Two indicators, namely, the extent to which young husbands supported their wives during conflicts with family members and the extent to which married young women expressed their views when they disagreed with their husbands, were used to assess changes in partner support and the nature of the spousal relationship. Longitudinal data were used for these indicators.

Figure 4.17:

Extent of spousal communication on contraceptive use, baseline and endline surveys
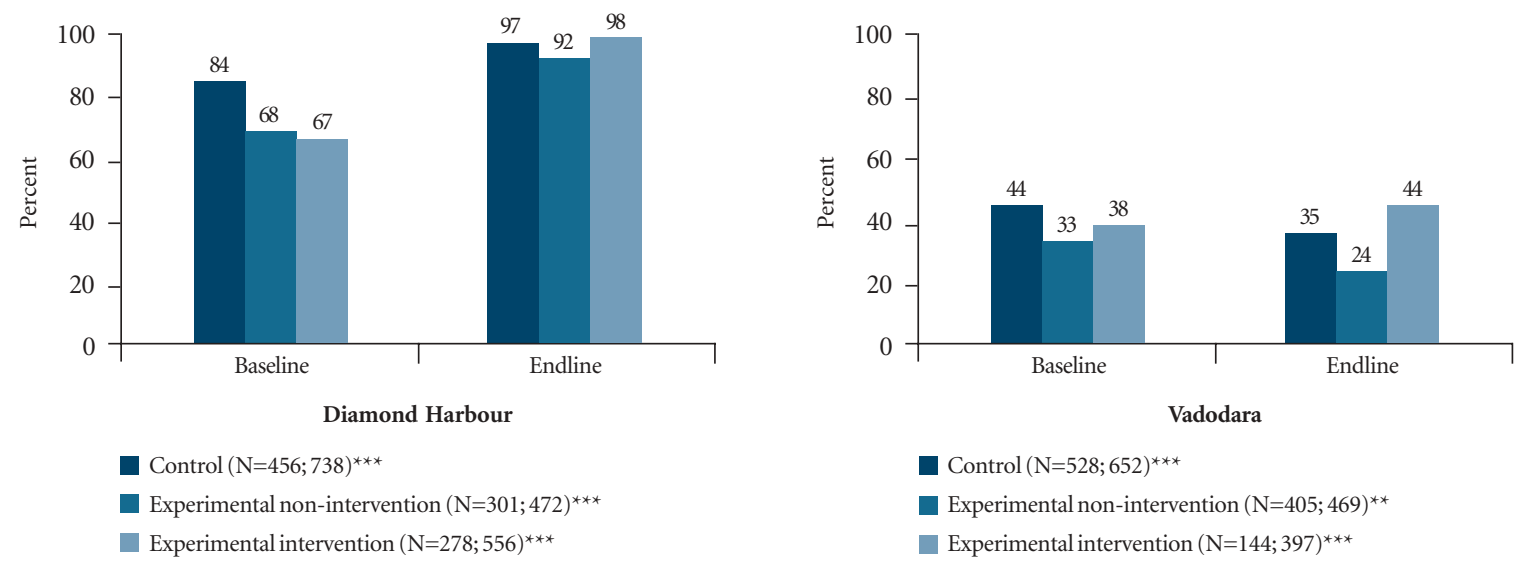

Note: ${ }^{* *}$ indicates that the difference between the baseline and endline cohorts is significant at $p \leq .01 ;{ }^{* * *} p \leq .001$.

Numbers in brackets refer to the baseline and endline cohorts, respectively. 
Table 4.9:

Effects of exposure to the intervention on spousal communication on contraceptive use: Summary of regression results using the $\mathrm{DiD}$ model

\begin{tabular}{|c|c|c|c|c|c|c|}
\hline \multirow[t]{3}{*}{ Dependent variable } & \multirow{3}{*}{$\begin{array}{l}\text { Analysis } \\
\text { approach }\end{array}$} & \multirow{3}{*}{$\begin{array}{l}\text { Regression } \\
\text { type }\end{array}$} & \multicolumn{4}{|c|}{ Coefficient $^{\alpha}$} \\
\hline & & & \multicolumn{2}{|c|}{ Diamond Harbour } & \multicolumn{2}{|c|}{ Vadodara } \\
\hline & & & $\begin{array}{l}\text { Exposure to } \\
\text { any one } \\
\text { component }\end{array}$ & $\begin{array}{l}\text { Exposure to } \\
\text { two or more } \\
\text { components }\end{array}$ & $\begin{array}{l}\text { Exposure to } \\
\text { any one } \\
\text { component }\end{array}$ & $\begin{array}{l}\text { Exposure to } \\
\text { two or more } \\
\text { components }\end{array}$ \\
\hline $\begin{array}{l}\text { Discussed } \\
\text { contraceptive use } \\
\text { with husband }\end{array}$ & $\begin{array}{l}\text { Cross- } \\
\text { sectional } \\
\text { comparison }\end{array}$ & $\begin{array}{l}\text { Logistic } \\
\text { regression }\end{array}$ & $1.602^{* * *}$ & $1.951^{* * *}$ & $.694^{* *}$ & $.929^{*}$ \\
\hline
\end{tabular}

Note: ${ }^{\alpha}$ A positive co-efficient implies a positive net effect and vice-versa. ${ }^{*}$ indicates that the net effect of exposure to the intervention is significant at $p \leq .05 ;{ }^{* *} p=.01$; $* * * p \leq .001$.

\section{Husbands' support to wives during family conflicts}

Findings show that the extent to which husbands always supported their wives during conflicts with family members increased significantly across all groups in both sites. In Diamond Harbour, the percentage point increase between the baseline and endline surveys was similar among married young women who were exposed to the intervention and those from the control group, but marginally less among young women from the experimental non-intervention group. In Vadodara, the potential influence of exposure to the intervention was not evident.

The results of the regression analysis are presented in row 1 of Table 4.10. For convenience, findings are presented that compare the experiences of women from the experimental intervention group and those from the control group. Findings show that in both sites, after controlling for potentially confounding factors, exposure to the intervention did not have a significant positive net effect on husbands' support to their wives during conflicts with family members.

Figure 4.18:

Married young women who reported that their husbands always supported them during family conflicts, baseline and endline surveys
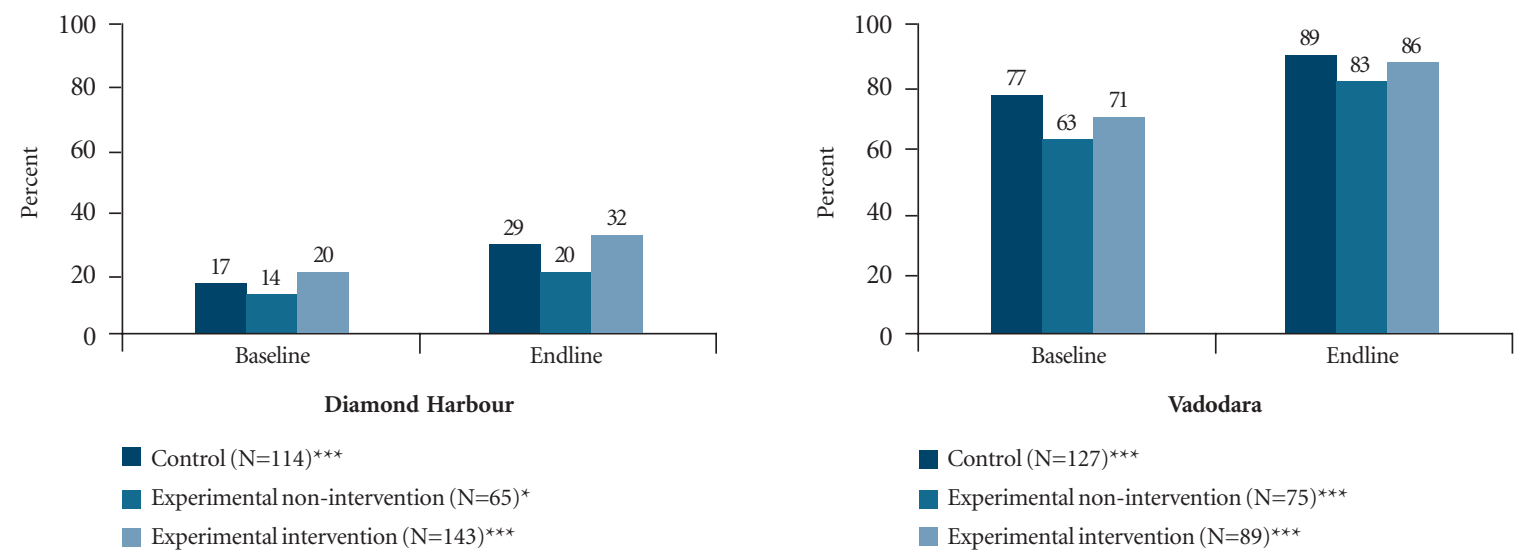

Note: ${ }^{*}$ indicates that the difference between the baseline and endline cohorts is significant at $p \leq .05 ;{ }^{* * *} p \leq .001$.

Those who reported that they had not had any conflict with family members were excluded from the analysis. 
Table 4.10:

Effects of exposure to the intervention on partner support: Summary of regression results

\begin{tabular}{|c|c|c|c|c|}
\hline \multirow[t]{2}{*}{ Dependent variable } & \multirow{2}{*}{$\begin{array}{l}\text { Analysis } \\
\text { approach }\end{array}$} & \multirow{2}{*}{$\begin{array}{l}\text { Regression } \\
\text { type }\end{array}$} & \multicolumn{2}{|c|}{ Odds ratio } \\
\hline & & & $\begin{array}{l}\text { Diamond } \\
\text { Harbour }\end{array}$ & Vadodara \\
\hline $\begin{array}{l}\text { Husband always supported wife } \\
\text { during family conflicts }\end{array}$ & $\begin{array}{l}\text { Longitudinal } \\
\text { comparison }\end{array}$ & $\begin{array}{l}\text { Logistic } \\
\text { regression }\end{array}$ & .500 & .071 \\
\hline $\begin{array}{l}\text { Expressed opinion to husband } \\
\text { when she disagreed with him }\end{array}$ & $\begin{array}{l}\text { Longitudinal } \\
\text { comparison }\end{array}$ & $\begin{array}{l}\text { Logistic } \\
\text { regression }\end{array}$ & $3.884^{\star}$ & .805 \\
\hline
\end{tabular}

Note: ${ }^{*}$ indicates that the net effect of exposure to the intervention is significant at $p \leq .05$.

\section{Expressing own opinion to husbands when they} disagreed with them

Findings with regard to married young women's ability to express their opinion when they disagreed with their husbands, show an improvement across all groups in both sites (Figure 4.19). In Diamond Harbour, the largest increase was observed among young women who were exposed to the intervention (an increase of 28 percentage points, versus 18 percentage points among those from the experimental non-intervention group and 15 percentage points among those from the control group). In Vadodara too, the largest increase was observed in the intervention group; an increase of 24 percentage points compared to 23 percentage points in the experimental non-intervention group and 19 percentage points in the control group.

The results of the regression analysis, presented in row 2 of Table 4.10, suggest that the effects of the intervention varied across the two sites. In Diamond Harbour, after controlling for potentially confounding factors, exposure to the intervention had a positive net effect on married young women's ability to express their opinion to their husbands when they disagreed with them. In contrast in Vadodara, no such positive net effect was observed.

Figure 4.19:

Married young women who expressed their opinion to their husbands when they disagreed with them, baseline and endline surveys
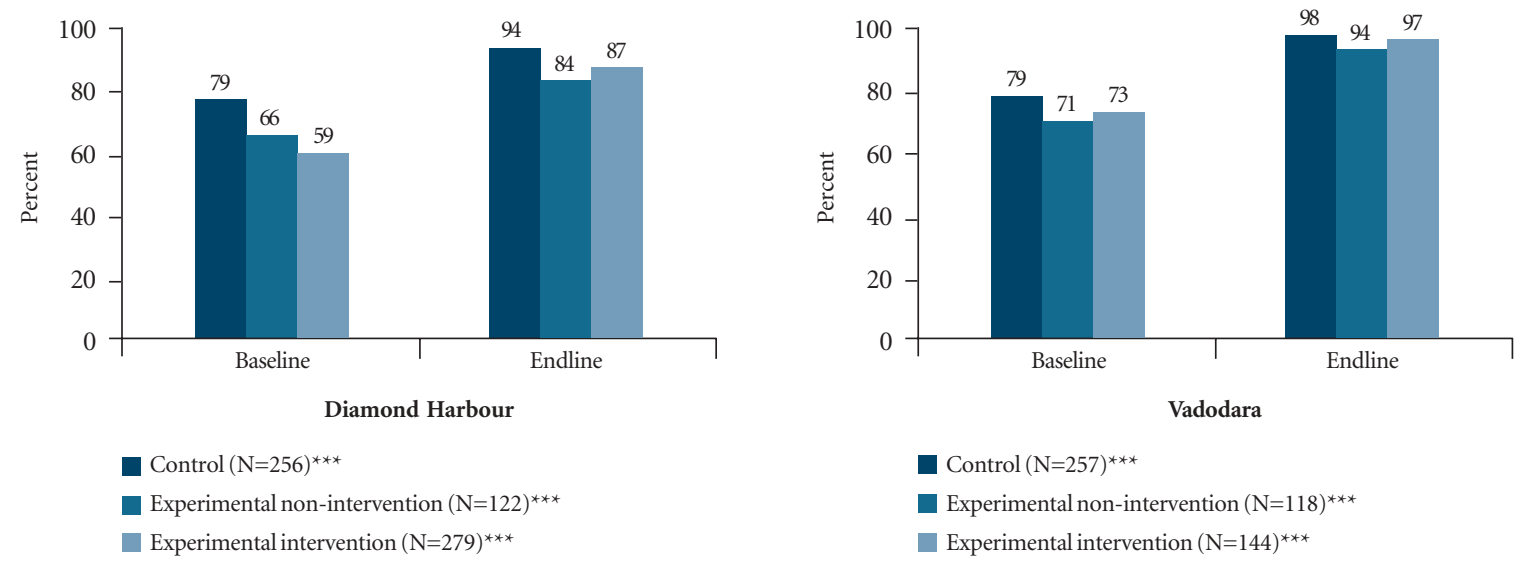

Note: ${ }^{* *}$ indicates that the difference between the baseline and endline cohorts is significant at $p \leq .001$. 


\section{Summary and recommendations}

This chapter summarises the major findings of the study and highlights key lessons learned for programming for married young women.

\section{Summary}

The First-time Parents Project was designed to improve married young women's reproductive health knowledge and practices, increase their ability to act in their own interest and expand their social support networks. Implemented in two rural sites-in Diamond Harbour (West Bengal) by CINI and in Vadodara (Gujarat) by DCT—-the project adopted a multi-pronged approach to directly reach married young women, and influential adults in their lives, with information on reproductive and sexual health in their homes; provide a safe, acceptable space where married young women could make connections with friends and mentors, take action as a group, and learn about their rights and the world around them; and make reproductive health services, particularly pregnancy-related services, more accessible.

A quasi-experimental research design, with cross-sectional surveys undertaken in control and intervention villages prior to the implementation of intervention activities and at its conclusion, was used to evaluate the effects of the intervention. Findings indicate that in both sites the intervention had a significant, positive net effect on most indicators reflecting married young women's autonomy, social support networks, partner communication and knowledge of sexual and reproductive health.
However, the net effect of exposure to the intervention was mixed with regard to indicators related to gender role attitudes and attitudes towards domestic violence. While exposure to the intervention had a significant, positive net effect on gender role attitudes in one of the sites, it did not influence attitudes towards domestic violence in either site.

Likewise, the net effect of exposure to the intervention was mixed with regard to reproductive health practices. The exposure to the intervention had a significant, positive net effect on such indicators as use of contraceptives to delay the first birth, comprehensive antenatal care, delivery preparations, routine postpartum check-ups and breastfeeding practices in one or both sites. It did not, however, appear to positively influence institutional delivery at first birth in either site. We believe that this may be because many young women had gone to their natal home for the first delivery, and the intervention was not able to influence family or health service environments outside the project sites. Although the project made conscious efforts to address this issue by arranging for female outreach workers to meet young women before they left for their natal home for the first delivery, and male outreach workers to meet husbands of young women even after they left for their natal home, findings underscore that these efforts were not adequate. In addition, given that the reproductive practices that the intervention sought to address, such as early antenatal check-up and institutional delivery, are typically the focus of 
government's programmes, and the unanticipated, and rather extensive, exposure of the control group to government programmes in both sites over the course of the intervention, it was difficult to isolate the changes entirely attributable to exposure to the intervention.

Of particular note are differences in the net effect of exposure to the intervention in the two sites. Married young women in Diamond Harbour showed significant changes attributable to the intervention in four out of six indicators related to women's agency and social support networks. In Vadodara, only two out of six indicators improved as a result of the intervention. In terms of family planning and maternal and newborn health practices, the intervention in Diamond Harbour resulted in significant changes in five out of nine indicators. In Vadodara, the intervention effected significant positive changes in only two indicators. With regard to partner communication and support, in both sites significant changes were evident in two out of three indicators.

There are several possible explanations for the more robust findings from Diamond Harbour than Vadodara. First, political unrest forced DCT to discontinue intervention activities for a few months, thereby denying married young women sustained exposure to the intervention in Vadodara. Second, as findings show, young women in Vadodara were less likely than those in Diamond Harbour to report sustained exposure to the intervention. Third, in Vadodara the intervention was implemented in villages where DCT had been working for many years, resulting in relatively high baseline scores for most indicators. Consequently, in order to show a significant positive net effect of exposure to the intervention on these indicators, far greater change over time was needed in Vadodara than would have been expected if the intervention had been implemented in villages where no activities had been conducted prior to the launching of the intervention, as in Diamond Harbour.

Moreover, while the clinic-based activities of the Vadodara intervention were strong, its social empowerment component was not as strong as in Diamond Harbour. Hence, it is not surprising that respondents in Diamond Harbour demonstrated improvements across a greater number of indicators of agency and social support networks than respondents in Vadodara. It is also possible that the intervention was more effective in improving health practices in Diamond Harbour than in Vadodara for the same reasons. In other words, it is possible that "supply-side" stand-alone health service delivery interventions may not be adequate to meet the special needs of married young women; to be effective, they must be coupled with interventions that address young women's social isolation and relative lack of power. However, this is an area for further analysis and investigation. Other possible explanations may be rooted in the political environment in the two sites at the time of the intervention. Greater involvement of the community and panchayat raj institutions in the project was observed in West Bengal, as compared to Gujarat. While this conclusion is speculative as data from this study did not track political practices, this is clearly an area for further research.

While this study has several limitations that may have exaggerated the effects of the intervention, such as self-selection of young women into the intervention activities and loss to follow-up, other shortcomings may have worked to conceal the effects of the intervention. Most notably, while few married young women in control villages reported receiving 
services at baseline, at endline it was clear that during the course of the intervention, a substantial proportion of women in these villages had received information and services from government programmes; thus, it was difficult to identify changes entirely attributable to the intervention. Also, as a result of the movement of married young women between their marital and natal homes, exposure to the intervention was diminished for many participants. However, despite these shortcomings, the overall pattern and general consistency of the findings give us confidence in the results.

\section{Recommendations}

Several lessons can be drawn from the experience of implementing the First-time Parents Project, which could be relevant for programmes targeted at married young women. These are outlined below:

\section{- Addressing the diversity of the target population.} Even within the subset of young women who are married, there is diversity, including women who are trying to conceive, hoping to delay the first pregnancy, those pregnant and recent mothers. Hence there is a critical need to tailor information and the provision of services to the distinct life stages and needs of each group within the subset of married young women.

- Including programme elements that maintain ties with married young women even after they leave for their natal home. Married young women in many settings in India travel frequently to their natal home, and often go there for first delivery. It is important to ensure that young women continue to maintain their ties with the intervention even after they leave the project area through, for example, ongoing contact with young women's husbands and providing young women with information materials that they can take to their natal home. In addition, young women can be provided with a kit that includes, for example, condoms, reminders about antenatal services still needed and a list of reputable providers in the natal village, which can be taken to their natal home.

- Allaying the fears of influential adults in the family. While there was little resistance to the health information and services components of the intervention, in some cases mothers-in-law and husbands did not approve of their daughters-inlaw or wives attending the group meetings. Indeed, the social empowerment component of the intervention was sometimes perceived as a threat by other members of the family. In this scenario, it is important to train staff to build in activities in the intervention that allay the fears of influential adults in the family when working with married young women.

- Orienting health providers to the special needs of married young women and reaching out directly to young women with information and services. Evidence shows that as a result of their lack of awareness, decision-making authority, control over resources and restricted mobility, young women in India who are recently married, first-time pregnant or first-time mothers are less likely to seek appropriate and timely health care than older women. Our experience suggests that providers need to be sensitised to the special needs of married young women; and special efforts are needed to provide reproductive health information and services directly to married young women through outreach services. 
- Addressing the factors underlying married young women's social and economic disadvantages is essential but requires specially directed efforts. The experience of several livelihoods programmes and social cohesion building interventions to mitigate the social and economic disadvantages of adolescent girls suggests that these efforts may not reach - or may not adequately reach -many adolescent girls who are married. The experience of the First-time Parents Project shows that married young women can participate in such initiatives, but require specially focused efforts. Moreover, findings suggest that efforts to enhance married young women's agency and reduce their social isolation can also contribute to improve their reproductive health practices.

In brief, the findings from this study are encouraging. The experience of implementing the First-time Parents Project demonstrates that it is possible to improve married young women's reproductive health knowledge and practices, expand their sources of social support, involve them in activities with peers in safe spaces outside the home and empower them in their marital and familial relationships. Moreover, the positive effects of exposure to the intervention on women's agency and maternal and newborn health practices could have a beneficial influence on other longer-term indicators not captured in this study, such as practices surrounding the second birth, child health outcomes, and indicators such as girls' education that are affected by a mother's status. Equally important is the finding that the intervention was feasible to implement and acceptable to the community. This model could be integrated into existing NGO or government services, without much additional investment, and could be tested for replication or implementation on a larger scale in other settings where the practice of early marriage is common. 


\section{References}

Bhatia, J.C. 1988. A Study of Maternal Mortality in Anantpur District, Andhra Pradesh, India. Bangalore: Indian Institute of Management.

Clark, S., J. Bruce and A. Dude. 2006. "Protecting young women from HIV/AIDS: The case against child and adolescent marriage," International Family Planning Perspectives 32(2): 79-88.

Haberland, N. E. Chong and H. Bracken. 2004. A World Apart: The Disadvantage and Social Isolation of Married Adolescent Girls. New York: Population Council.

Hirve, S.S. and B.R. Ganatra. 1994. "Determinants of low birth weight: A community-based prospective cohort study," Indian Paediatrics 31(10): 1221-25.

International Institute for Population Sciences (IIPS). 2006. Reproductive and Child Health-District Level Household Survey (DLHS-2) 2002-04: India. Mumbai: IIPS.

International Institute for Population Sciences (IIPS) and Macro International. 2007a. National Family Health Survey (NFHS-3), 2005-06: India, Volume 1. Mumbai: IIPS.

International Institute for Population Sciences (IIPS) and Macro International. 2007b. National Family Health Survey (NFHS-3), 2005-06, Fact Sheet: West Bengal. Mumbai: IIPS.

International Institute for Population Sciences (IIPS) and Macro International. 2007c. National Family Health Survey (NFHS-3), 2005-06, Fact Sheet: Gujarat. Mumbai: IIPS.

International Institute for Population Sciences (IIPS) and Population Council. 2007. Youth in India: Situation and Needs, 2006-2007, Fact Sheet: Maharashtra. Mumbai: IIPS.

Jejeebhoy, S., J. 2006. "Sexual and reproductive health of young people: Expanding the research and programme agenda," Paper presented at the David and Lucile Packard Foundation's Population Program Review Task Force Meeting, California, January 19-20.

Kalyanwala, S., R. Acharya, SEWA Academy et al. 2006. Building Agency among Rural Adolescent Girls: Findings from a Livelihoods Intervention in Gujarat. New Delhi: Population Council.

Krishna, U.R. 1995. "The status of women and safe motherhood," Journal of the Indian Medical Association 93(2):34-35.

Kumar, R., P. Jha, P. Arora et al. 2006. “Trends in HIV-1 in young adults in south India from 2000 to 2004: A prevalence study," The Lancet 367 (9517): 1164-72.

Mehta, S.H. A. Gupta, S. Sahay et al. 2006. "High HIV prevalence among a high-risk subgroup of women attending sexually transmitted infection clinics in Pune, India," Journal of Acquired Immune Deficiency Syndrome 41(1): 75-80. 
Ministry of Health and Family Welfare (MOHFW). 2000. National Population Policy 2000. New Delhi: Government of India.

Ministry of Health and Family Welfare (MOHFW). 2006. Implementation Guide on RCH II: Adolescent Reproductive Sexual Health Strategy for State and District Programme Managers. New Delhi: Government of India.

Ministry of Youth Affairs and Sports. 2003. National Youth Policy 2003. New Delhi: Government of India.

Mishra, S. and C.S. Dawn. 1986. "Retrospective study of teenage pregnancy and labour during a 5-year period from January 1978 to December 1982 at Durgapur Subdivisional Hospital," Indian Medical Journal 80(9): 150-52.

National Research Council (NRC) and Institute of Medicine. 2005. Growing Up Global: The Changing Transitions to Adulthood in Developing Countries. Washington, D.C.: The National Academies Press.

Office of the Registrar General and Census Commissioner, India. 2006. Population Projections for India and States 2001-2026 (Revised December 2006). New Delhi: Office of the Registrar General and Census Commissioner.

Pachauri, S. and A. Jamshedji. 1983. "Risks of teenage pregnancy," Journal of Obstetrics and Gynaecology $33(3): 477-82$.

Pal, A., K.B. Gupta and I. Randhawa. 1997. “Adolescent pregnancy: A high risk group,” Journal of the Indian Medical Association 95(5): 127-28.

Registrar General of India (RGI). 2001. Census of India 2001. New Delhi: Office of the Registrar General.

Reynolds, H.W., E.L. Wong and H. Tucker. 2006. "Adolescents' use of maternal and child health services in developing countries," International Family Planning Perspectives 32 (1): 6-16.

Santhya, K.G. and S.J. Jejeebhoy. 2003. "Sexual and reproductive health needs of married adolescent girls," Economic and Political Weekly 38(41): 4370 - 77.

Santhya, K.G. and S.J. Jejeebhoy. 2006. "How early marriage compromises sexual and reproductive health: The situation and needs of married adolescent girls in India," Paper presented at the workshop entitled Child Marriage in India: Social Legal and Human Rights Dimension, New Delhi, July 13-14.

Santhya, K.G. and S.J. Jejeebhoy. 2007. "Early marriage and HIV/AIDS: Risk factors among young women in India," Economic and Political Weekly 42(14):1291-97.

Santhya, K.G., S.J. Jejeebhoy, S. Ghosh et al. 2007. Addressing the Sexual and Reproductive Health Needs of Young People: Perspectives and Experiences of Stakeholders from the Health and Non-health Sectors. New Delhi: Population Council.

Swain, S., K.N. Ojha, A. Prakash et al. 1993. “Maternal and perinatal mortality due to eclampsia,” Indian Paediatrics 30(6): 771-73. 


\section{Appendices}

Appendix 1:

Reasons for loss to follow-up of baseline respondents at endline

Reasons (\%)
Households migrated
Respondents not available
Respondents transitioned out of eligibility
criteria
Refused
Others
$\mathbf{N}$

\begin{tabular}{|c|c|}
\hline \multicolumn{2}{|c|}{ Diamond Harbour } \\
\hline $\begin{array}{c}\text { Intervention } \\
\text { village }\end{array}$ & $\begin{array}{c}\text { Control } \\
\text { village }\end{array}$ \\
\hline 12.8 & 20.6 \\
8.6 & 8.8 \\
& \\
5.9 & 6.4 \\
2.4 & 6.4 \\
0.9 & 1.1 \\
$\mathbf{5 8 0}$ & $\mathbf{4 5 6}$ \\
\hline
\end{tabular}

\begin{tabular}{|c|c|}
\hline \multicolumn{2}{|c|}{ Vadodara } \\
\hline $\begin{array}{c}\text { Intervention } \\
\text { village }\end{array}$ & $\begin{array}{c}\text { Control } \\
\text { village }\end{array}$ \\
\hline 34.8 & 26.8 \\
13.3 & 19.8 \\
& \\
2.4 & 4.0 \\
1.3 & 0.6 \\
0.2 & 0.4 \\
$\mathbf{5 5 0}$ & $\mathbf{5 2 9}$ \\
\hline
\end{tabular}

Appendix 2:

Characteristics of married young women, baseline survey

\begin{tabular}{|c|c|c|c|c|}
\hline \multirow[t]{2}{*}{ Characteristics } & \multicolumn{2}{|c|}{ Diamond Harbour } & \multicolumn{2}{|c|}{ Vadodara } \\
\hline & $\begin{array}{c}\text { Intervention } \\
\text { village }\end{array}$ & $\begin{array}{l}\text { Control } \\
\text { village }\end{array}$ & $\begin{array}{c}\text { Intervention } \\
\text { village }\end{array}$ & $\begin{array}{c}\text { Control } \\
\text { village }\end{array}$ \\
\hline $\begin{array}{l}\text { Age }^{\mathbf{1}^{* * *}} \\
\text { Mean age }\end{array}$ & 19.0 & 19.9 & 19.4 & 19.4 \\
\hline $\begin{array}{l}\text { Husbands' age } \mathbf{e}^{\mathbf{t}^{* * *}} \\
\text { Mean age }\end{array}$ & 25.2 & 26.6 & 22.1 & 22.3 \\
\hline $\begin{array}{l}\text { Current status (\%) } \\
\text { Newly-married } \\
\text { First-time pregnant } \\
\text { First-time mother }\end{array}$ & $\begin{array}{l}31.0 \\
13.8 \\
55.2\end{array}$ & $\begin{array}{l}32.7 \\
13.8 \\
53.5\end{array}$ & $\begin{array}{r}37.6 \\
9.8 \\
52.5\end{array}$ & $\begin{array}{l}36.3 \\
12.7 \\
51.0\end{array}$ \\
\hline $\begin{array}{l}\text { Years of schooling comp } \\
\text { Mean years of schooling }\end{array}$ & 4.4 & 5.5 & 5.6 & 5.7 \\
\hline $\begin{array}{l}\text { Age at marriage } \\
\text { Median age at marriage }\end{array}$ & 17 & 18 & 17 & 17 \\
\hline $\begin{array}{l}\text { Religion }(\%)^{1^{* * *}} \\
\text { Hindu } \\
\text { Muslim }\end{array}$ & $\begin{array}{l}23.4 \\
76.6\end{array}$ & $\begin{array}{l}73.5 \\
26.5\end{array}$ & $\begin{array}{r}99.5 \\
0.5\end{array}$ & $\begin{array}{r}99.4 \\
0.4\end{array}$ \\
\hline $\begin{array}{l}\text { Type of family (\%) } \\
\text { Nuclear } \\
\text { Non-nuclear }\end{array}$ & $\begin{array}{l}31.1 \\
68.9\end{array}$ & $\begin{array}{l}27.5 \\
72.5\end{array}$ & $\begin{array}{r}8.4 \\
91.6\end{array}$ & $\begin{array}{r}8.9 \\
91.1\end{array}$ \\
\hline $\begin{array}{l}\text { Standard of living index } \\
\text { Low } \\
\text { Medium } \\
\text { High }\end{array}$ & $\begin{array}{r}51.3 \\
42.9 \\
5.8\end{array}$ & $\begin{array}{l}34.7 \\
51.4 \\
13.8\end{array}$ & $\begin{array}{r}9.3 \\
60.7 \\
30.1\end{array}$ & $\begin{array}{l}11.7 \\
58.6 \\
29.7\end{array}$ \\
\hline $\mathbf{N}$ & 580 & 456 & 550 & 529 \\
\hline
\end{tabular}

Note: ${ }^{1}$ The differences between respondents in intervention and control villages were significant in Diamond Harbour. ${ }^{* * *} p \leq .001$. See Appendix 6 for details of computation of the standard of living index. 
Appendix 3:

Participation in activities similar, but external to, the intervention

\begin{tabular}{|c|c|c|c|c|}
\hline \multirow[t]{2}{*}{ Characteristics (\%) } & \multicolumn{2}{|c|}{ Diamond Harbour } & \multicolumn{2}{|c|}{ Vadodara } \\
\hline & $\begin{array}{c}\text { Intervention } \\
\text { village } \\
(\mathrm{N}=1,329)\end{array}$ & $\begin{array}{l}\text { Control } \\
\text { village } \\
(\mathrm{N}=\mathbf{8 6 4})\end{array}$ & $\begin{array}{c}\text { Intervention } \\
\text { village } \\
(\mathrm{N}=1,335)\end{array}$ & $\begin{array}{c}\text { Control } \\
\text { village } \\
(\mathrm{N}=1,027)\end{array}$ \\
\hline $\begin{array}{l}\text { Married young women who: } \\
\text { Received sexual and reproductive health } \\
\text { information from sources other than } \\
\text { intervention activities }\end{array}$ & 37.3 & 62.5 & 11.8 & 32.1 \\
\hline $\begin{array}{l}\text { Reported membership in groups other than } \\
\text { project-initiated groups }\end{array}$ & 0.5 & 1.2 & 4.0 & 1.9 \\
\hline
\end{tabular}

Appendix 4:

Characteristics of baseline respondents who were exposed to the intervention and those who were not

\begin{tabular}{|c|c|c|c|c|}
\hline \multirow[t]{2}{*}{ Characteristics } & \multicolumn{2}{|c|}{ Diamond Harbour } & \multicolumn{2}{|c|}{ Vadodara } \\
\hline & $\begin{array}{l}\text { Respondents } \\
\text { exposed to } \\
\text { the } \\
\text { intervention } \\
(\mathrm{N}=279)\end{array}$ & $\begin{array}{c}\text { Respondents } \\
\text { not exposed } \\
\text { to the } \\
\text { intervention } \\
(\mathrm{N}=301)\end{array}$ & $\begin{array}{l}\text { Respondents } \\
\text { exposed to } \\
\text { the } \\
\text { intervention } \\
(\mathrm{N}=144)\end{array}$ & $\begin{array}{c}\text { Respondents } \\
\text { not exposed } \\
\text { to the } \\
\text { intervention } \\
(\mathrm{N}=406)\end{array}$ \\
\hline $\begin{array}{l}\text { Current age }{ }^{1^{* *}} \\
\text { Mean age }\end{array}$ & 18.7 & 19.3 & 19.3 & 19.4 \\
\hline $\begin{array}{l}\text { Current status }(\%)^{1^{* * *} ; 2^{*}} \\
\text { Newly married } \\
\text { First-time pregnant } \\
\text { First-time mother }\end{array}$ & $\begin{array}{l}40.1 \\
19.0 \\
40.9\end{array}$ & $\begin{array}{r}22.6 \\
9.0 \\
68.4\end{array}$ & $\begin{array}{l}45.1 \\
12.5 \\
42.4\end{array}$ & $\begin{array}{r}35.0 \\
8.9 \\
56.2\end{array}$ \\
\hline $\begin{array}{l}\text { Years of schooling }{ }^{2^{* *}} \\
\text { Mean years of schooling completed }\end{array}$ & 8.1 & 7.7 & 6.2 & 5.3 \\
\hline $\begin{array}{l}\text { Standard of living index } \\
\text { Mean score }\end{array}$ & 5.6 & 5.6 & 12.8 & 11.7 \\
\hline $\begin{array}{l}\text { Religion }(\%)^{1^{*}} \\
\text { Hindu } \\
\text { Muslim }\end{array}$ & $\begin{array}{l}27.2 \\
72.8\end{array}$ & $\begin{array}{l}19.9 \\
80.1\end{array}$ & $\begin{array}{r}98.6 \\
1.4\end{array}$ & $\begin{array}{r}99.8 \\
0.2\end{array}$ \\
\hline $\begin{array}{l}\text { Residence status in the intervention } \\
\text { sites }(\%)^{1^{* *} ; 2^{* * *}} \\
\text { Marital home } \\
\text { Natal home }\end{array}$ & $\begin{array}{l}87.8 \\
12.2\end{array}$ & $\begin{array}{l}79.7 \\
20.3\end{array}$ & $\begin{array}{l}89.6 \\
10.4\end{array}$ & $\begin{array}{l}73.4 \\
26.6\end{array}$ \\
\hline
\end{tabular}

Note: ${ }^{I}$ The difference between respondents who were exposed to the intervention and those who were not were significant in Diamond Harbour. ${ }^{2}$ The differences between respondents who were exposed to the intervention and those who were not were significant in Vadodara.

${ }^{*} p \leq .05 ;{ }^{* *} p \leq .01 ;{ }^{* * *} p \leq .001$. 
Appendix 5:

Characteristics of baseline respondents who were followed up at endline and those who were not

\begin{tabular}{|c|c|c|c|c|}
\hline \multirow[t]{2}{*}{ Characteristics } & \multicolumn{2}{|c|}{ Diamond Harbour } & \multicolumn{2}{|c|}{ Vadodara } \\
\hline & $\begin{array}{l}\text { Respondents } \\
\text { who were } \\
\text { followed up } \\
(\mathrm{N}=662)\end{array}$ & $\begin{array}{c}\text { Respondents } \\
\text { not followed } \\
\text { up } \\
(\mathbf{N}=374)\end{array}$ & $\begin{array}{l}\text { Respondents } \\
\text { who were } \\
\text { followed up } \\
(\mathrm{N}=522)\end{array}$ & $\begin{array}{c}\text { Respondents } \\
\text { not followed } \\
\text { up } \\
(\mathbf{N}=557)\end{array}$ \\
\hline $\begin{array}{l}\text { Current age } \\
\text { Mean age }\end{array}$ & 19.3 & 19.6 & 19.4 & 19.4 \\
\hline $\begin{array}{l}\text { Current status }(\%)^{1} \\
\text { Newly-married } \\
\text { First-time pregnant } \\
\text { First-time mother }\end{array}$ & $\begin{array}{l}33.2 \\
15.3 \\
51.5\end{array}$ & $\begin{array}{l}29.1 \\
11.2 \\
59.6\end{array}$ & $\begin{array}{l}39.3 \\
12.5 \\
48.3\end{array}$ & $\begin{array}{l}34.8 \\
10.1 \\
55.1\end{array}$ \\
\hline $\begin{array}{l}\text { Years of schooling }{ }^{1^{*}} \\
\text { Mean years of schooling completed }\end{array}$ & 5.1 & 4.6 & 5.7 & 5.6 \\
\hline $\begin{array}{l}\text { Standard of living index }{ }^{1^{*}, 2^{*}} \\
\text { Mean score }\end{array}$ & 6.8 & 6.0 & 12.4 & 11.4 \\
\hline $\begin{array}{l}\text { Religion (\%) } \\
\text { Hindu } \\
\text { Muslim }\end{array}$ & $\begin{array}{l}46.4 \\
53.6\end{array}$ & $\begin{array}{l}43.9 \\
56.1\end{array}$ & $\begin{array}{r}99.0 \\
1.0\end{array}$ & $\begin{array}{r}99.8 \\
0.0\end{array}$ \\
\hline 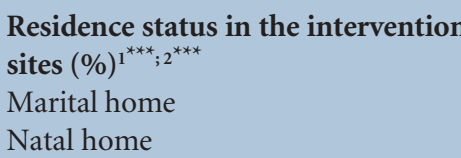 & $\begin{array}{r}91.2 \\
8.8\end{array}$ & $\begin{array}{l}79.7 \\
20.3\end{array}$ & $\begin{array}{l}85.6 \\
14.4\end{array}$ & $\begin{array}{l}70.7 \\
29.3\end{array}$ \\
\hline
\end{tabular}

Note: ${ }^{1}$ The differences between respondents who were followed up and those who were not were significant in Diamond Harbour.

${ }^{2}$ The differences between respondents who were followed up and those who were not were significant in Vadodara.

${ }^{*} p \leq .05 ;{ }^{* * *} p \leq .001$. 
Appendix 6:

Computation of standard of living index

A composite index was computed based on type of house, ownership of agricultural land/livestock and ownership of household durables. The score assigned to each individual item was similar to that of the NFHS-2. A detailed description of the variables and the score assigned in computing the standard of living index follows.

House type: 4 for pucca, 2 for semi-pucca and 0 for kachha

Ownership of agricultural land: 3 for households owning 3 or more acres, 2 for those owning 1-3 acres, 1 for those owning less than 1 acre and 0 for landless

Ownership of livestock: 2 if household owns livestock and 0 if they do not

Pressure cooker: 1 if household owns a pressure cooker and 0 if not

Electric fan: 2 if household owns a fan and 0 if not

Bicycle: 2 if household owns a bicycle and 0 if not

Radio: 2 if household owns a radio and 0 if not

Sewing machine: 2 if household owns a machine and 0 if not

Telephone: 2 if household owns a telephone and 0 if not

Refrigerator: 3 if household owns a refrigerator and 0 if not

Television: 4 if household owns a television and 0 if not

Motorcycle: 3 if household owns a motorcycle and 0 if not

Car/tractor: 4 if household owns a car/tractor and 0 if not

The composite index was computed by summing up the scores given to each item. The value of the index ranged from 0 to 34. On the basis of distribution, 0-4 was classified as low, 5-14 as medium and 15 and above as high. 


\section{Authors}

K.G. Santhya, Senior Programme Officer, Population Council, New Delhi

Nicole Haberland, Programme Associate, Population Council, New York

Arup Das, Senior Project Officer, Child In Need Institute, Kolkata

Aruna Lakhani, formerly Director, Deepak Charitable Trust, Vadodara

F. Ram, Professor, International Institute for Population Sciences, Mumbai

R.K. Sinha, Professor, International Institute for Population Sciences, Mumbai

Usha Ram, Reader, International Institute for Population Sciences, Mumbai

S.K. Mohanty, Reader, International Institute for Population Sciences, Mumbai 



\section{(P) Population Council}

South \& East Asia-Regional office

Zone 5-A Ground Floor

India Habitat Centre

Lodi Road

New Delhi 110 003, India 